\title{
REGULATION OF PYRUVATE KINASE IN HYPOMETABOLIC STATES
}

\author{
Michael Brant Smolinski
}

B.Sc. (Hons.), 2013

Carleton University

\begin{abstract}
A Thesis Submitted to the Faculty of Graduate Studies and Research in partial fulfillment of the requirements for the degree of
\end{abstract}

\author{
Master of Science \\ Department of Biology
}

Carleton University

Ottawa, Ontario, Canada

(C) Copyright 2016

Michael B. Smolinski 
The undersigned hereby recommend to the Faculty of Graduate Studies and Research acceptance of this thesis

\section{REGULATION OF PYRUVATE KINASE IN HYPOMETABOLIC STATES} submitted by

Michael Brant Smolinski, B.Sc.

in partial fulfillment of the requirements for the degree of Master of Science

Chair, Department of Biology

Thesis Supervisor

Carleton University 


\begin{abstract}
Survival in extreme environments requires drastic changes to animals' physiology and biochemistry, requiring many animals to decrease their metabolic rate. Enzymes are the mediators of metabolic functions and their regulation is critical to surviving these conditions. This thesis explores the properties of a key enzyme of glycolysis, pyruvate kinase (PK), in the freeze tolerant wood frog (Rana sylvatica), the anoxia tolerant snail (Littorina littorea) and the hibernating ground squirrel (Urocitellus richardsonii).The studies showed that temperature, allosteric effectors and other local environmental conditions play a role in regulating pyruvate kinase in response to freezing, anoxia and during hibernation. Furthermore, reversible protein phosphorylation appears to be a common regulatory mechanism of PK by reducing the activity of the enzyme in all three animals. Together, these studies show that PK is a common regulatory target of animals surviving in extreme conditions and that multiple regulatory mechanisms, especially protein phosphorylation, contribute to its regulation.
\end{abstract}




\section{Acknowledgements}

I would like to begin by thanking both Ken and Jan Storey. Ken, thank you so much for giving me the opportunity to work in your lab. I have learned so much from you throughout the years and have tried my best to incorporate your many lessons into my life. If I can only find something for which I have half as much passion as you do for studying enzymes, I'll consider myself lucky. No matter how many times I left, you always had a spot for me here and I cannot thank you enough for it. Jan, thank you for all of the help and guidance and for answering my many questions at a moment's notice. You have made me a better scientist and writer and given me confidence in my own work, and I think the entire lab can say the same.

I would also like to thank all of the Storey lab members, past and present, who've shared with me their knowledge, advice, or a beer at Mike's Place. I genuinely cannot imagine a more supportive environment in which to have completed my degree. Thank

you to all who've humored my interests in politics and current affairs; if not for you, who knows what I would be doing now? You've all challenged me to become a better scientist and person, and I've done my best to rise to the occasion. Keep Jonesin' and sleep fast.

Finally, I would like to thank all of my friends, family, and my wonderful girlfriend Brit for the continued, unwavering support throughout my degree. You were always there for me if I needed anything at all and you helped me through many stressful times. I am infinitely grateful to have you by my side as I move forward into uncharted territory! 
Title Page

Acceptance Sheet II

Abstract III

$\begin{array}{lll}\text { Acknowledgements IV } & \text { IV }\end{array}$

Table of Contents $\quad$ V

List of Abbreviations $\quad$ VI

List of Figures $\quad$ VIII

List of Tables $\quad$ X

$\begin{array}{ll}\text { List of Appendices } & \text { XI }\end{array}$

Chapter 1 General Introduction 1

Chapter 2 Purification and Characterization of Pyruvate Kinase 20

from Skeletal Muscle of the Freeze Tolerant Wood

Frog, Rana sylvatica

Chapter $3 \quad$ Purification and Characterization of Pyruvate Kinase 52

from the Foot Muscle of the Freeze Tolerant Marine

Snail, Littorina littorea

Chapter $4 \quad$ Purification and Characterization of Pyruvate Kinase 81

from Liver of the Hibernating Ground Squirrel, Urocitellus richardsonii

$\begin{array}{lll}\text { Chapter } 5 \quad \text { General Discussion } & 108\end{array}$

$\begin{array}{ll}\text { References } & 123\end{array}$

$\begin{array}{ll}\text { Appendices } & 138\end{array}$ 


\section{List of Abbreviations}

6PGDH 6-phosphogluconate dehydrogenase

$\beta$-GP $\quad \beta$-glycerophosphate

$\beta$-MeSH $\quad \beta$-mercaptoethanol

ADP

Adenosine diphosphate

ANOVA

One-way analysis of variance

AMP

Adenosine monophosphate

AMPK

AMP activated protein kinase

ATP

Adenosine triphosphate

cAMP

3'-5'-cyclic adenosine monophosphate

CAT

Catalase

$\mathrm{CM}^{-}$

Carboxymethyl

$\mathrm{C}_{\mathrm{m}}$

Concentration required to reduce $\mathrm{V}_{\max }$ by $1 / 2$

$\mathrm{E}_{\mathrm{a}}$

Activation energy

ECL

Enhanced chemiluminescence

EDTA

Ethylenediamine-tetraacetic acid

EGTA

Ethylene glycol-bis(2-aminoethylether)-N,N, $\mathrm{N}^{\prime}, \mathrm{N}^{\prime}$-tetraacetic acid

FA

Fatty acid

FABP

FA binding protein

FBP

Fructose-1,6-bisphosphate

FBPase

Fructose-1,6-bisphosphatase

G6PDH

Glucose-6-phosphate dehydrogenase

GAPDH

Glyceraldehyde-3-phosphate dehydrogenase

GP

Glycogen Phosphorylase

GR

Glutathione reductase

HA

Hydroxyapatite

HK

Hexokinase

$\mathrm{I}_{50}$

Half maximal inhibitory concentration

$\mathrm{K}_{m}$

Substrate concentration at $1 / 2$ maximal enzyme velocity 


\begin{tabular}{|c|c|}
\hline $\mathrm{K}_{\mathrm{a}}$ & Activator concentration producing half-maximal enzyme activation \\
\hline $\mathrm{kDa}$ & kiloDalton \\
\hline LDH & Lactate dehydrogenase \\
\hline NADH & $\beta$-Nicotinamide adenine dinucleotide, reduced form \\
\hline PAGE & Polyacrylamide gel electrophoresis \\
\hline PEP & Phosphoenolpyruvate \\
\hline PDH & Pyruvate dehydrogenase \\
\hline PDK & Pyruvate dehydrogenase kinase \\
\hline PK & Pyruvate kinase \\
\hline PKA & Cyclic AMP dependent protein kinase A \\
\hline PMSF & Phenylmethylsulfonyl fluoride \\
\hline PTM & Post-translational modification \\
\hline PVDF & Polyvinylidene difluoride membrane \\
\hline RGS & Richardson's ground squirrel \\
\hline ROS & Reactive oxygen species \\
\hline RPP & Reversible protein phosphorylation \\
\hline RQ & Respiratory quotient \\
\hline SDS & Sodium dodecyl sulfate \\
\hline $\mathrm{T}_{50}$ & Temperature at which half of the protein irreversibly denatured \\
\hline$t_{m}$ & Time required to reduce $V_{\max }$ by $1 / 2$ \\
\hline $\mathrm{T}_{b}$ & Body temperature \\
\hline TCA & Tricarboxylic acid cycle \\
\hline TBS & Tris-buffered saline \\
\hline TBST & Tris-buffered saline containing the detergent Triton- $\mathrm{X}$ \\
\hline WAT & White adipose tissue \\
\hline 13-LGS & 13-Lined ground squirrel \\
\hline
\end{tabular}




\section{List of Figures}

Page

Figure 2.1. 10\% SDS-PAGE gel with Coomassie staining of samples taken at each step in the purification of PK from muscle of control R. sylvatica

Figure 2.2. Relative stability of purified pyruvate kinase from $R$. sylvatica muscle 50 tissue determined through the enzyme incubations at high temperature and in high concentrations of urea

Figure 2.3. Quantification of post-translational modifications of

purified PK from muscle of control and frozen

R. sylvatica using dot blots.

Figure 3.1. $10 \%$ SDS-PAGE gel with Coomassie staining of purified

PK from muscle of control L. littorea

Figure 3.2. Effect of alanine and combinations of alanine with various

activating compounds (FBP, Isoleucine, and Aspartate) on the $\mathrm{V}_{\text {maz }}$ of purified PK from the foot muscle of L. littorea.

Figure 3.3. Relative stability of purified pyruvate kinase from

L. littorea foot muscle determined through enzyme incubations at $60^{\circ} \mathrm{C}$.

Figure 3.4. Relative levels of threonine and tyrosine phosphorylation of purified pyruvate kinase from control, frozen and anoxic foot muscle tissue of Littorina littorea determined through western blotting.

Figure 4.1. 10\% SDS-PAGE gel showing entire purification of PK from euthermic liver of $U$. richardsonii

Figure 4.2. Relative levels of post-translational modifications determined through western blotting of purified pyruvate kinase from euthermic and hibernating liver tissue of $U$. richardsonii.

Figure 4.3. Quantification stability of purified PK from liver of euthermic and hibernating $U$. richardsonii.

Figure A1.1. Relative levels of serine phosphorylation of purified PK from control, dehydrated and anoxic muscle tissue of $R$. sylvatica.

Figure A2.1. Patterns of anaerobic metabolism in marine invertebrates. 


\section{List of Tables}

Page

Table 2.1. Typical purification scheme of pyruvate kinase from

$R$. sylvatica muscle tissue.

Table 2.2. Kinetic and structural properties of skeletal muscle pyruvate kinase 46 taken from control and frozen muscle samples of $R$. sylvatica

Table 2.3. Effects of various substrates and allosteric effectors on the

$\mathrm{K}_{\mathrm{m}}$ PEP of purified pyruvate kinase from control and frozen muscle samples of $R$. sylvatica

Table 2.3. Effects of various substrates and allosteric effectors on the $\mathrm{V}_{\max }$ of purified pyruvate kinase from control and frozen muscle samples of $R$. sylvatica

Table 3.1. $\quad$ Purification and yield of L. littorea PK from foot muscle of control snails.

Table 3.2. Kinetic parameters of purified foot muscle PK from control, frozen and anoxic L. littorea.

Table 3.3. Effects of various inhibitors on the $\mathrm{V}_{\max }$ of purified pyruvate kinase from control, frozen and anoxic foot muscle samples of L. littorea.

Table 3.4. Effects of various activating compounds on the $\mathrm{V}_{\max }$ of purified pyruvate kinase from control, frozen and anoxic foot muscle samples of $L$. littorea.

Table 4.1. Purification and yield of $U$. richardsonii $\mathrm{PK}$ from liver tissue of euthermic squirrels.

Table 4.2. Kinetic parameters of purified liver PK from euthermic and hibernating $U$. richardsonii.

Table 4.3. Effects of $\mathrm{pH}$ on purified liver $\mathrm{PK}$ from euthermic and hibernating $U$. richardsonii.

Table 4.4. Effects of allosteric effectors on purified liver PK from euthermic and hibernating U. richardsonii.

Table A1.1. $\quad \mathrm{K}_{\mathrm{m}} \mathrm{PEP}$ of skeletal muscle pyruvate kinase taken from 


\section{List of Appendices}

Page

Appendix I Study of the effects dehydration and anoxia on the the activity of $\mathrm{PK}$ in the muscle of $R$. sylvatica

Appendix II Supplementary figures

Appendix III Communications at Scientific Meetings

Aoppendix IV Thesis Defense Lecture Slides 
Chapter 1

\section{General Introduction}




\section{Metabolic rate depression}

Animals surviving in extreme conditions employ a number of different strategies to survive harsh seasonal or periodic changes in their environments. Some stresses may only persist for a few hours, such as short-term exposure to a lack of oxygen according to tidal patterns. Other animals endure months-long periods of stress like seasonal freezing or dehydration during extreme cold and dry seasons. The challenges facing animals remaining in these environments are varied, but can include limited access to food and dwindling energy reserves as is the case with hibernating mammals, subjection to anoxic or hypoxic conditions commonly confronted by anoxia-tolerant turtles, and extreme low temperatures and cellular dehydration facing the North American wood frog (Milton \& Prentice, 2007; Carey et al., 2003; Storey \& Storey, 1984). As such, many animals exhibit adaptations that allow them to withstand a given environmental stress until more favorable conditions return.

One of the most commonly-observed adaptations is the initiation of a global metabolic rate depression and a subsequent entrance into a dormant state (Storey \& Storey, 2004a). This allows animals to conserve what little energy they have and survive on what was accumulated during more favorable periods. This is crucial, as typically these animals could not survive extended periods of environmental stress consuming energy at their usual metabolic rate. Of course, conservation of fuel is not necessarily the only reason an animal would drop its metabolic rate; many animals surviving short-term bouts of anoxia exhibit metabolic rate depression as well. In this case, anoxia or ischemic conditions limit the amount of oxygen available to conduct aerobic respiration. In order to meet the ATP demands of the cell using only anaerobic fermentative pathways, which 
generate significantly less cellular energy than aerobic pathways, metabolic rate depression is employed. By lowering the metabolic rate and energetic requirements of the cell, anaerobic respiration can generate sufficient energy for cellular function (Storey \& Storey, 2004b). Metabolic rate depression is found throughout the animal kingdom, and the degree to which it is employed varies greatly. For example, some small hibernating mammals can decrease their metabolic rate by $95 \%$ during torpor, resulting in savings of nearly $90 \%$ of the energy that would typically be expended in a euthermic state (Geiser, 2004; Wang, 1989). Meanwhile, marine invertebrates surviving in anoxic environments have been shown to suppress their metabolic rate to just $10 \%$ of the corresponding aerobic rate (Storey \& Storey, 1990). All of this is to say that metabolic rate depression is a multi-functional mechanism contributing to the survival of animals inhabiting a wide variety of environmental stresses.

In order to allow such dramatic drops in metabolic rate, significant changes in animal behavior, physiology and biochemistry are necessary. Behavioral changes include animals ceasing to feed and most move during the period of dormancy. Physiological changes include significantly decreased heart and breathing rates, which have been shown to cease entirely in the freeze tolerant wood frog, Rana sylvatica (Storey, 1990), while hibernating ground squirrels can drop their heart rate from $200 \mathrm{bpm}$ to less than 10 bpm (Milsom et al., 1999). Arguably the most important aspect to metabolic rate depression, however, are the biochemical adaptations and regulations.

Generally speaking, animals undergoing metabolic rate depression rely on the establishment of a new equilibrium between ATP production and ATP consumption with both processes being suppressed significantly. To reduce ATP consumption, processes 
that are ATP-expensive and not vital to the animal's survival are switched off. Protein turnover is a particularly good example of a cellular process that is highly regulated at multiple levels by animals that undergo metabolic rate depression. In the anoxia-tolerant freshwater turtle, Trachemys scripta elegans, both protein synthesis and proteolysis have been demonstrated to be significantly repressed in response to anoxic conditions (Krivoruchko \& Storey, 2015). Similar responses have also been observed in anoxiatolerant marine invertebrates, where, in response to anoxia, both transcription and translation have been shown to be suppressed during bouts of anoxia (Storey et al., 2013). Multiple other studies have suggested an involvement of regulatory miRNAs in contributing to translational suppression in hibernating mammals, anoxic turtles and freeze-tolerant amphibians (Biggar \& Storey, 2010). Indeed, protein turnover has been estimated to account for up to $22 \%$ of a cell's energetic budget, and therefore large energy savings can accrue by limiting the rate of this process (Lobley et al, 1979; Land \& Hochachka, 1994). Another highly-regulated process during metabolic rate depression is the cell cycle. The process of cell division is highly energy expensive, requiring the duplication of DNA and synthesis and many new proteins and cellular components. It is of little surprise, then, that the cell cycle is often found to be arrested in animals enduring environmental stress. In the wood frog, expression of key cell cycle proteins cyclin A, B1, and cyclin-dependent kinases were all decreased in response to freezing, anoxia and dehydration, severely limiting the rate at which cells divide (Zhang \& Storey, 2012). Similar patterns were observed in hibernating ground squirrels where decreases in the expression of cyclins D and $\mathrm{E}$ together with increases in cyclin-dependent kinase inhibitors $\mathrm{p} 15^{\mathrm{INK} 4 \mathrm{~b}}$ and $\mathrm{p} 21^{\mathrm{CIP} 1}$ strongly suggest that the cell cycle is arrested during 
torpor in these animals as well (Wu \& Storey, 2012). Despite clear suppression of these high-energy processes, it should be noted that not all processes are suppressed. Depending on the needs of the animal, there are examples of certain pathways that are activated in response to stress. The expression of many pro-survival genes are, in fact, increased. For instance, protein chaperones of the heat-shock protein (HSP) family are upregulated in anoxia tolerant turtles during anoxia, including Hsp25, Hsp40, Hsp70 and Hsp90 (Krivoruchko, \& Storey, 2010). These results demonstrate that metabolic rate depression is not ubiquitous across all pathways in all animals, but is dependent on the specific needs of a given animal or tissue.

Ultimately, however, regulation of specific molecular pathways and processes is not sufficient in enabling the scale of metabolic rate depression required for the survival of these animals. Although this decreases the rate of ATP consumption, the rate of ATP production must also be reduced to effectively conserve energy stores. To accomplish this, many ATP-producing metabolic pathways are suppressed during periods of environmental stress by regulating the enzymes constituting these pathways. This allows animals to effectively decrease the rate of catabolism and cellular energy production. However, simply decreasing the expression of metabolic enzymes is inadequate, and in fact can be detrimental to the animal. Although it would be conceivable to reduce the expression of metabolic enzymes during dormancy to decrease their activity, these enzymes would then have to be quickly resynthesized during recovery to enable animals to become active immediately post-stress. In the case of estivating land snails, animals awaken from their period of torpor within five minutes of being rehydrated (Storey, 2002). The freeze tolerant wood frog, Rana sylvatica, engages in energy-costly activities, 
such as mating, shortly after thawing (Sinclair et al., 2012). Therefore, it is important that enzymes are regulated through means other than mass seasonal protein turnover such that they can be activated or inactivated as quickly as possible. This is generally accomplished through enzymatic regulation via reversible phosphorylation or other post-translational modifications.

\section{Reversible Post-translational Modifications}

Reversible post-translational modifications (PTMs) are covalent modifications added specifically to target proteins following their translation which can alter the target's structure and/or function. The reversible, covalent nature of the addition of these functional groups makes them stable and they can be quickly added or removed from a target protein, making them particularly effective regulatory mechanisms. There are more than 200 post-translational modifications that have been discovered to date with some playing very specific, well-defined roles (i.e. ubiquitination; protein degradation) while others serve multifunctional purposes (i.e. phosphorylation) (Jensen, 2006; Prabakaran et al., 2012). The sheer variety of PTMs known and their ability modify the functional properties of proteins makes them of significant interest with respect to studying hypometabolism and survival of environmental stress.

Arguably the most-studied PTM with respect to its involvement in metabolic rate depression is reversible protein phosphorylation (RPP). RPP is a reversible mechanism of regulation and the reversibility of RPP, crucial to its efficacy as a regulatory mechanism, is mediated by the actions of protein kinases and phosphatases. These functional proteins add and remove phosphate groups from specific serine, threonine and tyrosine residues of target proteins. RPP has been observed to alter the structure, function, and cellular 
localization of target proteins, demonstrating the versatility of this particular PTM (Cohen, 2002). It has also been implicated in nearly every cellular process including the cell cycle, intercellular communication, and cell movement, and has been known to exist for quite some time (Johnson \& Barford, 1993; Johnson, 2009). What makes this PTM particularly interesting with respect to studying metabolic rate depression and hypometabolism, however, is its well-documented involvement in regulating metabolic enzymes. Indeed, in yeast (Saccharomyces cerevisiae), proteomics studies have revealed that over half of the enzymes in the organism's metabolic network have been identified as phosphoproteins including glycogen phosphorylase (GP), fructose-1,6-bisphosphatase (FBPase) and pyruvate dehydrogenase (PD) (reviewed in Oliveira \& Saur, 2012). Although the functional relevancy has not been confirmed for all of these modifications, it suggests nonetheless that RPP plays a significant role in the regulation of metabolic pathways.

The reversible nature of RPP makes it a rapid, energetically economical regulatory mechanism compared to an energy exhaustive seasonal protein turnover to survive stress. By selectively (de)phosphorylating specific enzymes during stress, metabolic pathways can be suppressed or activated, avoiding the energetic cost and other problems associated with degrading and then resynthesizing the same enzymes. It is not surprising, then, to note that RPP of enzymes has been repeatedly demonstrated to play a significant role in the response to environmental stress. For example, in the freeze tolerant wood frog, RPP mediates the activities of enzymes involved in glucose metabolism, including GP, glucose-6-posphate dehydrogenase (G6PDH), and hexokinase (HK), to conserve high levels of cryoprotectants and enable survival of freezing (Crerar 
et al., 1988; Dieni \& Storey, 2008; Dieni \& Storey, 2010). Antioxidant defenses such as catalase (CAT) and superoxide dismutase (SOD) are also regulated by RPP to increase free-radical scavenging capacity during freezing (Dawson \& Storey, 2016, Dawson et al., 2015), and even protein kinases themselves, which can act on the various proteins requiring phosphorylation during freezing, are regulated in this manner (Dieni \& Storey, 2014). The season-long period of freezing survived by the wood frog is relatively longterm, yet RPP has also been observed in animals surviving harsh conditions on the order of hours as opposed to months. Marine gastropods and mollusks living in intertidal spaces generally survive periods of anoxia lasting about 6 hours (Storey et al., 2013). Despite this shorter time frame, they also exhibit significant stress-responsive phosphorylation of metabolic enzymes. In the common periwinkle (Littorina littorea), for example, a number of enzymes of carbohydrate metabolism including GP, glycogen synthase (GS) and PD exhibited decreased activity consistent with reversible phosphorylation that would contribute to a global metabolic rate depression (Russell \& Storey, 1995). Another study in this animal revealed that G6PDH is heavily regulated by serine-phosphorylation, as it exhibited 2.5-fold higher serine phosphorylation levels in the aerobic animal when compared to the anoxic animal (Lama et al., 2013). This increase in phosphorylation is thought to be responsible for an increase in G6PDH activity required to maintain high levels of NADPH for antioxidant defense during anoxia exposure. Clearly, reversible protein phosphorylation of enzymes plays a critical role in animal survival of environmental stress, regardless of the duration of said stress. 


\section{Glycolytic Regulation}

Glycolysis is the metabolic pathway responsible for converting carbohydrate energy sources in the form of glucose to pyruvate, generating high-energy ATP and NADH in the process. The pyruvate generated by this pathway can be further catabolized to generate even more energy through a variety of aerobic and anaerobic pathways such as the citric acid cycle, oxidative phosphorylation and various fermentative pathways. Unsurprisingly, glucose metabolism is a key element of survival in nearly all living organisms and it is highly regulated by multiple mechanisms (Berg et al., 2002; Zierler, 1999). For example, before glucose metabolism even begins, rates of glucose uptake can be regulated by controlling the cellular localization of glucose transport proteins in response to insulin signaling (Khan \& Pessin, 2002). Furthermore, glycogen phosphorylase (GP), the enzyme responsible for the breakdown of glycogen into glucose monomers for glycolysis, is highly regulated by reversible phosphorylation whereby phosphorylation of GP switches the enzyme from an inactive form to a highly active form, increasing the pool of glucose available of catabolism (Morgan \& Parmeggiani, 1964). However, the rate glycolysis is primarily controlled through the regulation of a few key enzymes within the pathway.

Hexokinase $(\mathrm{HK})$, which catalyzes the first reaction of glycolysis, is the first main control point of the pathway. This enzyme is primarily regulated by feedback inhibition, as glucose-6-phosphate, the product of HK, inhibits the enzyme as its concentration increases (Scrutton \& Utter, 1968; Lenzen, 2014). Many animals surviving in extreme conditions exhibit regulation of this enzyme, including the freeze-tolerant wood frog Rana sylvatica, the anoxia-tolerant snail Littorina littorea, and the dehydration- 
tolerant clawed frog Xenopus laevis (Dieni \& Storey, 2011; Lama et al., 2013; Childers \& Storey, 2016). Evidence from these animals suggests the HK can be either activated or inhibited by reversible phosphorylation to control glycolytic rates as required by the animal for survival. In the wood frog, for example, decreased activity of HK is beneficial in conserving high levels of glucose to act as a cryoprotectant. In X. laevis, however, activation of $\mathrm{HK}$ contributes to increasing glycolytic energy production to overcome decreased rates of oxidative phosphorylation due to ischemia. The second main control point of glycolysis is the enzyme phosphofructokinase (PFK), which catalyzes the addition of a phosphate group to fructose-6-phosphate (Underwood \& Newsholme, 1965; Marsin et al., 2000). This enzyme has also been shown to be highly regulated in animals surviving in hypometabolic states during extreme environmental conditions through allosteric and post-translational regulatory mechanisms. For example, in the anoxiatolerant snail L. littorea, PFK was found to be both less active during winter and had a lower substrate affinity in animals exposed to anoxic conditions, observations that are consistent with regulation via reversible phosphorylation (Greenway \& Storey, 2001). In the wood frog R. sylvatica, levels of fructose-6-phosphate increased significantly in frozen animals suggesting an inhibitory block of glycolysis at the level of PFK was present (Churchill \& Storey, 1994). In the hibernating mammals, altered PFK kinetics suggest that a less-active form is present during hibernation and that post-translational modifications are responsible for these alterations (Storey, 1987). Furthermore, lower cellular concentrations during hibernation of fructose-2,6-bisphosphate, a potent activator of PFK, suggest that the enzyme is less activated during hibernation (Brooks \& Storey, 1992a). These numerous examples of HK and PFK regulation in response to 
environmental stress suggest that glycolysis is a highly-regulated pathway during hypometabolism and in response to stress in general. However, pyruvate kinase, the final main control point of glycolysis, has yet to be studied thoroughly in response to many of these stresses. Its potential regulation in response to freezing, hypoxia and hibernation is therefore of great interest.

\section{Pyruvate Kinase}

Pyruvate kinase (PK; E.C. 2.7.1.40) is a key enzyme of glucose metabolism catalyzing the terminal, nearly irreversible reaction of glycolysis. This enzyme, located in the cytosol, catalyzes the transfer of a phosphate group on phosphoenolpyruvate (PEP) to ADP, producing ATP and pyruvate, and is therefore one of the two substrate-level phosphorylation steps of glycolysis. Its product pyruvate can be further metabolized in the mitochondria to produce ATP via oxidative phosphorylation or fermented in the cytosol by lactate dehydrogenase (LDH) to produce lactic acid. PK is also one of two enzymes operating at the PEP branch point, where PEP can be oxidized by PK or alternatively, in some animals conducting anaerobic metabolism, can be converted to oxaloacetate through the actions of phosphoenolpyruvate carboxykinase (PEPCK). Given the enzyme's situation at a metabolic branch point, the fact that the enzyme directly produces ATP and its product having multiple potential metabolic fates, it should come as no surprise that PK is one of the main control points of glycolysis. Indeed, the regulation of $\mathrm{PK}$ is known to be important for controlling levels of glycolytic intermediates and ATP while inhibition of PK is thought to be a mechanism used to promote gluconeogenesis (Krebs \& Eggleston, 1965; Argaud et al., 1993; Rognstad et al., 1977; Llorente et al., 1970; Jurica et al., 1998). 
PK operates as a tetramer of identical subunits whose molecular weights have been found to vary between $57 \mathrm{kDa}$ in rats (Cottam et al., 1969) to $55 \mathrm{kDa}$ in amphibians (Flanders et al., 1971) to $58 \mathrm{kDa}$ in yeast (Aust \& Suelter, 1978). Each subunit contains its own active site, and residues within the active site are highly conserved between cat, chicken, rat and yeast forms of the enzyme (Muirhead et al., 1986). The tetrameric enzyme contains four metal-biding sites and requires both monovalent ions (normally $\left.\mathrm{Na}^{+}\right)$and divalent ions $\left(\mathrm{Mg}^{2+}\right)$ to be fully active (Munoz \& Ponce, 2003). It has also been shown that PK contains a separate allosteric binding site which is usually occupied by the upstream allosteric activator fructose-1,6-bisphosphate (FBP) and enhances PK activity during times of high glycolytic activity (Jurica et al., 1998). Many other allosteric regulators of PK have also been discovered, though their mechanisms of action are less clear. These include inhibitors ATP, alanine, and citrate and activators AMP and aspartate (Tanaka et al., 1967; Veelen et al., 1979; Baysdorfer et al., 1984; Storey, 1986). The high degree of allosteric regulation of PK makes it a particularly interesting enzyme to study.

Equally interesting are the multiple, structurally unique tissue-specific isoforms of PK observed in mammals and most other vertebrates. In mammals, for example, four types of pyruvate kinase have been identified including type L which is found predominantly in the liver, type $M_{1}$ which is found in most muscle tissue, type $M_{2}$ which is found in rapidly growing and fetal tissues, and type $\mathrm{R}$ which is found in red blood cells (Saheki et al., 1982). Crucially, the different isozymes exhibit significantly different kinetic parameters. The $\mathrm{M}_{1}$-type shows Michaelis-Menten kinetics, the $\mathrm{R}$ - and L-types tend to show allosteric kinetics and the $\mathrm{M}_{2}$-type exhibits varying kinetic parameters 
depending on the species. Furthermore, both L- and R-types appear to be more sensitive allosteric regulation than do the M-types (Hall \& Cottam, 1978). The different isozymes of PK are also known to be differentially phosphorylated. In mammals, for example, the liver form of the enzyme is highly regulated through phosphorylation by cyclic-AMP (cAMP) dependent protein kinases while the predominant muscle form of $\mathrm{PK}, \mathrm{PKM}_{1}$, is not (Titanj et al., 1976; Saheki et al., 1982). In invertebrates the situation is less clear. While some invertebrates like annelids and grasshoppers have been shown to possess multiple isozymes, others express only one, like some sea urchins and snails (Wu et al., 1978). The variety of PK isozymes, their unique kinetic characteristics and their different phosphorylation patterns make PK an even more interesting topic of study. Together with the high degree of allosteric and phopho-regulation of PK, its locus at a metabolic branch point and the fact that it catalyzes an ATP-producing step of glycolysis, PK makes for a good candidate for regulation, especially in response to environmental stress.

Inhibition of PK activity can aid in any system where suppression of carbohydrate catabolism is prioritized or simply where metabolic rate in general must be reduced. In hibernating mice, for example, PK activity in the liver decreases during short-term hibernation. This results in a slower rate of carbohydrate breakdown, allowing gluconeogenesis to occur more easily and regenerate limited carbohydrate stores that are depleted during hibernation and fasting (Storey, 1987b). Similar effects are observed in L-type PK in response to fasting in general. It has also been shown that PK is regulated in response to glucagon and insulin; being phosphorylated and inactivated in the presence of glucagon during fasting such that gluconeogenesis in favored over glycolysis (Blair et al., 1976). Anoxia-tolerant marine invertebrates are another model where PK has been 
studied a great deal. PK has been shown to be sensitive to anoxic stress, generally resulting in decreased enzyme activity due to reversible phosphorylation (Russell \& Storey, 1995; Plaxton \& Storey, 1984). It is thought that this inhibition functions both to decrease energy consumption in general during anoxia exposure and also to promote the activation of alternative anaerobic metabolism pathways, like the succinate pathway. Because of the demonstrated high degree of regulation, PK was chosen as the model enzyme to be investigated in response to environmental stress and hypometabolic conditions.

\section{Model Animals}

Rana sylvatica, the freeze tolerant wood frog

The freeze tolerant wood frog $R$. sylvatica is one of the only vertebrates known to survive whole-body freezing. On account of this animal's excellent freeze tolerance capacity, the wood frog has become the primary animal model for vertebrate freeze tolerance research. During the winter, these animals remain dormant underneath a layer of leaf litter and snow at temperatures as low as $-8^{\circ} \mathrm{C}$ and can survive as much $70 \%$ of their total body water freezing in extracellular spaces (Costanzo et al, 1993). These conditions present the wood frog with a variety of difficulties, including cellular dehydration, a lack of oxygen and accumulation of reactive oxygen species, and the complete arrest of heart beat and breathing. To cope with these hardships, a number of adaptations are necessary, including an extreme metabolic rate depression, activation of pro-survival genes, and, crucially, the accumulation of up $300 \mathrm{mM}$ glucose (up from $5 \mathrm{mM}$ in control frogs) intracellularly to act as a colligative cryoprotectant (Storey \& Storey, 2004c). At the onset of freezing, glycogen is broken down into glucose and released from the liver of the animal into the 
bloodstream where it can be delivered to all tissues. Once inside cells, glucose limits intracellular ice formation and associated physical damage. It also limits cellular dehydration caused by osmotic flow of water out of the cell to join ice crystals forming in extracellular spaces. Due to the importance of carbohydrates and cryoprotectants in these animals for their survival, it has been found that pathways of carbohydrate metabolism are highly regulated in response to freezing. Enzymes of glycolysis and glycogenolysis have been found to be heavily regulated by RPP in such a way that breakdown of glycogen is promoted but glucose catabolism is suppressed. These enzymes include HK, which is inhibited following freezing exposure and GP which is activated in the liver upon freezing (Dieni \& Storey, 2011; Storey \& Storey, 1985). The presence of extensive enzyme regulation in these pathways led to the decision to characterize PK in the muscle of this animal to determine if and how it is regulated in response to freezing and metabolic rate depression.

\section{Littorina littorea, the freeze tolerant gastropod}

The common periwinkle L. littorea inhabits the intertidal zones of the North Atlantic coastlines. At low tide when the snails are out of water they are exposed to anoxic and potentially freezing conditions, depending on the climate. As such, they exhibit high anoxia and freeze tolerance. Indeed, these animals are able to survive up to 8 days at $-8^{\circ} \mathrm{C}$ and 6 days of anoxia exposure (Wieser, 1980; Churchill \& Storey, 1996). Contrary to the wood frog, these animals do not accumulate colligative cryoprotectants and more than likely they rely on the normally high osmolality of cells caused by seawater and free amino acids to avoid cellular dehydration and ice formation (Churchill \& Storey, 1996). Survival during anoxia and freezing exposure necessitates the establishment of a new 
balance of ATP production and consumption which is facilitated through a global metabolic rate depression, and as a consequence these animals drop their metabolic rates by up to $95 \%$ in response to anoxia exposure (Storey et al., 2013). Furthermore, a variety of metabolic enzymes exhibit strong suppression during this period consistent with inactivation via phosphorylation, including GP, GS, and PDH (Russell \& Storey, 1995). A lack of oxygen also requires the initiation of anaerobic pathways to produce ATP, and depending on the length of the anoxia exposure, multiple pathways may be engaged. This leads to the accumulation of multiple anaerobic end products including lactate, alanine, succinate, and propionate and therefore requires strict control of the enzymes of carbohydrate metabolism as animals transition from early- to late-stage anaerobiosis (Storey, 1993). Due to the necessity to strongly regulate the enzymes of carbohydrate metabolism in response to freezing and anoxia, PK was characterized in the foot muscle of L. littorea to determine how it is regulated in response to these conditions.

\section{Urocitellus richardsonii, the hibernating ground squirrel}

Richardson's ground squirrel (U. richardsonii), also known as the prairie gopher, is found across the Canadian prairies and the northern Midwest of the United States. During the winter, these ground-dwelling burrowing animals undergo hibernation individually in chambers called hibernaculum. Hibernation is an adaptation often adopted by mammals faced with surviving subzero temperatures in northern climates during the winter months. During this period, animals must survive with dangerously low food availability and rely on energy stores, particularly lipid-based, accumulated during more favorable periods. To do this, hibernating mammals enter an aerobic dormant state known as torpor which is interspersed with brief periods of arousal known as interbout arousals. The periods of 
aerobic torpor are characterized by a decrease in heart and respiratory rates, repression of their metabolism by as much as $95 \%$ and body temperatures as low as $5^{\circ} \mathrm{C}$ (Geiser, 2004). During hibernation, mammals undergo a significant reorganization of their metabolism which involves suppression of carbohydrate oxidation and an activation of lipid metabolism and gluconeogenesis. This allows them to utilize energy accumulated and stored as fat during the summer months and conserve limited carbohydrate reserves. Indeed, the activity of some enzymes involved in carbohydrate oxidation have been shown to decrease during hibernation, including GP and PFK (Storey, 1987b). Conversely, expression and/or activity of enzymes of lipolysis and gluconeogenesis appears to increase during hibernation (Green et al., 1984; Wilson et al., 1992; Bauer et al., 2001; Squire et al., 2003). Given the importance of suppressing carbohydrate oxidation and activation of gluconeogenesis, PK was characterized in the liver of Richardson's ground squirrel to elucidate its potential role during hibernation.

\section{Objectives}

Many animals exposed to harsh environmental conditions are capable of suppressing their metabolic rate until conditions improve. Generally, this is mediated through the coordinated regulation of biochemical and metabolic pathways and their constitutive enzymes. Reversible protein phosphorylation of metabolic enzymes has been found to be one of the most important regulatory mechanisms in enabling metabolic rate depression. Enzymes regulated in this manner have been identified in many species capable of entering a hypometabolic state including the freeze tolerant wood frog $(R$. sylvatica), the anoxia-tolerant periwinkle (L. littorea), and the hibernating Richardson's

ground squirrel (S. richardsonii). Despite each of the animals being exposed to different 
types of environmental stress, they have all been shown to undergo metabolic rate depression. As previously outlined, one of the core principles of hypometabolism is the need to regulate fuel consumption to ensure limited energy stores can be catabolized slowly throughout the length of the dormancy period. For each of the previously mentioned animals, regulation of carbohydrate metabolism is imperative for survival. In the wood frog, carbohydrates act as the primary cryoprotectants and prevent intracellular freezing and dehydration, while in the periwinkle anaerobic conditions require fermentative pathways to take precedence over aerobic cellular respiration. Finally, the ground squirrel relies in fatty acid metabolism for energy during hibernation and gluconeogenic pathways are prioritized over glycolysis. The research described in this thesis aims to determine whether or not PK, the final enzyme of glycolysis, is regulated in response to environmental stress and whether or not this regulation is mediated through reversible phosphorylation or another post-translational modification entirely. To answer this question, PK will be characterized kinetically, structurally and posttranslationally in the three animal models mentioned above, providing insight into the role this enzyme plays in response to freezing, anaerobiosis and hibernation using the frog, periwinkle and ground squirrel, respectively, as models.

\section{Hypotheses and Predictions}

Based on the importance of regulating carbohydrate metabolism in all three of the animal models investigated in here, I propose that the metabolism of this fuel will be regulated in response to freezing, anoxia and hibernation. This will be accomplished by specifically regulating the activity of PK, a key glycolytic enzyme and control point of glycolysis. Further, I propose that reversible post-translational modifications, namely 
phosphorylation, will mediate this regulation. The three main hypotheses guiding this research are as follows:

1. In the wood frog $R$. sylvatica, metabolic rate is reduced significantly in response to freezing exposure to conserve energy throughout the period of freezing. Furthermore, it is important that the animal maintain elevated levels of glucose intracellularly to act as a cryoprotectant, preventing cellular dehydration and freezing. Therefore, in response to freezing, I hypothesize that PK in the wood frog will be modified such that its activity decreases, ultimately ensuring that cryoprotectant levels remain high and metabolic rate depression is enabled.

2. In the periwinkle L. littorea, survival at low tides depends on decreasing metabolic rate such that anaerobic metabolism can supply adequate energy to fuel vital functions. It also depends on the initiation of multiple anaerobic pathways of metabolism originating at the PEP branch point. Therefore, in response to both freezing and anoxic conditions, I hypothesize that PK in the periwinkle will exhibit decreased activity to contribute to a metabolic rate depression and enable alternative fermentative pathways to be utilized for energy production.

3. In the ground squirrel $U$. richardsonii, survival of hibernation hinges on the animal's ability to decrease its metabolic rate such that limited energy can fuel the animal throughout the hibernation period. It is also important for the animal to imitate gluconeogenesis during hibernation to replenish what limited carbohydrate stores exist. Therefore, I hypothesize that the activity of PK in the liver of Richardson's ground squirrels will decrease during hibernation to enable a metabolic rate depression and facilitate gluconeogenesis. 


\section{Chapter 2}

\section{Purification and Characterization of Pyruvate Kinase from Skeletal Muscle of the Freeze Tolerant Wood Frog, Rana sylvatica}




\section{Introduction}

The freeze tolerant wood frog Rana sylvatica displays some of the most remarkable survival mechanisms of all cold-hardy animals. Sheltering in the subniviean space beneath an insulating layer of leaf litter and snow, it is one of the only vertebrates, along with the box turtle Terrapene Carolina (Constanzo \& Claussen, 2005), known to survive long-term whole-body freezing at temperatures as low as $-5^{\circ} \mathrm{C}$, interspersed with brief periods of thawing (Storey \& Storey, 1988). A variety of metabolic and physiological changes contribute to the animals' survival, including metabolic rate depression, the coordinated accumulation of up to $70 \%$ of the animal's total body water as ice in extracellular spaces, and accumulation of intracellular glucose to depress cellular freezing temperatures well below $0^{\circ} \mathrm{C}$ and decrease cellular dehydration (Storey, 1990; Costanzo et al, 1993; Storey \& Storey, 1986a). During freezing there is also a cessation of breathing and blood circulation, resulting in ischemic and anoxic conditions which ultimately contribute to oxidative damage and impaired access to nutrients (Dawson et al., 2014; Joanisse \& Storey, 1996; Storey, 1990). Generally less-favorable cellular conditions also result from cellular dehydration; a result of ice formation in extracellular spaces causing water to flow out of cells and creating osmotic stress. In turn, molecules become crowded intracellularly and concentrations of urea can accumulate to $90 \mathrm{mM}$ in some tissues (Constanzo \& Lee, 2005).

For many freeze-tolerant animals the accumulation of high levels of small molecular weight cryoprotectants intracellularly and in bodily fluids is key to winter survival. As colligative cryoprotectants, their primary function is to reduce the amount of cellular volume reduction due to extracellular ice formation and therefore prevent the 
shrinking of cells. However, they can also limit intracellular freezing and damage caused by intracellular ice formation and act as effective protein stabilizers during harsh conditions (Storey et al., 1996). These cryoprotectants can take many forms, but are usually small carbohydrate-derived molecules like glucose, glycerol or sorbitol. In the case of the wood frog, glucose is the primary cryoprotectant and can accumulate to levels up to $400 \mathrm{mM}$ during freezing, up from $1-5 \mathrm{mM}$ when unfrozen (Storey and Storey, 1984; Storey \& Storey, 1986b). The animal's metabolism must therefore be highly regulated to support the accumulation and maintenance of these concentrations of glucose during freezing.

Metabolic regulation in $R$. sylvatica has been demonstrated repeatedly to be accomplished through the reversible regulation of enzymes associated with glucose production and catabolism. HK, for example, exhibited a significant decrease in both activity and substrate affinity in response to freezing to strongly limit the rate of muscle glucose catabolism during freezing. Furthermore, studies on the phosphorylation state of the enzyme revealed that reversible desphosphorylation of HK was responsible for these changes in activity (Dieni \& Storey, 2011). The regulation of LDH has also been explored in wood frog muscle in response to freezing-associated dehydration (Abboud \& Storey, 2013). This study showed an increased affinity of lactate dehydrogenase (LDH) for its substrates lactate and NAD during dehydration exposure with a corresponding reduction in $\mathrm{LDH}$ acetylation, the proposed mechanism of enzyme regulation. Finally, enzymes involved in gluconeogenesis, including PEPCK and FBPase, have been shown to be upregulated during freezing in wood frog liver, ensuring that glucose concentrations remain elevated during stress and enabling rapid delivery of the sugar to other tissues 
(Cowan \& Storey, 2001). The prevalence of regulation of enzymes involved in glucose metabolism strongly suggests that it is one of the most important mechanisms ensuring winter survival for these animals.

Pyruvate kinase $(\mathrm{PK})$ is the final enzyme of glycolysis and catalyzes the following irreversible reaction:

$$
\text { Phosphoenolpyruvate }+ \text { ADP } \rightarrow \text { Pyruvate }+ \text { ATP }
$$

In amphibians, much like in mammals, multiple tissue-specific isoforms of the enzyme exist including unique liver and muscle isozymes, each exhibiting different kinetic properties (Dworkin et al., 1987; Isben et al., 1980). In mammalian muscle tissue the enzyme generally displays Michaelis-Menten kinetics while allosteric regulatory mechanisms and post-translational modifications are uncommon (Hall \& Cottam, 1978; Flanders et al., 1971). While the kinetic properties of amphibian muscle PK appear to be similar to mammalian muscle PK, the status of PTMs in amphibian PK is less clear (Fournier \& Gurdeley, 1986). Therefore, there is still significant work to be done to determine if and how PK is regulated in amphibians.

Post-translational modification by RPP is the best-characterized PTM. RPP is an established regulatory mechanism known to act in various cellular processes from metabolism to cellular signaling (Johnson, 2009; Humphrey et al., 2015). The ability of kinases and phosphatases to quickly and reversibly add and remove phosphate groups to a target protein makes it an energy-efficient regulatory method. Animals that survive extreme environmental conditions are known to employ RPP and it has been 
demonstrated to both positively and negatively modulate the activity of metabolic enzymes depending on the needs of the animal. In the wood frog, stress-responsive RPP is responsible for the regulation of many metabolic enzymes. Together with the previously-mentioned example of RPP-mediated suppression of HK activity, evidence of decreased affinity of G6PDH for its substrate G6P due to RPP support a role for RPP in regulating glucose metabolism in the wood frog (Dieni \& Storey, 2011; Dieni \& Storey, 2010). Otherwise, RPP has been demonstrated to play a role in the regulation of antioxidant defense by activing catalase in wood frog muscle during freezing while RPPmediated activation of creatine kinase was proposed as a mechanism of maintaining ATP levels in wood frog muscle during freezing (Dawson \& Storey, 2016; Dieni \& Storey, 2009).

In this chapter, it is demonstrated that PK in the freeze-tolerant wood frog is regulated by RPP in such a way that the maintenance of intracellular glucose is prioritized over its consumption as fuel. This is exemplified by the decrease in PEP affinity of PK when the animal is in its frozen and dehydrated states, which is accompanied by a simultaneous reduction in serine phosphorylation. Furthermore, it is demonstrated that an increase in enzyme stability occurs during freezing, shown through PK incubations in denaturants and high temperature. This stability change after serine phosphorylation is evidence of RPP promoting increased protein stability during freezing when cellular conditions are relatively less favorable. Together, the results from this study show that the regulation of PK in the wood frog muscle may play a role in maintaining levels of glucose intracellularly during freezing and dehydration. 


\section{Materials and Methods}

\section{Animals}

Male wood frogs ( $R$. sylvatica) were captured from the Ottawa area. Animals were washed and kept in plastic containers with a damp moss bed at $5^{\circ} \mathrm{C}$ for two weeks (control condition) before being subjected to experimental conditions. For freezing conditions, frogs were placed in a plastic box lined with damp paper towel and placed in an incubator set to $-4^{\circ} \mathrm{C}$ for $24 \mathrm{~h}$ before sampling. Placing frogs in a desiccator lined with a silica gel desiccant simulated dehydration conditions. A $1 \mathrm{~cm}$-thick layer of sponge separated the frogs from the desiccant. Frogs were weighed at regular intervals until they had lost $40 \%$ of total body water. Frogs were subjected to anoxic conditions by being placed in sealed containers flushed with nitrogen gas. A small amount of water was left in the bottom of the containers to maintain hydration throughout the procedure. Animals were held in these containers for $24 \mathrm{~h}$ at $5^{\circ} \mathrm{C}$. Control and experimental animals were sacrificed by pithing followed by rapid dissection. Tissues were flash-frozen in liquid nitrogen and stored at $-80^{\circ} \mathrm{C}$ until use. All experiments performed were in accordance with the Carleton University Animal Care Committee (B09-22) and abided by the guidelines set down by the Canadian Council on Animal Care.

\section{Preparations of tissue}

PK was isolated from both control and frozen samples of hind-leg skeletal muscle of Rana sylvatica. Tissue samples were quickly weighed and added to 5 volumes of icecold homogenization buffer A which included: 10 mM MES, pH 6.0, 2 mM EDTA, 2 mM EGTA, $15 \mathrm{mM} \beta$-glycerophosphate, $15 \mathrm{mM} \beta$-mercaptoethanol ( $\beta$-MeSH), $10 \% \mathrm{v} / \mathrm{v}$ 
glycerol, with a small scoop of phenylmethylsulphonyl fluoride (PMSF) crystals added immediately before homogenization. Samples were homogenized completely using a Polytron homogenizer (Brinkmann Instruments, Westbury, NY, USA) and spun in an Eppendorf 5810R centrifuge (22331 Hamburg, GER) for $30 \mathrm{~min}$ at $13500 \mathrm{x} g$ and $5^{\circ} \mathrm{C}$. The supernatant (crude homogenate) was decanted and held on ice until use.

\section{Pyruvate Kinase Assay}

Pyruvate kinase activity was measured by coupling its reaction to the consumption of NADH by LDH, which was measured using a microplate reader (Multiskan Spectrum, Thermo Labsystems, Finland) measuring absorbance at $340 \mathrm{~nm}$. Optimal assay conditions were found to be $50 \mathrm{mM}$ Tris at $\mathrm{pH}$ 7.2, $20 \mathrm{mM} \mathrm{KCl}, 2 \mathrm{mM}$ ADP, $5 \mathrm{mM} \mathrm{MgCl} 2,1 \mathrm{mM}$ PEP, $1 \mathrm{U}$ of $\mathrm{LDH}$ and $0.15 \mathrm{mM} \mathrm{NADH}$. Reactions were carried out in a total volume of $200 \mu \mathrm{L}$. Assays were started by the addition of PK. $\mathrm{V}_{\max }$, $\mathrm{K}_{\mathrm{m}}$ and $\mathrm{I}_{50}$ values were determined at optimal assay conditions, as stated above.

Low-temperature assays were carried out by placing the spectrophotometer in a VWR International BOD 2020 Incubator (Sheldon Manufacturing Inc., OR, USA) set to the desired temperature and left to equilibrate to either $13^{\circ} \mathrm{C}$ or $5^{\circ} \mathrm{C}$. All assay reagents and buffers were also equilibrated at the corresponding temperature prior to starting the assay. Temperatures of reagents and incubator were monitored using a telethermometer (Traceable, TX, USA).

\section{Purification of Pyruvate Kinase}

A $1 \mathrm{~mL}$ aliquot of crude homogenate was added to a $\mathrm{CM}^{-}$sephadex column $(0.75$ $\mathrm{cm}$ X $10 \mathrm{~cm}$ ) that had been previously equilibrated with $20 \mathrm{~mL}$ of buffer A. The column 
was then washed with $15 \mathrm{~mL}$ of buffer B (MOPS, pH 6.75, 2mM EDTA, 2mM EGTA, $15 \mathrm{mM} \beta$-glycerophosphate, $15 \mathrm{mM} \beta-\mathrm{MeSH}, 10 \% \mathrm{v} / \mathrm{v}$ glycerol) and the enzyme was eluted with $30 \mathrm{~mL}$ of a $0.5 \mathrm{mM}$ PEP solution made in buffer B. Using an automated fraction collector (Gilson Medical Electronics, Inc., Middleton, WI, USA) $1.2 \mathrm{~mL}$ fractions of column eluant were collected. To determine where PK eluted from the column, $10 \mu \mathrm{L}$ of each fraction was taken and used to measure PK activity spectrophotometrically as seen above. Peak activity fractions were pooled, reduced to $\mathrm{pH}$ 6.0 and diluted 3:1 by adding buffer C (10 mM MES, pH 5.9, 2 mM EDTA, 2 mM EGTA, $15 \mathrm{mM} \beta$-glycerophosphate, $15 \mathrm{mM} \beta$-MeSH and 10\% v/v glycerol). The pooled fractions were then added to a second $\mathrm{CM}^{-}$sephadex column, identical to the first equilibrated in buffer A. PK was eluted with a $0-1 \mathrm{M} \mathrm{KCl}$ gradient made in buffer $\mathrm{A}$ and collected in $1.2 \mathrm{~mL}$ fractions which were then assayed for PK activity using $10 \mu \mathrm{L}$ from each fraction, as before. Peak fractions were pooled and used for all subsequent experiments. Protein concentrations were determined using Coomassie blue G-250 dyebinding reagent (Bio-Rad, Hercules, CA, USA) as instructed by the manufacturer using bovine serum albumin as a standard (Bradford, 1976).

\section{Incubation experiments}

Incubation experiments were performed to determine the stability of PK under different environmental conditions; (i) high temperature, and (ii) high concentrations of urea.

(i) Aliquots of $750 \mu \mathrm{L}$ of purified enzyme samples were incubated at $52^{\circ} \mathrm{C}$ using a dry block heater (Fischer Scientific, Dubuque, IA, USA) for up to $90 \mathrm{~min}$, with or without $400 \mathrm{mM}$ glucose present. $25 \mu \mathrm{L}$ aliquots of sample were removed from the stock sample at specified time intervals and immediately 
placed on ice. Following removal of the final aliquot after $90 \mathrm{~min}$, samples were left to equilibrate at room temperature before being assayed at optimal conditions. The reported value $\left(\mathrm{t}_{\mathrm{m}}\right)$ is the incubation time that resulted in a $\mathrm{V}_{\max }$ reduced to $50 \%$ of the non-incubated value.

(ii) Urea incubations were performed by incubating samples of purified PK in increasing concentrations of urea (up to $3 \mathrm{M}$ ) for a $90 \mathrm{~min}$ period at room temperature, with or without $400 \mathrm{mM}$ glucose present. Following completion of the 90 min incubation period, samples were immediately assayed at optimal conditions. The reported value $\left(\mathrm{C}_{\mathrm{m}}\right)$ is the concentration of urea that resulted in a $\mathrm{V}_{\max }$ that had been reduced to $50 \%$ of the original $\mathrm{V}_{\max }$, following the 90 min incubation.

\section{SDS Polyacrylamide Gel Electrophoresis and Immunoblotting}

Purity and identity of PK were confirmed using SDS-PAGE and western blotting experiments. Following purification of PK, purified samples were mixed in a 1:1 (v/v) ratio of SDS-PAGE loading buffer consisting of 100mM Tris buffer at $\mathrm{pH} 6.8,4 \% \mathrm{w} / \mathrm{v}$ SDS, $20 \% \mathrm{v} / \mathrm{v}$ glycerol, $0.2 \% \mathrm{w} / \mathrm{v}$ bromophenol blue and $10 \% \mathrm{v} / \mathrm{v} \beta-\mathrm{MeSH}$ and were boiled for 5 minutes before being stored at $-20^{\circ} \mathrm{C}$ until use. Samples were resolved on a $10 \%$ SDS polyacrylamide gel (10\% v/v acrylamide, $400 \mathrm{mM}$ Tris, $\mathrm{pH} 8.8,0.1 \% \mathrm{w} / \mathrm{v}$ SDS, $0.2 \% \mathrm{w} / \mathrm{v}$ ammonium persulfate (APS), $0.04 \% \mathrm{v} / \mathrm{v}$ TEMED) with a $5 \%$ stacking gel consisting of 5\% acrylamide, $190 \mathrm{mM}$ Tris, $\mathrm{pH} 6.8,0.1 \% \mathrm{w} / \mathrm{v}$ SDS, $0.15 \% \mathrm{w} / \mathrm{v}$ APS, and $0.1 \% \mathrm{v} / \mathrm{v}$ TEMED. Samples were separated through electrophoresis at a constant voltage

of $180 \mathrm{~V}$ for $55 \mathrm{~min}$ at room temperature in SDS-PAGE running buffer ( $25 \mathrm{mM}$ Tris-base, $\mathrm{pH} 8.5,190 \mathrm{mM}$ glycine, and 0.1\% w/v SDS). A protein molecular weight ladder 
(Froggabio, Cat. \#PM005-0500) and a commercially purified sample of rabbit muscle pyruvate kinase (Sigma Life Sciences, Cat. \#P1506) were also run on every gel. Following the completion of gel electrophoresis, gels were either (1) stained directly in Coomassie blue stain to determine protein purity $(0.25 \% \mathrm{w} / \mathrm{v}$ Coomassie brilliant blue, $7.5 \% \mathrm{v} / \mathrm{v}$ acetic acid, 50\% methanol) or (2) transferred to polyvinylidiene difluoride (PVDF) membranes for western blotting.

For direct Coomassie blue staining, gels were initially fixed for $1 \mathrm{~h}$ in fixing solution $(10 \% \mathrm{v} / \mathrm{v}$ acetic acid, $25 \%(\mathrm{v} / \mathrm{v})$ methanol) before being rinsed gently with $\mathrm{ddH}_{2} \mathrm{O}$ and then stained completely in Coomasie blue solution overnight with gentle rocking. The stain solution was then removed, and the gels rinsed with $\mathrm{ddH}_{2} \mathrm{O}$ before being submerged in destain solution ( $10 \% \mathrm{v} / \mathrm{v}$ acetic acid, $25 \% \mathrm{v} / \mathrm{v}$ methanol) with gentle rocking until protein bands could be seen clearly. The gels were then rehydrated in $\mathrm{ddH}_{2} \mathrm{O}$ and imaged using ChemiGenius Bio Imaging System (Syngene, Frederick, MD).

\section{Western Blotting}

Western-blotting was used to compare the levels of serine phosphorylation of control, dehydrated and anoxic forms of PK and to confirm the identity of purified PK. For western-blotting, after the SDS-PAGE was run the proteins were transferred to polyvinylidiene difluoride (PVDF) membranes using a wet transfer procedure as follows: PVDF membranes were first equilibrated in methanol prior to the protein transfer. Electroblotting was carried out in transfer buffer (25 mM Tris, $\mathrm{pH}$ 8.5, $192 \mathrm{mM}$ glycine, and $20 \% \mathrm{v} / \mathrm{v}$ methanol) at a constant amperage of $160 \mathrm{~mA}$ for $90 \mathrm{~min}$ and were maintained at $5^{\circ} \mathrm{C}$ throughout. To prevent non-specific antibody:protein interactions, membranes were blocked with a $1.5 \%$ (w:v) skim milk protein solution made in tris- 
buffered saline solution with Tween (TBST) (20 mM Tris-base, pH 7.6, $140 \mathrm{mM} \mathrm{NaCl}$, $0.05 \%$ Tween-20) solution for 20 minutes with gentle rocking at room temperature. The blocking solution was removed and the membranes were washed three times for 5 minutes ( 3 X $5 \mathrm{~min}$ ) in TBST. Membranes were then incubated in primary antibody overnight (rabbit anti-pyruvate kinase (muscle), Genetex, Irvine, CA, USA Cat. \#GTX107977; rabbit anti-phosphoserine, Cat. \#618100, Invitrogen, Carlsbad, CA, USA) diluted 1:1000 in TBST at $4^{\circ} \mathrm{C}$. Primary antibody was removed the following day and the blots were washed ( 3 X $5 \mathrm{~min}$ ) in TBST prior to incubation in goat anti-rabbit horseradish peroxidase-conjugated secondary antibody (Bioshop, Cat. \#APA007P.2) for $45 \mathrm{~min}$ at room temperature with gentle rocking. Membranes were washed in TBST $(3 \mathrm{x}$ 5 min) before being visualized by enhanced chemiluminescence (peroxide and luminol) with the ChemiGenius Bio Imaging System. Membranes were then stained with Coomassie blue to be used to standardize the chemiluminescence signals. Blot quantification and analysis was performed using genetools software (Syngene, v 4.02).

\section{Dot Blots}

Dot blots were used to identify and quantify the posttranslational modifications on completely purified PK from control and frozen tissue using a Bio-Dot Microfiltration apparatus (Bio-Rad, Hercules, CA, USA). Nitrocellulose membranes were hydrated in TBST and placed in the Bio-Dot apparatus according to manufacturer's instructions. Purified PK samples were applied to nitrocellulose membranes (Bio-Rad, Hercules, CA, USA) and allowed to filter through the membrane by gravity flow. Membranes were then washed twice with $100 \mu \mathrm{L}$ of $\mathrm{ddH}_{2} \mathrm{O}$, removed from the apparatus, and blocked in $1.5 \%$ W:V milk protein solution for 20 minutes followed by washing in TBST ( 3 X $5 \mathrm{~min}$ ). 
Membranes were then incubated overnight at $4^{\circ} \mathrm{C}$ with gentle rocking with one of the following primary antibodies (from Invitrogen, Carlsbad, CA, USA): (1) rabbit antiphosphoserine (Cat. \#618100); (2) rabbit anti-phosphothreonine (Cat. \#718200); (3) mouse anti-phosphotyrosine (Cat. \#615800); (from Santa Cruz Biotechnology, Dallas, TX, USA) (4) rabbit anti-pan-Acetyl (Cat. \# sc-8663-R). All primary antibodies were diluted 1:1000 v/v in TBST with a small amount of sodium azide added. After the primary antibody overnight incubation, membranes were washed with TBST ( 3 X $5 \mathrm{~min})$ and incubated with either goat anti-rabbit- or rabbit anti-mouse peroxidase-conjugated secondary antibody for $45 \mathrm{~min}$ with gentle rocking at room temperature. Membranes were washed in TBST ( 3 X 5 min) before being visualized. All visualization and quantification procedures were performed as described previously for Western Blotting.

\section{Differential Scanning Fluorimetry}

Purified control and frozen samples of PK were concentrated $20 \mathrm{X}$ using Amicon Ultra-4 centrifugal filters with a $10 \mathrm{kDa}$ cutoff (Merck Millipore Ltd., Tullagreen, Carrigtwohill, Co., Cork, IRL) by centrifugation at $8,000 \times \mathrm{g}$ for $30 \mathrm{~min}$. Differential scanning fluorimetry (DSF) was used to study protein unfolding and thermal stability as previously-described (Biggar et al. 2012). In a reaction mixture with a total volume of 20ul, 2.5uL of 40X diluted stock SYPRO Orange dye (Invitrogen, Carlsbad, CA, USA) was added to $17.5 \mathrm{uL}$ of purified enzyme $(0.03 \mathrm{mg} / \mathrm{mL})$ in a 96 -well plate and sealed with optical adhesive film. The thermocycling protocol, which increased the temperature by $1^{\circ} \mathrm{C}$ every $30 \mathrm{~s}$ from $15^{\circ} \mathrm{C}$ to $95^{\circ} \mathrm{C}$, was run in a MyIQ2 qRT-PCR thermocycler (BioRad, Hercules, CA, USA). The fluorescence of SYPRO Orange was measured every $5 \mathrm{~s}$ (excitation filter: $485 \pm 30 \mathrm{~nm}$, emission filter: $625 \pm 30 \mathrm{~nm}$ ) using the MyIQ2 software 
(version 3.0.6070, BioRad, Hercules, CA, USA). Data were analyzed using Origin Pro 8.5 software (OriginLab corp, Northampton, MA, USA) to determine the temperature at which half of the protein had unfolded $\left(\mathrm{T}_{\mathrm{m}}\right)$ using a Boltzmann distribution curve.

\section{Data and Statistical Analyses}

All enzyme assays were analyzed using a microplate analysis program (Brooks, 1994) while kinetic parameters ( $\mathrm{I}_{50}$ and $\mathrm{K}_{\mathrm{m}}$ values) were determined using a nonlinear least squares regression computer program (Kinetics v. 3.51; Brooks, 1992b). A Hill equation curve $(\mathrm{h}>0)$ was used to fit the data points and determine the kinetic parameters.

Data for all kinetic parameters, dot blots and DSF comparing the control and frozen samples were analyzed using the Student's $t$-test (two-tailed) where a significant result was $p<0.05$. Data for all kinetic parameters and western blots comparing the control, frozen, dehydrated and anoxic forms of PK were compared using a one-way analysis of variances (ANOVAs) followed by Dunnett's post hoc test $(p<0.05)$. All statistical analyses were carried-out using Sigmaplot v12 (SYSTAT, San Jose, CA, USA).

\section{Results}

\section{Purification of Pyruvate Kinase}

PK was successfully purified from control and frozen samples of skeletal muscle of $R$. sylvatica by column chromatography using two consecutive $\mathrm{CM}^{-}$sephadex columns. PK was eluted from the first column using $0.5 \mathrm{mM}$ PEP at a $\mathrm{pH}$ of 6.75 
followed by elution from the second $\mathrm{CM}^{-}$column using a $0-1 \mathrm{M} \mathrm{KCl}$ gradient. The first $\mathrm{CM}^{-}$column gave a 16.2 -fold purification (27\% yield) with a specific activity of 22.2 $\mathrm{U} / \mathrm{mg}$, while the second and final step resulted in a final 41 -fold purification with a specific activity of $56.5 \mathrm{U} / \mathrm{mg}$ and a final $23 \%$ yield (table 2.1 ). This two-step purification resulted in PK being purified to $>95 \%$ purity as determined by SDS-PAGE and staining with coomassie blue. The purified PK had a molecular weight of $63 \mathrm{kDa}$ (figure 2.1), determined through the relative migration distance method. The identity of purified PK was confirmed by western blotting (data not shown).

\section{Kinetic activity of PK}

The $\mathrm{V}_{\max }$ and total activity of PK did not differ significantly between the control and frozen forms of the enzyme at any temperature tested $\left(5^{\circ} \mathrm{C}, 13^{\circ} \mathrm{C}\right.$, or $\left.22^{\circ} \mathrm{C}\right)($ table 2.2). The $K_{m} P E P$ of $P K$ increased significantly in the frozen $(0.098 \pm 0.003 \mathrm{mM})$ and dehydrated $(0.092 \pm 0.008 \mathrm{mM})$ animals when compared to the control $(0.065 \pm 0.003$ $\mathrm{mM})$ while no significant change was observed between the anoxic $(0.073 \pm 0.002)$ and control forms of PK (table 2.2; table A1.1). No significant change was observed in the $\mathrm{K}_{\mathrm{m}} \mathrm{ADP}(0.22 \mathrm{mM})$ between the control and frozen forms of PK. Furthermore, the activation energy $\left(E_{a}\right)$ of the reaction was found to be same $(35.12 \mathrm{~kJ} / \mathrm{mol})$ in both conditions (table 2.2).

The addition of various potential allosteric effectors $(400 \mathrm{mM}$ glucose, $5 \mathrm{mM}$ ATP, $5 \mathrm{mM}$ AMP, $2 \mathrm{mM} \mathrm{FBP}$ ) did not significantly alter the $\mathrm{K}_{\mathrm{m}} \mathrm{PEP}$ of the control or frozen forms of PK. However, the presence of $100 \mathrm{mM}$ urea resulted in a significant increase in the $\mathrm{K}_{\mathrm{m}} \mathrm{PEP}$ under both control and frozen conditions (0.5-fold and 0.7 -fold 
increases, respectively; table 2.3 ). The $\mathrm{K}_{\mathrm{m}} \mathrm{PEP}$ was consistently found to be significantly higher in the frozen tissue than in the control tissue with one exception; the addition of 5 $\mathrm{mM}$ AMP. When 5mM AMP was added the control and frozen $\mathrm{K}_{\mathrm{m}} \mathrm{PEP}$ values did not differ significantly.

Addition of both urea and ATP had an inhibitory effect on the $\mathrm{V}_{\max }$ of PK, though the resulting $\mathrm{I}_{50}$ values were the same for the control and frozen forms of the enzyme $\left(\mathrm{I}_{50}\right.$ urea $\left.=0.43 \mathrm{M} ; \mathrm{I}_{50} \mathrm{ATP}=11.1 \mathrm{mM}\right)$. Additionally, the inclusion of $400 \mathrm{mM}$ glucose in the assay well resulted in a nearly 4-fold increase of the I50urea for both control and frozen PK (table 2.4). AMP, FBP, alanine and aspartate (up to $25 \mathrm{mM}$ ) and glucose (up to $750 \mathrm{mM}$ ) had no effect, activating or inhibitory, on the $\mathrm{V}_{\max }$ of $\mathrm{PK}$ (table 2.4).

\section{Post-translational modifications of PK}

Immunoblotting using a dot blot apparatus was used to assess the differences in the post-translational modifications of purified muscle PK from control and frozen conditions. Phosphorylation via serine residues of the frozen form of PK was 0.5 -fold higher than the control form of PK (figure 2.3). The phosphorylation levels of threonine and tyrosine residues as well as total acetylation levels between control and frozen PK did not differ significantly. Western blotting was used to investigate serinephosphorylation in the anoxic and dehydrated forms of PK, as well. While the anoxic form did not change relative to the control, serine phosphorylation of dehydrated PK was found to be $25 \%$ higher than the control (figure A1.1). 


\section{Structural stability of PK}

Structural stability of pyruvate kinase was investigated by examining stability under various durations of high temperature (i) and under various high concentrations of urea for $90 \mathrm{~min}$ (ii) (figure 2.2).

(i) During incubations at $52^{\circ} \mathrm{C}$, the control form of $\mathrm{PK}$ was significantly less stable than the frozen form with the $\mathrm{V}_{\max }$ being reduced by $50 \%$ after 3.00 $\pm 0.02 \mathrm{~min}$ and $13.7 \pm 0.02 \mathrm{~min}$, for control and frozen tissue PK respectively. This trend of PK from frozen muscle remaining more stable than PK from control muscle was also found when the proteins were incubated at $52{ }^{\circ} \mathrm{C}$ with $400 \mathrm{mM}$ glucose (figures 2.2A and 2.2B).

(ii) Similarly, when PK was incubated in increasing concentrations of urea the $\mathrm{V}_{\max }$ was reduced to $50 \%$ at a significantly lower concentration of urea in the control form $(0.832 \pm 0.01 \mathrm{M})$ compared to the frozen form $(1.24 \pm$ $0.03 \mathrm{M}$ ) (figure 2.2C). When incubated with $400 \mathrm{mM}$ glucose the PK purified from control tissue was still less stable than the frozen form with $\mathrm{V}_{\max }$ values being reduced to $50 \%$ at $1.01 \pm 0.02 \mathrm{M}$ urea and $1.31 \pm 0.06$ $\mathrm{M}$ urea respectively (figure 2.2D).

When PK was incubated in urea for 90 minutes or incubated at $52^{\circ} \mathrm{C}$ for any duration, control PK was found to be significantly stabilized when $400 \mathrm{mM}$ glucose was included in the incubation solution, while frozen PK was not affected 
(figure 2.2). When DSF was performed to determine the melting temperature of control and frozen PK no significant difference was detected with both demonstrating an averaged $\mathrm{T}_{\mathrm{m}}$ of $47.93^{\circ} \mathrm{C}$ (table 2.2 ).

\section{Discussion}

Like other freeze-tolerant animals, metabolic rate depression and the accumulation of glucose as a cryoprotectant are paramount to the wood frog's coldhardiness (Storey, 1997a; Slotsbo et al., 2008; Constanzo \& Lee, 2013; Storey \& Storey, 2013). In order to accomplish a buildup of glucose, the tight regulation of the enzymes responsible for glucose metabolism is critical, making enzyme regulation crucial for $R$. sylvatica survival. This led to the postulation that pyruvate kinase, the terminal enzyme of glycolysis, would be regulated in such a way that glucose metabolism is hampered during freezing and other environmental stress. Certainly, the results of this study reveal that the frozen and dehydrated forms of PK exhibit notably different properties compared to the control form. Furthermore it is demonstrated that stress-responsive reversible phosphorylation is a likely mechanism responsible for the observed changes in the kinetic properties of PK.

Wood frog skeletal muscle PK from control and frozen tissues was purified to homogeneity through ion-exchange chromatography using both substrate specific and non-specific elution methods. Typical purifications resulted in the enzyme becoming purified to $56.48 \mathrm{U} / \mathrm{mg}$ protein, a 41 -fold purification and that retained $23 \%$ of the crude activity (table 2.1). This purification was adapted from Scopes (1977) by using a combination of $\mathrm{pH}$ and specific metabolites to elute $\mathrm{PK}$ from a $\mathrm{CM}^{-}$column. It validates the notion that proteins can be purified rapidly and efficiently without the use of affinity 
chromatography. The simplicity of this procedure allows for a highly reproducible method for the purification of PK from other tissues and animals.

The kinetic properties of $R$. sylvatica PK were significantly different between the control condition and both the frozen and the dehydrated conditions, suggesting that the enzyme is being regulated when the frog is enduring these conditions (table 2.2; table A1.1). Principally, the $K_{m} P E P$ was significantly higher ( $\sim .5$-fold) in both of these experimental conditions compared to the control, while the anoxic and control forms did not differ significantly. Furthermore, the frozen $\mathrm{K}_{\mathrm{m}} \mathrm{PEP}$ was consistently higher than that of the control regardless of the additions of various metabolites and potential allosteric regulators (table 2.3). This strongly suggests that $\mathrm{PK}$ is being negatively regulated during environmental freezing and dehydration. Accordingly, previous studies have demonstrated that PK is differentially regulated in response to environmental stress. The estivating spadefoot toad, Scaphiopus couchii, is capable of surviving the loss of up to $50 \%$ of their total body water while surviving in desert environments (McClanahan, 1967). In response to this severe dehydration, muscle PK displays a decreased affinity for PEP, corroborating the results observed in this study (Cowan \& Storey, 1999). It is also interesting to note, then, that dehydration-tolerance is hypothesized to be the evolutionary predecessor to freeze-tolerance. This theory has been primarily supported through observations that dehydration alone is sufficient to induce a freeze tolerance-like response in both freeze-tolerant and freeze-intolerant species of frogs. This response includes the accumulation of cryoprotectants like glucose and urea (Churchill \& Storey, 1994; Churchill \& Storey, 1995; Edwards et al., 2004; Costanzo et al., 1993). If the freezing response is similar to the dehydration response, and freeze tolerant species are 
usually also dehydration resistant (but not necessarily vice versa), there is reason to believe that freeze tolerance evolved from dehydration tolerance. The data from the current study supports this hypothesis, revealing that the regulation of PK is similar in response to both freezing and dehydration, but not to anoxia. It also shows that not only do cryoprotectants accumulate during dehydration in a similar manner to freezing, but that enzymes are also regulated similarly.

A decrease in PK activity would be beneficial to the winter survival of $R$. sylvatica for multiple reasons: (1) the negative regulation of this glycolytic enzyme would contribute to an overall metabolic rate depression to conserve energy, and (2) it would limit the consumption of the vital cryoprotectant, glucose by slowing the rate of glycolysis. To address the former point, significant literature has been published in support of metabolic rate depression as a primary mechanism of surviving freezing and other environmental stress (reviewed in: Storey \& Storey, 2013). By entering a hypometabolic state, animals avoid expending energy on processes that are not necessary for survival or are too energetically-costly to conduct when there is limited fuel storage and energy is generated primarily through anaerobic respiration. This phenomenon has been observed in animals ranging from freeze-tolerant insects to mammalian hibernators (Storey \& Storey, 2012; Storey \& Storey, 2010; Storey, 2010), all of which demonstrate a downregulation of processes consuming large quantities of ATP including protein transcription and translation and membrane ion transport. Metabolic rate depression is equally important for winter survival of wood frogs as it ensures limited fuel stores can last the entire freezing period and that sufficient energy remains post-freezing to allow for energy-costly activities such as mating. The inhibition of PK through reversible 
phosphorylation would contribute to reducing energy expenditure during freezing by limiting glycolytic flux, ultimately slowing the production of pyruvate and the downstream pathways it is fed into. Furthermore, ATP production is suppressed directly as PK catalyzes a reaction of ATP synthesis through substrate-level phosphorylation.

With respect to the conservation of the frog's cryoprotectant, glucose, the results from this study lend support to the theory that glucose consumption must be limited during cold exposure to preserve cryoprotectant levels. The importance of glucose in winter survival of the wood frog has already been well-established (Storey \& Storey, 1992). By accumulating to levels of up to $400 \mathrm{mM}$, wood frogs can depress their intracellular freezing point to significantly below $0^{\circ} \mathrm{C}$ and limit cellular dehydration. By decreasing glycolytic activity, glucose levels can remain high enough that freezetolerance can be maintained. The significant decrease in affinity for its substrate, exhibited by a $50 \%$ increase in the $\mathrm{K}_{\mathrm{m}} \mathrm{PEP}$ during freezing and dehydration, suggests that PK is being regulated to restrict its activity, and the rate of glycolysis in general. Enzyme-dependent down-regulation of glycolysis in the wood frog has been clearly demonstrated through a series of studies on early glycolytic enzymes. For example, HK demonstrated a decrease in total activity and affinity for its substrate following freezing exposure (Dieni \& Storey, 2011), showing direct limitation of glycolysis. Studies of enzymes also suggest that the pentose-phosphate pathway is suppressed in wood frog muscle during freezing, as the activities of both G6PDH and 6-phosphogluconate dehydrogenase (6PGDH), two enzymes of this pathway, decrease upon freeze exposure (Dieni \& Storey, 2010; Cowan \& Storey, 2001). This has the effect of limiting the rate at which glucose-6-phoshpate is removed from the cryoprotectant pool and shunted into 
another metabolic pathway. Further support for this theory comes from the finding that PEPCK, the gluconeogenic enzyme that directly opposes the action of PK, shows an increased activity in wood frog liver in response to freezing (Cowan \& Storey, 2001), emphasizing the importance of gluconeogenesis in responding to this stress. There is also evidence to show that muscle glycogen stores are converted into glucose early in freezing, despite the inhibition of glycolysis. Levels of glycogen in muscle tissue have been shown to decrease by as much as $50 \%$ through the first $72 \mathrm{~h}$ of freezing while glucose levels increase accordingly and apparently are not consumed for energy. This demonstrates the importance of accumulating this cryoprotectant for freeze survival (Storey \& Storey, 1986b). Together with the results presented in the current study, there is significant evidence showing that wood frog metabolism is regulated during freezing stress to hinder glycolysis and glucose catabolism in muscle tissue and support accumulation of glucose as a cryoprotectant.

Finally, the observation that the $\mathrm{K}_{\mathrm{m}} \mathrm{PEP}$ increases 0.5 -fold (table 2.3) in the presence of $100 \mathrm{mM}$ urea in both control and frozen tissues suggests that urea could act as a regulator of PK during freezing, contributing to both metabolic rate depression and conservation of glucose. Urea has been previously shown to accumulate to levels up to 90 $\mathrm{mM}$ in cold-acclimated frogs (Costanzo \& Lee, 2005), suggesting that its effect on PK could be a physiological mechanism to regulate the activity of the enzyme during stress. These results appear to support findings from a study by Muir et al. (2008) in which ureatreated organs of R. sylvatica had significantly-depressed metabolic rates (up to a $50 \%$ decrease) compared to control organs. This study led to the proposal of the ureahypometabolism hypothesis, which supposes that accumulated urea in the wood frog acts 
as a mediator of metabolic rate depression. Similar urea-induced metabolic rate depression was observed in organs of other urea-accumulating animals, including amphibians Spea bombifrons and Ambystoma tigrinum, the diamondback turtle Malaclemys terrapin and the marine invertebrate Anguispira alternate (Muir et al., 2010). The evidence presented here suggests that the decrease in metabolic rate observed by Muir et al. is caused in part by urea-mediated inhibition of metabolic enzymes. As levels of urea increase during freezing, the activity of PK decreases accordingly. Other enzymes may be inhibited similarly by urea and act in concert to reduce the metabolic rate of the animal during times of environmental duress.

An increase in serine phosphorylation of PK was observed after exposure to freezing ( 0.5 -fold increase, figure 2.3$)$ and dehydration ( 0.25 -fold increase, figure A1.1) relative to the control. In combination with the analysis of PEP substrate affinity in these states it can be suggested that the phosphorylation of serine residues is a potential mechanism for decreasing the affinity of PK for PEP during both dehydration and freezing conditions. Reversible serine phosphorylation on PK therefore is a likely mechanism that contributes to the overall metabolic rate depression and conservation of glucose in R. sylvatica. The phosphorylation of serine residues could be causing a conformational change in the structure of PK resulting in hindered access to the active site and the observed increase in the $\mathrm{K}_{\mathrm{m}} \mathrm{PEP}$. There is significant evidence supporting phosphorylation as the regulatory mechanism of enzymes during periods of environmental stress, including many instances in the wood frog. These include G6PDH, CK and CAT (Dieni \& Storey, 2010; Dieni \& Storey, 2009; Dawson \& Storey, 2016). 
These results suggest that PK, too, is a target of regulation via RPP in the wood frog during freezing.

It is very possible that the differential phosphorylation patterns observed between the control, frozen, and dehydrated forms of the enzyme are due to differential regulation of upstream protein kinases. Recent studies have shown that protein kinase A, (PKA) C (PKC) and 5' AMP-activated protein kinase (AMPK) exhibit different properties in control, frozen and dehydrated wood frog tissues (Holden \& Storey, 2010; Dieni \& Storey, 2014; Rider et al., 2006). In the liver, for example, PKA is activated in response to low temperatures, with evidence suggesting a conformational change occurring at $10^{\circ} \mathrm{C}$ results in an increased affinity for its substrate (Holden \& Storey, 2000). Similarly, studies on wood frog skeletal muscle reveal that both dehydration and freezing, but not anoxia, induces an increase in the percentage of PKA as the free catalytic subunit (PKAc) within minutes of stress exposure, suggesting that this kinase plays a role in preparing muscle tissue for both dehydration and freezing exposure (Holden \& Storey, 1997; Holden \& Storey, 1996). It was postulated that this response in skeletal muscle may contribute to increased ischemia endurance or perhaps activation of GP to promote glucose accumulation in muscle cells. However, together with the results found in the current study, these results suggest that the role of PKA in muscle during dehydration and freezing may instead be, in part, to phosphorylate and inactivate PK. Indeed, previous studies have shown that PK in mammals is inactivated through phosphorylation via PKA (Ljungström et al., 1974; Riou et al., 1978). Activation of PKA during freezing and dehydration, then, may result in the phosphorylation-induced inactivation of PK observed in the wood frog muscle in this study. If this were confirmed, it would be the first known 
case of muscle PK being inhibited via PKA phosphorylation and suggests a common regulatory mechanism exists between L-type and M-type PK.

The stability of PK is significantly increased during freezing as demonstrated when PK is exposed to both increased urea and high temperature (figure 2.2). This increased stability suggests that RPP also results in increased enzyme stability during times of environmental freezing. This would be advantageous to the wood frog as cellular conditions are significantly less favorable during freezing which makes modifications to ensure protein stability warranted. Concentrations of urea accumulate to $90 \mathrm{mM}$ during freezing and increases in oxidative stress defenses suggest that oxidative damage is occurring (Joanisse \& Storey, 1996; Costanzo \& Lee, 2005). Stress-responsive changes in protein stability have been observed previously in the wood frog. In response to freezing, MnSOD purified from muscle showed an increased stability together with increased serine phosphorylation (Dawson et al, 2015). A similar effect was observed in this study, and although causation cannot be inferred, it is consistent with other observed examples of stress-induced changes in protein stability correlating with changes in protein phosphorylation state (Dieni \& Storey, 2011; Xiong \& Storey, 2012; Childers \& Storey, 2016). This body of evidence suggests that covalent modification via phosphorylation may be modulating conformational changes in proteins that affect enzyme stability as well as kinetic properties.

A second reason for which increased enzyme stability is desirable during freezing stress is directly attributed to the energetic cost of protein turnover. Indeed, protein synthesis and degradation are highly energy expensive processes. In vivo measurements estimate the total energetic cost of each peptide bond to be as much as 7.5 units of ATP 
and mathematical modelling estimates protein turnover accounting for $19 \%$ of cellular ATP use (Gill et al., 1989; De Vries, 1975). By stabilizing the enzyme during environmental stress exposure, energy can be conserved by limiting the rate at which it unfolds and therefore must be resynthesized. The stabilization of PK observed in this study may represent a common mechanism of energy conservation given the abundance of other examples of increased enzyme stability during stress. Although it is possible that an increase in enzyme stability would be desirable to cope with the changing cellular environment during stress and to conserve energy, it is also possible that changes in protein stability and structure are simply directed at influencing the kinetic properties of the enzymes to suit the needs of the animal's stress response.

Studying the regulation of PK in the freeze tolerant frog $R$. sylvatica provides an excellent opportunity to better understand carbohydrate metabolism during stress. PK from frozen and dehydrated frogs exhibit a lesser affinity for PEP and greater levels of serine phosphorylation. Furthermore, frozen PK is more stable than PK from control frogs. These differences suggest that reversible phosphorylation is used as a regulatory mechanism of PK during times of environmental stress and functions by decreasing substrate affinity and increasing protein stability. Decreased PK activity would contribute to both an overall metabolic rate depression and conserve energy as well as suppress consumption of glucose, a key cryoprotectant in the wood frog. 
Table 2.1: Typical purification scheme of PK from $R$. sylvatica muscle tissue.

\begin{tabular}{llllll}
\hline $\begin{array}{l}\text { Purification } \\
\text { Step }\end{array}$ & $\begin{array}{l}\text { Total } \\
\text { Protein } \\
(\mathrm{mg})\end{array}$ & $\begin{array}{l}\text { Total } \\
\text { Activity }(U)\end{array}$ & $\begin{array}{l}\text { Specific } \\
\text { Activity } \\
\text { (U/mg) }\end{array}$ & $\begin{array}{l}\text { Fold } \\
\text { Purification }\end{array}$ & \% Yeld \\
\hline Crude & 8.02 & 11.00 & 1.37 & --- & --- \\
CM $^{-}$PEP & 0.14 & 3.04 & 22.19 & 16.2 & 27.63 \\
$\mathrm{CM}^{-} \mathrm{KCl}$ & 0.04 & 2.49 & 56.48 & 41.00 & 22.63 \\
\hline
\end{tabular}


Table 2.2: Kinetic and structural properties of skeletal muscle PK purified from control and frozen muscle samples of $R$. sylvatica. Data are mean $\pm \mathrm{SEM}, \mathrm{n}=4$.

\begin{tabular}{lll}
\hline Kinetic Parameter & Control & Frozen \\
\hline $\mathrm{K}_{\mathrm{m}}$ PEP $22^{\circ} \mathrm{C}(\mathrm{mM})$ & $0.065 \pm 0.003$ & $0.098 \pm 0.003^{a}$ \\
& & \\
$\mathrm{~K}_{\mathrm{m}} \mathrm{ADP} 22^{\circ} \mathrm{C}(\mathrm{mM})$ & $0.22 \pm 0.02$ & $0.21 \pm 0.008$ \\
& & \\
$\mathrm{~V}_{\max }(\mathrm{kU} / \mathrm{g}$ wet weight $)$ & $5.63 \pm 0.05$ & $4.75 \pm 0.03$ \\
& & \\
$\mathrm{~V}_{\max } 5^{\circ} \mathrm{C}(\mathrm{U} / \mathrm{mg})$ & $0.59 \pm 0.12$ & $0.58 \pm 0.07$ \\
$\mathrm{~V}_{\max } 13^{\circ} \mathrm{C}(\mathrm{U} / \mathrm{mg})$ & $0.88 \pm 0.15$ & $0.75 \pm 0.07$ \\
$\mathrm{~V}_{\max } 22.5^{\circ} \mathrm{C}(\mathrm{U} / \mathrm{mg})$ & $1.48 \pm 0.20$ & $1.35 \pm 0.14$ \\
& & \\
$\mathrm{E}_{\mathrm{a}}(\mathrm{kJ} / \mathrm{mol})$ & $35.70 \pm 1.98$ & $34.53 \pm 7.12$ \\
& & \\
$\mathrm{~T}_{\mathrm{m}}\left({ }^{\circ} \mathrm{C}\right)$ & $46.84 \pm 0.34$ & $47.02 \pm 0.20$ \\
\hline
\end{tabular}

$a$ indicates significantly different from the corresponding control value, Student's $t$-test, $\mathrm{P}<0.05$. 
Table 2.3: Effects of various substrates and allosteric effectors on the $K_{m}$ PEP of purified $\mathrm{PK}$ from control and frozen muscle samples of $R$. sylvatica. Data are mean $\pm \mathrm{SEM}, \mathrm{n}=4$

\begin{tabular}{lll}
\hline Kinetic Parameter & Control & Frozen \\
\hline $\mathrm{K}_{\mathrm{m}}$ PEP 400 mM Glucose $(\mathrm{mM})$ & $0.07 \pm 0.006$ & $0.10 \pm 0.007^{a}$ \\
$\mathrm{~K}_{\mathrm{m}}$ PEP 5 mM ATP $(\mathrm{mM})$ & $0.06 \pm 0.004$ & $0.08 \pm 0.003^{a}$ \\
$\mathrm{~K}_{\mathrm{m}}$ PEP 5 mM AMP $(\mathrm{mM})$ & $0.07 \pm 0.006$ & $0.08 \pm 0.004$ \\
$\mathrm{~K}_{\mathrm{m}}$ PEP 2 mM FBP $(\mathrm{mM})$ & $0.07 \pm 0.004$ & $0.10 \pm 0.003^{a}$ \\
$\mathrm{~K}_{\mathrm{m}}$ PEP 100 mM Urea $(\mathrm{mM})$ & $0.10 \pm 0.004^{b}$ & $0.17 \pm 0.015^{a b}$ \\
\hline
\end{tabular}

$a$ indicates significantly different from the corresponding control value, Student's $t$-test, $\mathrm{P}<0.05$. $b$ indicates significantly different from the corresponding $\mathrm{K}_{\mathrm{m}} \mathrm{PEP}$ value from table 2.2 of the same condition with no additional metabolites added, Student's $t$-test, $\mathrm{P}<0.05$. 
Table 2.4: Effects of various substrates and allosteric effectors on the $\mathrm{V}_{\max }$ of $\mathrm{PK}$ from control and frozen muscle samples of $R$. sylvatica. Data are mean $\pm \mathrm{SEM}, \mathrm{n}=4$

\begin{tabular}{llll}
\hline Substrate & $\begin{array}{l}\text { Observed Effect } \\
\text { (Parameter reported) }\end{array}$ & Control & Frozen \\
\hline Urea & Inhibition $\left(\mathrm{I}_{50}, \mathrm{M}\right)$ & $0.44 \pm 0.02$ & $0.42 \pm 0.04$ \\
Urea $+400 \mathrm{mM}$ Glucose & Inhibition $\left(\mathrm{I}_{50}, \mathrm{M}\right)$ & $1.65 \pm 0.1^{b}$ & $1.63 \pm 0.07^{b}$ \\
ATP & Inhibition $\left(\mathrm{I}_{50}, \mathrm{mM}\right)$ & $10.1 \pm 0.34$ & $12.1 \pm 1.13$ \\
AMP & No effect up to $25 \mathrm{mM}$ & N/A & N/A \\
FBP & No effect up to $25 \mathrm{mM}$ & N/A & N/A \\
Alanine & No effect up to $25 \mathrm{mM}$ & N/A & N/A \\
Glucose & No effect up to $750 \mathrm{mM}$ & N/A & N/A \\
Aspartate & No effect up to $25 \mathrm{mM}$ & N/A & N/A \\
\hline
\end{tabular}

$b$ indicates significantly different from the corresponding value of the same condition without glucose, Student's $t$-test, $\mathrm{P}<0.05$. 


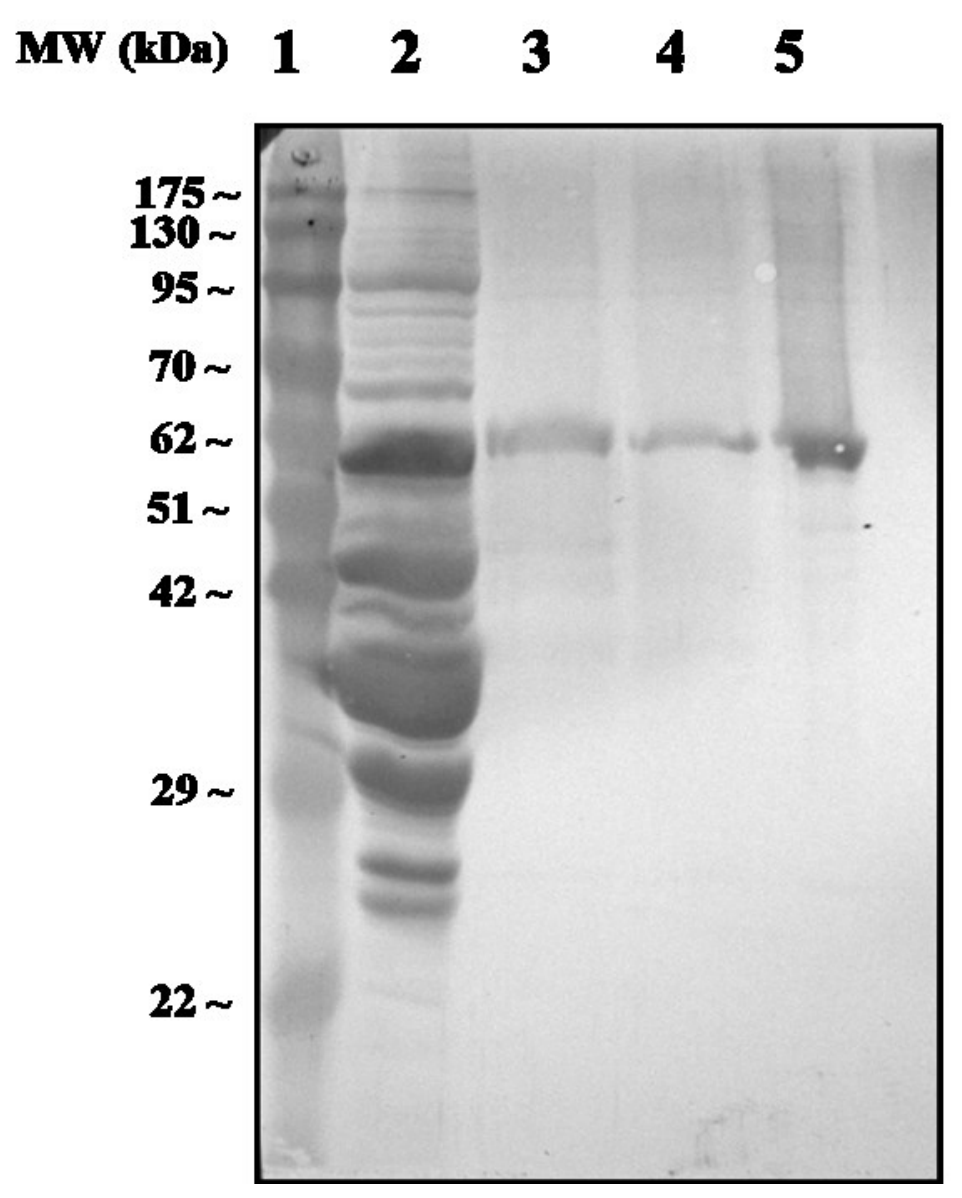

Figure 2.1: 10\% SDS-PAGE gel showing entire purification of PK from control muscle of $R$. sylvatica. Lanes (1): molecular weight ladder (Froggabio); (2): crude homogenate; (3) pooled peak fraction after elution from CM Sephadex column with PEP; (4) pooled peak fraction after elution from $\mathrm{CM}^{-}$Sephadex column with $\mathrm{KCl}$; (5) commerciallyavailable purified rabbit PK (positive control; Sigma life sciences). 

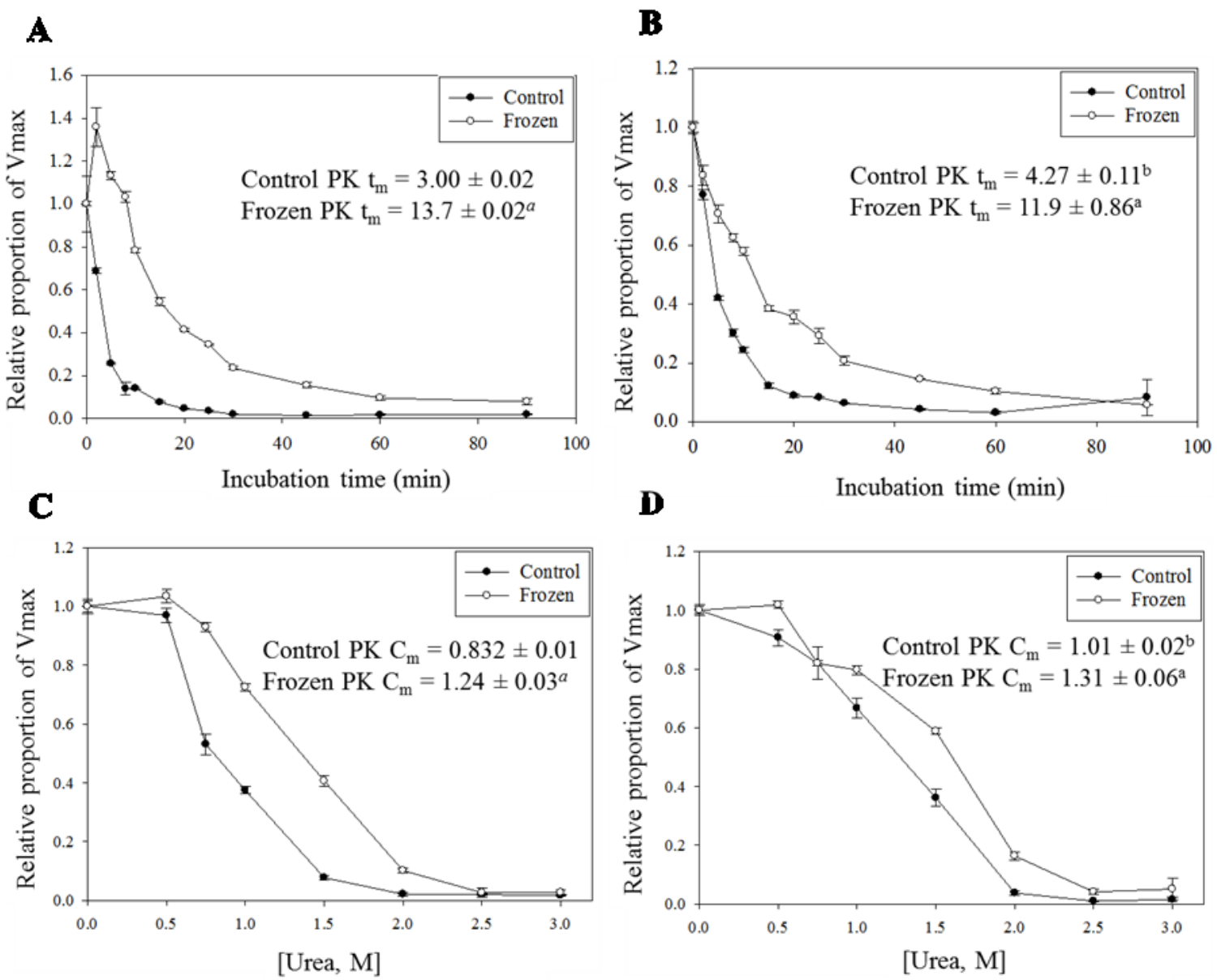

Figure 2.2: Relative stability of purified PK from $R$. sylvatica muscle tissue determined through the enzyme incubations at high temperature and in high concentrations of urea. (A) $52^{\circ} \mathrm{C}$ incubation; (B) $52^{\circ} \mathrm{C}$ incubation with $400 \mathrm{mM}$ glucose; (C) 90 min urea incubation; (D) 90 min urea incubation with $400 \mathrm{mM}$ glucose. The reported value is either the incubation time at $52^{\circ} \mathrm{C}(\mathrm{A}, \mathrm{B})$ or the concentration of urea during a $90 \mathrm{~min}$ incubation $(C, D)$ that resulted in a $V_{\max }$ reduced to $50 \%$ of the non-incubated value. Data are mean $\pm \mathrm{SEM}, \mathrm{n}=4$. $a$ indicates significantly different from the corresponding control value, Student's $t$-test, $\mathrm{P}<0.05 . b$ indicates significantly different from the corresponding value of the same condition without glucose, Student's $t$-test, $\mathrm{P}<0.05$. 
Control

Frozen

P-Serine

ECL

Coomassie
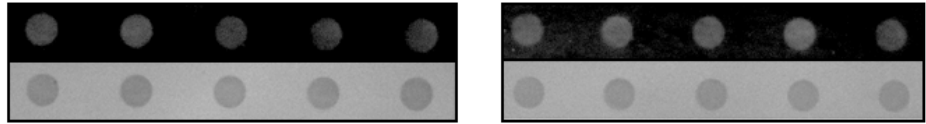

P-Tyrosine

ECL

Coomassie
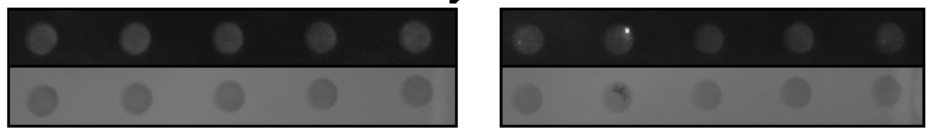

P-Threonine

ECL

Coomassie
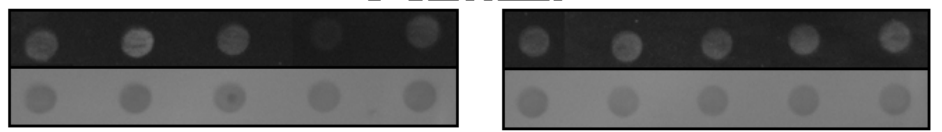

Acetylation

ECL

Coomassie
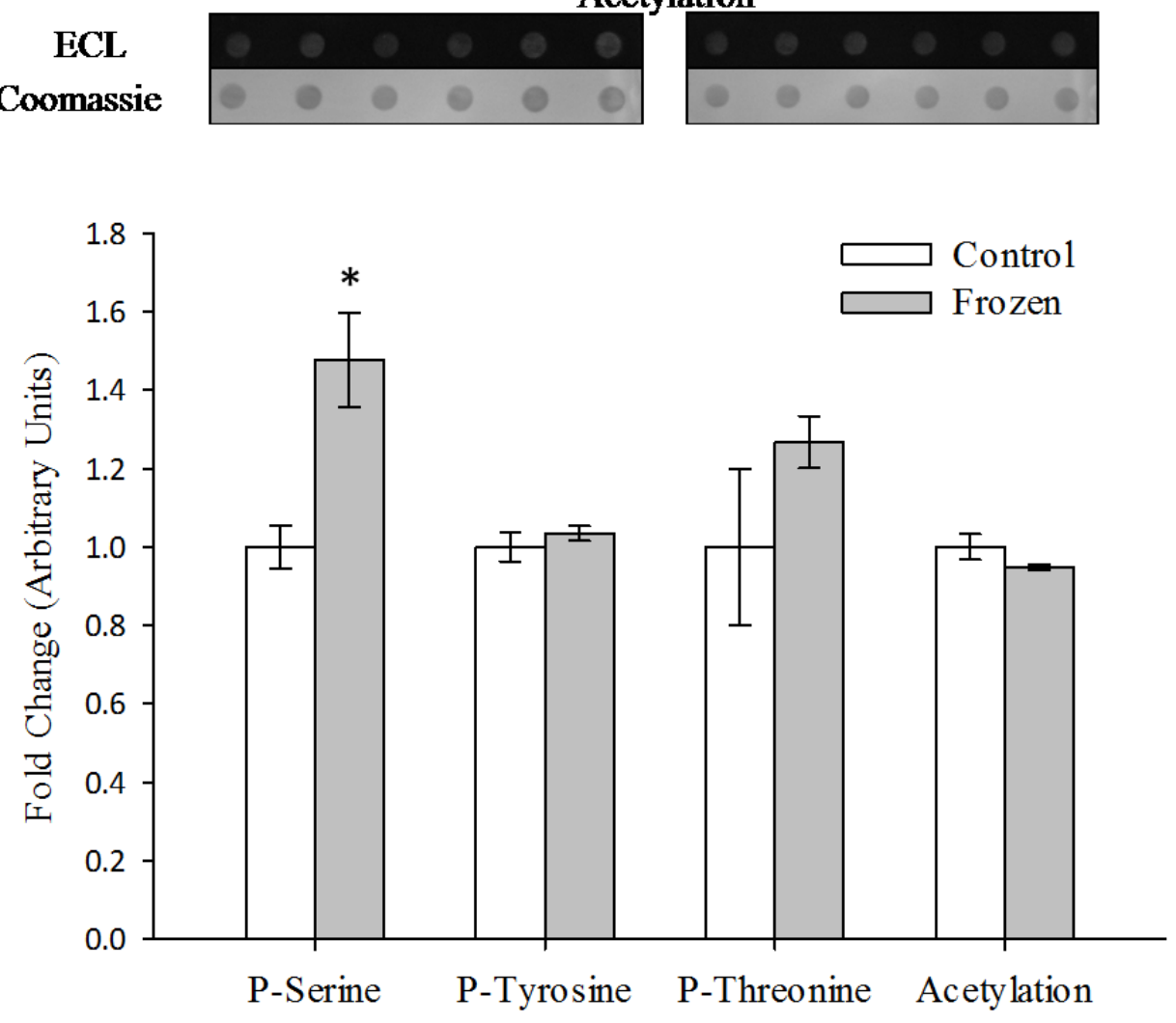

Figure 2.3: Relative levels of post-translational modifications determined through dot blots of purified PK from control and frozen muscle tissue of Rana sylvatica.

Chemiluminescence signal intensities were standardized to protein amount, and the value for frozen PK was expressed relative to the control value that was set to 1. Data are mean \pm SEM, $n=5-6$ determinations on purified enzyme samples. Asterisk indicates significant difference from the corresponding control value, Student's $t$-test, $P<0.05$. 


\section{Chapter 3}

\section{Purification and Characterization of Pyruvate Kinase from the Foot Muscle of the Anoxia and Freeze Tolerant Marine Snail, Littorina littorea}




\section{Introduction}

Sessile animals living in intertidal spaces are subjected to a myriad of different stresses as the environment in which they live alternates multiple times per day in accordance with the changing tides. Alternating between a submerged and an aerial environment means that these animals are exposed to periodic bouts of anoxia and, depending on the climate, potentially freezing conditions at low tide. Furthermore, if isolated in a tidal pool, animals may be subjected to osmotic stress as hyper-salinic conditions can develop due to evaporating seawater. Physiological adaptations are required to survive these periods of environmental stress, and have been observed in many species of marine invertebrates. The common periwinkle, Littorina littorea, is one such animal capable of surviving periodic bouts and anoxia and, depending on the climate, freezing. In fact, laboratory experiments have shown that it can survive at least 6 days of anoxia exposure and up to 8 days of freezing at $-8^{\mathrm{p}} \mathrm{C}$ (Wieser, 1980; Churchill \& Storey, 1996). Generally speaking, during low tide the animals would be exposed to the aerial environment for no more than 6 hours, therefore their exhibited anoxic and freezing tolerance is in far excess of what is ecologically-necessary.

L. littorea demonstrates a variety of adaptations which contribute to its survival in anoxic conditions. Pro-survival genes are upregulated during anoxic stress including antioxidant defenses and protein chaperones to combat the accumulation of ROS and other harmful metabolites. Levels of the low molecular weight antioxidant defense glutathione increased by 2.8- and 1.6-fold in the hepatopancreas and foot muscle, respectively, of L. littorea relative to non-stressed control animals. Furthermore, upon aerobic recovery from anoxia, the activity of antioxidant enzymes, including SOD, 
increased 2-fold relative to the initial control levels while CAT and glutathione reductase (GR) showed similar trends (Pannunzio \& Storey, 1998). Expression of protein chaperones HSP70 and HSP27 were also observed to increase in response to anoxia exposure in the foot muscle of $L$. littorea, facilitating the re-folding of proteins damaged by anoxia-induced accumulation of harmful molecules, including ROS (Storey et al., 2013). As with most other anoxia-tolerant animals though, arguably the most important adaptation facilitating survival is a global metabolic rate depression and strict control of anaerobic energy metabolism. Anoxia-induced metabolic rate depression is a commonlyobserved adaptation enabling survival of this stress. In marine mollusks, metabolic rates have been observed to decrease by as much as $95 \%$ in response to anaerobic conditions (Famme et al., 1981; Shick et al., 1983). Specifically in L. littorea, metabolic rates were observed to decrease by $31 \%$ in response to increase $\mathrm{CO}_{2}$ concentrations (Melatunan et al., 2011). A lack of oxygen deprives animals of the ability to produce sufficient energy to maintain their current metabolic state and therefore non-essential processes are shut down allowing only the most vital pathways to proceed. Processes such as transcription and translation have both been shown to be suppressed during anoxia exposure in the periwinkle (Larade \& Storey, 2007; Larade \& Storey, 2002), while stress-responsive miRNA expression patterns suggest that the cell cycle is also arrested (Biggar et al, 2012). This allows the animals to conserve energy to maintain only vital cellular functions.

Another contributor to metabolic rate depression is regulation of metabolic enzymes, commonly via reversible phosphorylation, which has been observed extensively in L. littorea (Storey et al., 2013) as well as other anoxia-tolerant species 
(reviewed in Krivoruchko \& Storey, 2015; Brooks \& Storey, 1997, Hand \& Hardewig, 1996). In the periwinkle, enzymes governing carbohydrate metabolism have been the focus of study due to the importance of regulating the rate of carbohydrate fermentation and anaerobic ATP generation. A study by Russell \& Storey (1995) investigated the kinetic properties of a series of carbohydrate metabolic enzymes including GP, GS, PK and PDH. Changes in these enzymes' activities and kinetic parameters were consistent with covalent modification and a general curtailing of carbohydrate metabolism resulting in decreased activity during freezing and/or anoxic stress. Hexokinase has also been studied in L. littorea where its activity was shown to decease significantly in the foot muscle, apparently due to a corresponding increase in serine phosphorylation (Lama et al., 2013). By inhibiting the activity of these enzymes of carbohydrate metabolism, the rate of glycolysis can be reduced significantly and energy stores can be conserved during anoxia. Lactate dehydrogenase (LDH) also exhibited a near $50 \%$ decrease in $\mathrm{V}_{\max }$ in response to anoxia, which the authors suggested was due to an observed decrease in LDH acetylation in response to anoxia (Shahriari et al., 2013). This suggests that even primary fermentative pathways may be suppressed in order to conserve fuel and establish a new ATP-generating and consuming equilibrium

Energy metabolism during anoxia in marine mollusks relies primarily on the consumption of fermentable fuels; namely glycogen and aspartate in L. littorea. During aerobic metabolism, ATP is generated through the conversion of PEP into pyruvate which is further metabolized in the mitochondria through the actions of the tricarboxylic acid (TCA) cycle. During anaerobic metabolism, however, PEP has multiple potential metabolic fates: early in anoxia exposure, PEP is converted to pyruvate which can 
undergo fermentation to produce lactate and 2 molecules of ATP per molecule of glucose. Alternatively, when coupled to the fermentation of aspartate, pyruvate can be converted to alanine through a reaction that is coupled to the conversion of aspartate to oxaloacetate (Storey, 2005). Oxaloacetate undergoes further catabolism, ultimately producing succinate via the succinate pathway (Storey, 1993). The advantages to this anaerobic pathway are two-fold; firstly, by coupling the production of alanine to the catabolism of aspartate, a net of 4 mol ATP per mole of glucose catabolized can be achieved (Storey \& Storey, 2004b). Secondly, the end-products of alanine and succinate are relatively less-acidic when compared to lactic acid. After prolonged exposure to anoxic conditions (more than 6 hours) however, aspartate reserves are depleted and only glycogen stores remain for fuel. In this scenario, instead of being converted to pyruvate by PK, PEP can shunted directly into the succinate pathway through the actions PEPCK to produce oxaloacetate with further fermentation in the mitochondria resulting in succinate and propionate production. This alternative pathway can generate up to 5 moles of ATP per mole of glucose catabolized (Storey \& Storey, 2004b). Both of these potential anaerobic pathways are displayed in figure A2.1.

Pyruvate kinase, the final enzyme of glycolysis, is a cytosolic enzyme which catalyzes the conversion of PEP to pyruvate, generating one molecule of ATP per reaction. Being situated at such an important locus of ATP production and the PEP branch point of early/late stage anaerobic respiration, PK is a common regulatory site of carbohydrate metabolism in mollusks surviving anoxia or freezing, including the marine whelk and the land snail O. lactea (Plaxton \& Storey, 1984; Whitwam \& Storey, 1990). Preliminary studies in the periwinkle $L$. littorea suggest that PK is also regulated in this 
animal in response to anoxia and freezing, though many of the details remain obscure (Russell \& Storey, 1995). In this chapter, I investigate the final enzyme of glycolysis, PK, in significantly greater detail than has been performed previously in response to both anoxia and freezing in L. littorea. By purifying and comparing the kinetic parameters and phosphorylation states of this enzyme in control, anoxic, and frozen conditions, I will demonstrate that $\mathrm{PK}$ is being regulated during anoxia such that global metabolic rate depression is enabled, but, curiously, this is not the case during freezing. I will also demonstrate if phosphorylation is the mechanism of regulation of PK.

\section{Materials and Methods}

\section{Animals}

L. littorea were purchased from the Kowloon market in Ottawa, Canada. The animals were quickly rinsed first in tap water, then briefly in sea water. Next, the snails were placed in a $30 \mathrm{~L}$ tub of aerated sea water made to $34.74 \mathrm{~g} / \mathrm{L}$ of Instant Ocean Sea Salt and held in an incubator at $9^{\circ} \mathrm{C}$ in complete darkness. This acclimation procedure was continued for 5 days with the water being changed periodically. Control animals were sampled directly from the acclimated conditions.

To simulate anoxic conditions, snails were placed in sealed jars which contained a small amount of deoxygenated sea water. The jars were previously equilibrated with nitrogen gas. Upon addition of the snails, the jars were gassed for 15 min with $\mathrm{N}_{2}$, after which time the jars were sealed with parafilm and returned to $9^{\circ} \mathrm{C}$ for $24 \mathrm{~h}$. Freezing conditions were simulated by placing snails in containers lined with damp paper towel in incubators set to $-6^{\circ} \mathrm{C}$ and held there for $24 \mathrm{~h}$. Freezing occurred within the first hour of the experiment. Following experimental procedures, animals were rapidly dissected and 
tissues flash frozen in liquid nitrogen before being held at $-80^{\circ} \mathrm{C}$ until use. All experiments performed were in accordance with the Carleton University Animal Care Committee (B09-22) and abided by the guidelines set down by the Canadian Council on Animal Care.

\section{Preparations of tissue}

Tissue from control, frozen and anoxic samples of foot muscle of L. littorea were quickly weighed and added to 10 volumes of ice-cold homogenization buffer A which included; 10 mM MES, pH 6.0, 2 mM EDTA, 2 mM EGTA, 15 mM $\beta$-glycerophosphate, $15 \mathrm{mM} \beta$-mercaptoethanol ( $\beta$-MeSH), $10 \% \mathrm{v} / \mathrm{v}$ glycerol, with a small scoop of phenylmethylsulphonyl fluoride (PMSF) crystals added immediately before homogenization. Samples were homogenized completely using a Polytron homogenizer (Brinkmann Instruments, Westbury, NY, USA) and spun in an Eppendorf 5810R centrifuge (22331 Hamburg, GER) for $30 \mathrm{~min}$ at $13500 \mathrm{xg}$ and $5^{\circ} \mathrm{C}$. The supernatant (crude homogenate) was decanted and held on ice until use.

\section{Pyruvate Kinase Assay}

Pyruvate kinase activity was measured as previously described in chapter 2.

\section{Purification of Pyruvate Kinase}

A $2 \mathrm{~mL}$ aliquot of crude homogenate was added to a $\mathrm{CM}^{-}$sephadex column $(0.75$ $\mathrm{cm}$ X $10 \mathrm{~cm}$ ) that had been previously equilibrated with $20 \mathrm{~mL}$ of buffer A. The column was then washed with $15 \mathrm{~mL}$ of buffer A and the enzyme was eluted with $20 \mathrm{~mL}$ of buffer B (same as buffer B, but pH 6.5). Using an automated fraction collector (Gilson Medical Electronics, Inc., Middleton, WI, USA) $1.2 \mathrm{~mL}$ fractions of column eluant were 
collected. To determine where PK eluted from the column, $10 \mu \mathrm{L}$ of each fraction was taken and used to measure PK activity spectrophotometrically as previously described in chapter 2. Peak activity fractions were pooled and added to a hydroxyapatite (HA) column that had been previously equilibrated with buffer $\mathrm{C}$ (10 mM MOPS, $\mathrm{pH}$ 7.0, 2 mM EDTA, 2 mM EGTA, $15 \mathrm{mM} \beta$-glycerophosphate, $15 \mathrm{mM} \beta$-MeSH and 10\% v/v glycerol). PK was eluted from the column with a $0-500 \mathrm{mM}$ potassium phosphate gradient made in buffer $\mathrm{C}$ and collected in $1.2 \mathrm{~mL}$ fractions which were then assayed for PK activity using $10 \mu \mathrm{L}$ from each fraction, as before. Peak fractions were pooled and used for all subsequent experiments. Protein concentrations were determined using Coomassie blue G-250 dye-binding reagent (Bio-Rad, Hercules, CA, USA) as instructed by the manufacturer using bovine serum albumin as a standard (Bradford, 1976).

\section{Activator/Inhibitor treatments}

The activity of PK was tested in the presence of various activating and inhibiting compounds. In the experiment portrayed in figure 3.2, the conditions were as follows: In the negative treatment, suboptimal assay conditions were used which included $0.2 \mathrm{mM}$ PEP, $0.15 \mathrm{mM}$ NADH, $2 \mathrm{mM}$ ADP, $5 \mathrm{mM} \mathrm{MgCl} 2$ and $1 \mathrm{U}$ of $\mathrm{LDH}$ in $\mathrm{pH} 7.2$ Tris assay buffer. The alanine condition was the same as the control condition but also included 0.5 $\mathrm{mM}$ alanine. The FBP, isoleucine and aspartate conditions were the same as the alanine condition but also included $0.065 \mathrm{mM} \mathrm{FBP}, 1.5 \mathrm{mM}$ Isoleucine and $0.5 \mathrm{mM}$ aspartate, respectively. The relative $\mathrm{V}_{\max }$ of all treatments were compared to the $\mathrm{V}_{\max }$ value obtained from the negative treatment which was set to 1.0. 


\section{Incubation experiments}

Temperature incubation experiments to determine the stability of PK at high temperature were performed as previously described in chapter 2, except that the incubation temperature was set to $60^{\circ} \mathrm{C}$.

\section{SDS Polyacrylamide Gel Electrophoresis and Immunoblotting}

Western blots were performed as previously described in chapter 2 to compare the phosphorylation states of the control, frozen and anoxic forms of PK. The following primary antibodies, all obtained from Invitrogen, Carlsbad, CA, USA were used for western blotting:

(1) rabbit anti-phosphothreonine (Cat. \#718200); (2) mouse anti-phosphotyrosine (Cat. \#615800).

Purity of PK was confirmed by SDS-PAGE with coomassie blue staining as previously described in chapter 2.

\section{Data and Statistical Analyses}

All data and statistical analyses were performed as previously described in chapter 2 except that all kinetic and stability parameters were compared using one-way ANOVAs followed by Tukey's post hoc test $(p<0.05)$. 


\section{Results}

\section{Purification of Pyruvate Kinase}

PK was successfully purified from control, frozen and anoxic samples of $L$.

littorea foot muscle using a combination of ion-exchange and affinity column chromatography. PK was eluted from the first column by increasing the $\mathrm{pH}$ of the elution buffer from $\mathrm{pH} 6.0$ to $\mathrm{pH}$ 6.5. This step resulted in 2.2-fold purification with a $40 \%$ yield. The second step, a 0-500 mM phosphate gradient elution from an HA column, resulted in a 13 -fold purification with a $32 \%$ yield (table 3.1 ). This two-step purification resulted in PK being purified to $>95 \%$ purity as determined by SDS-PAGE and staining with coomassie blue. The purified PK had a molecular weight of $63 \mathrm{kDa}$ (figure 3.1).

\section{Kinetic activity of PK}

The $\mathrm{V}_{\max }$ was determined to be $2.96 \mathrm{U} / \mathrm{g}$ wet weight and total activity of PK did not differ significantly between the control, frozen and anoxic forms of the enzyme (table 2). The $\mathrm{K}_{\mathrm{m}} \mathrm{PEP}$ of PK increased significantly in the anoxic animals $(0.356 \pm 0.03 \mathrm{mM})$ when compared to the control $(0.159 \pm 0.03 \mathrm{mM})$ and frozen animals $(0.092 \pm 0.008$ $\mathrm{mM}$ ) (table 3.2). No significant change was observed in the $\mathrm{K}_{\mathrm{m}} \mathrm{ADP}$ between the control, frozen and anoxic forms of PK, which was found to be and average of $0.500 \mathrm{mM}$ (table $3.2)$.

Various allosteric effectors were added to the reaction to investigate the possibility of stress-specific allosteric regulatory patterns. While the inhibitory constants $\left(\mathrm{I}_{50}\right)$ of urea $(1.69 \mathrm{M}), \mathrm{AMP}(0.56 \mathrm{mM}), \mathrm{NaCl}(0.15 \mathrm{M})$ and ATP $(7.13 \mathrm{mM})$ did not 
differ significantly between the three conditions, the $\mathrm{I}_{50}$ of alanine was significantly lower in the anoxic form $(0.257 \pm 0.04)$ of PK than the control $(0.578 \pm 0.05)$ and frozen forms $(0.592 \pm 0.05 \mathrm{mM})$, as was the $\mathrm{I}_{50}$ of $\mathrm{KCl}(0.11 \pm 0.004 \mathrm{M}$ vs $0.54 \pm 0.04 \mathrm{M}, 0.65 \pm 0.04$ $\mathrm{M}$ for anoxic, control and frozen forms, respectively). The anoxic and frozen $\mathrm{I}_{50} \mathrm{NH}_{4}$ $(0.40 \pm 0.02 \mathrm{M}$ and $0.27 \pm 0.01 \mathrm{M}$, respectively) were also significantly high than that of the control $(0.19 \pm 0.01 \mathrm{M})$, while the anoxic form was significantly higher still than the frozen form.

Aspartate, FBP and isoleucine were also investigated as activators of PK. Although the $\mathrm{K}_{\mathrm{a}}$ values did not change between the three conditions for any of the compounds tested, the fold-activation (FA) was significantly higher for the anoxic form of PK compared to the control and frozen forms with respect to aspartate activation. For aspartate, the fold-activation values were $0.24,0.26$ and 0.40 for control, frozen and anoxic PK respectively. For FBP they ranged between 0.37 and 0.76 and for isoleucine they ranged between 0.18 and 0.58 , but did not differ significantly between the three conditions (table 3.4).

Figure 3.5 shows the effects and alanine, an inhibitor of PK, and alanine in combination with various activators of PK on the activity of the enzyme. Alanine alone decreased the $\mathrm{V}_{\max }$ by 30 to $40 \%$ of the uninhibited negative treatment. The combination of alanine and FBP resulted in the activity of PK being activated by 0.15 - to 0.30 -fold compared to the uninhibited, negative value. The combination of alanine and isoleucine resulted in $\mathrm{V}_{\max }$ values that were 19 to $23 \%$ less than the corresponding negative value and were statistically no greater than when alanine alone was added. The addition of 
aspartate resulted in a recovery of the $V_{\max }$ of the control enzyme to 0.1 -fold greater than the uninhibited value, however the anoxic form remained completely inhibited. The frozen form of PK recovered slightly upon the addition of aspartate, but the $\mathrm{V}_{\max }$ still remained $11 \%$ less than the uninhibited negative values.

\section{Post-translational modifications of PK}

Western blotting was used to assess the possible differences in the posttranslational modifications of purified foot muscle PK from control, frozen and anoxic conditions. Phosphorylation on threonine residues of the anoxic form of PK was nearly 2fold higher than the control or frozen form of PK (figure 3.4). The phosphorylation level of tyrosine residues between control, frozen and anoxic PK did not differ significantly. The status of serine phosphorylation was also investigated, but no quantifiable signal was observed (data not pictured).

\section{Structural stability of PK}

Structural stability of PK was investigated by examining stability under various durations of incubation at $60^{\circ} \mathrm{C}$ (figure 3.2). The control form of PK was significantly less stable than the frozen and anoxic forms with the $V_{\max }$ being reduced to $50 \%$ of its original max after $9.06 \pm 0.1 \mathrm{~min}$ while the anoxic and frozen tissue PK retained 50\% until $12.98 \pm 1.1 \mathrm{~min}$, and $13.23 \pm 0.68 \mathrm{~min}$, respectively. 


\section{Discussion}

For animals surviving in intertidal environments, strict control of metabolic rate is imperative to ensure that the limited energy production available through anaerobic metabolism can meet the needs of the animal during low tide and anoxia exposure. During low-tide, these animals are exposed not only to anoxia but, depending on the climate, they may also be exposed to subzero temperatures resulting in whole-body freezing. Survival is ensured through suppressing non-essential processes such as transcription and translation, global gene suppression, and an extreme metabolic rate depression mediated by regulation of metabolic enzymes. This is the case in marine invertebrates like the common periwinkle, L. littorea, where metabolic rate has been shown to be just $10 \%$ of its resting value when animals are exposed to anoxic conditions. This led to the hypothesis that pyruvate kinase, a key enzyme of carbohydrate metabolism, would be regulated during anoxic and freezing stress to enable metabolic rate depression. The results of this study suggest that anoxia exposure induces decreased activity of the enzyme, however, freezing does not. Further studies suggest that reversible phosphorylation may be responsible for the kinetic changes observed in response to anoxia.

The kinetic properties of PK changed between the control and anoxic conditions, suggesting that the enzyme is regulated in response to this stress. Of particular significance was the observed change in the $\mathrm{K}_{\mathrm{m}} \mathrm{PEP}$, which was 1.2-fold higher in the anoxic animal compared to the control animal (table 3.2). This significant decrease in substrate affinity is indicative of negative regulation of PK in response to anoxia. Interestingly, the anoxic form of PK was also found to be more susceptible to inhibition 
by alanine, exhibited by a $55 \%$ smaller I ${ }_{50}$ Alanine compared to the control (table 3.3 ). Furthermore, while the inhibitory effects of alanine on the control and frozen forms of PK were somewhat alleviated by the addition of aspartate, this was not the case for the anoxic form of PK which remained strongly inhibited.

The benefits of inhibiting the activity of PK in response to anoxia is rooted in the ability of L. littorea to engage multiple anaerobic pathways depending on fuel availability. During the early stages of anaerobic metabolism in marine mollusks, glycogen and aspartate are used as the primary fuel sources and glycolysis is run to completion before engaging the succinate pathway, producing lactate, alanine and succinate as end products. Later, as aspartate reserves are depleted, PEP is pushed through PEPCK instead of PK, ultimately producing primarily succinate and propionate as end products (Storey, 1993; Storey \& Storey, 2004b). The results from this study suggest that this late-stage anaerobic pathway is activated during 24 hour anoxia exposure. The decrease in affinity of PK for its substrate PEP would promote glycolytic flux through PEPCK instead of through PK. Moreover, it was observed that alanine is a stronger inhibitor of the anoxic form of PK than the control or frozen forms, demonstrated through a smaller $I_{50}$ alanine (table 3.3). In another anoxia-tolerant marine invertebrate, the cherrystone clam (Mercenaria mercenaria), levels of aspartate were found to be depleted within anywhere between 6 and 24 hours, depending on the tissue, and a corresponding increase in alanine concentration was observed (Storey \& Korycan, 1983). Therefore, the $24 \mathrm{~h}$ anoxia treatment performed in this study would likely leave the animals' aspartate reserves at least somewhat depleted while concentrations of alanine would have accumulated and would be heavily inhibiting the activity of PK. 
Thus, PEP would be channeled through PEPCK more effectively. The activation of PK by aspartate observed in this study lends further support to this theory. As long as aspartate reserves are plentiful, PK will be activated and lead to consumption of both aspartate and glycogen. However, as aspartate is depleted and alanine accumulates, the effects of aspartate activation of PK is lessened and PEP is likely pushed through PEPCK instead. Interestingly, PK was also found to be more-strongly activated by aspartate during anoxia than in the control or frozen conditions, exhibited by a higher foldactivation by this activator (table 3.4 ).

Similar regulatory patterns of PK have been observed in other animals surviving environmental stress and undergoing metabolic rate depression. Another marine invertebrate, the anoxia-tolerant marine whelk Busycotypus canaliculatum, exhibited a 10-fold increase in the $\mathrm{K}_{\mathrm{m}} \mathrm{PEP}$ while, similar to the results presented here, the $\mathrm{K}_{\mathrm{m}} \mathrm{ADP}$ did not change following anoxia exposure (Plaxton, 1985; table 3.2). It was also suggested that these kinetic changes were mediated by reversible phosphorylation of PK (Plaxton \& Storey, 1984). This is not the only example of PK regulation in response to environmental stress; similar patterns were also observed in the estivating land snail Otala lactea where a $\sim 0.5$-fold increase in the $\mathrm{K}_{\mathrm{m}} \mathrm{PEP}$ was observed in response to both estivation and anoxic conditions and was also attributed to reversible phosphorylation (Whitman \& Storey, 1990). Interestingly, both of these animals also exhibited anoxiainduced sensitivity of PK to alanine. In the whelk, for example, PK isolated from anoxic muscle tissue had an I50alanine that was 500-fold lower than PK from control, aerobic tissue, while a nearly 2 -fold decrease was observed in $O$. lactea. This suggests that these animals may be engaging the same anaerobic pathways as does L. littorea by inhibiting 
PK activity with cellular concentrations of alanine. The importance of pushing PEP through PEPCK during anoxia exposure cannot be overstated. A study by Sokolova et al (2001) revealed that the ratio of PEPCK:PK activity, a good reporter of anaerobic metabolic capacity, increased in different species of Littorina spp. that inhabit higher shore environments and therefore undergo more prolonged periods of anoxia exposure. Compared to species inhabiting low shore environments, high shore-dwelling animals had a significantly better ability to survive anoxia enabled by their increased PEPCK activity. Taken together, these studies present a strong argument in support of anoxiaresponsive regulation of $\mathrm{PK}$ via alanine inhibition in contribution to metabolic rate depression and activation of alternative pathways of anaerobic metabolism.

The effects of other inhibitory metabolites on PK activity were also investigated. The anoxic form of PK appeared to be more sensitive to inhibition by $\mathrm{KCl}$ than both the control and frozen forms of the enzyme (table 3.3). Indeed, dehydration of intertidal gastropods at low tide is a known phenomenon, and therefore intracellular solute concentrations would increase at low tide as cellular water evaporates into the surrounding aerobic environment (Newell, 1979; Hoyaux et al., 1975). An increased sensitivity to $\mathrm{KCl}$, like that observed in the current study, would further contribute to the goal of inhibiting PK activity and initiating metabolic arrest at low tide during bouts of anoxia. As aerobic exposure carries on, cellular dehydration (and therefore the $\mathrm{KCl}$ concentration) increases, further inhibiting PK activity. Furthermore, because the anoxic form of the enzyme was more sensitive to $\mathrm{KCl}$ inhibition, this effect would be amplified during anoxia. Both the anoxic and frozen forms exhibited increased sensitivity to ammonium $\left(\mathrm{NH}_{4}\right)$ inhibition relative to the control, which may have a similar effect to 
$\mathrm{KCl}$ during dehydration at low tides. The effects of activating compounds aspartate, FBP, and isoleucine were also compared. The $\mathrm{K}_{\mathrm{a}}$ did not vary between the three conditions for any of the activators tested. However, the fold-activation of the anoxic form was greater than that of the control and frozen forms for aspartate (table 3.4). When combined with alanine, the various activating compounds were found to rescue the activity of PK to varying degrees (figure 3.2). Most interestingly, however, is that when aspartate and alanine were used in combination the control form of PK recovered to its original $\mathrm{V}_{\max }$, the frozen form recovered to $90 \%$ of its original $\mathrm{V}_{\max }$, while the anoxic form showed no recovery at all (figure 3.2). It would seem as though the anoxic form of PK is generally more susceptible to allosteric regulation, but crucially to alanine and aspartate regulation that modulate its response to anaerobic conditions.

The stability of PK increased significantly in the anoxic and frozen animals compared to the non-stressed controls, demonstrated through incubation studies at $60^{\circ} \mathrm{C}$. The time required to reduce the $\mathrm{V}_{\max }$ of PK to $1 / 2$ of the non-incubated value increased $\sim 0.5$-fold in both of the stresses compared to the control. This phenomenon can be attributed to a necessity to maintain the structural integrity of proteins in order to limit denaturation during times of harsh cellular conditions accompanying anoxia or freezing. In doing so, animals ensure that energy is not consumed by transcription and translation to replace damaged proteins as the proteins and enzymes themselves are more stable. In the periwinkle, these observations are supported by previous studies showing increased expression of protein chaperone and antioxidant defenses in response to anoxia exposure (Pannunzio \& Storey, 1998; Storey et al., 2013). These studies show that the stabilization of proteins is prioritized during anoxic stress, and increased enzyme stability through 
reversible phosphorylation is another means of accomplishing this goal. Stress-responsive enzyme stabilization via post-translational modification has been observed in many other animals, including the freeze-tolerant wood frog Rana sylvatica (Smolinski et al., unpublished data; Dawson et al., 2015), the hibernating ground squirrel Ictidomys tridecemlineatus (Bell et al., 2014), and the anoxia-tolerant turtle, Trachemys scripta elegans (Bell \& Storey, 2012). The enzymes in these studies, including super-oxide dismutase, glyceraldehyde-3-phosphate dehydrogenase and glutamate dehydrogenase play varying roles in cellular function and this suggests that this mechanism of increasing protein stability is wide-spread in animals surviving extreme conditions and is not unique to enzymes of specific pathways.

Kinetically, an interesting pattern emerges when comparing the three conditions investigated. The anoxic form of PK displays significantly different kinetic properties than the control form on multiple occasions (table 3.2, 3.3, 3.4). However, the frozen form does not. This is interesting, since most freeze tolerant species exposed to freezing conditions are observed to be simultaneously exposed to anoxic conditions and, indeed, accumulate anaerobic end products. This is thought to be due to the low temperatures inducing ischemia which hinders adequate oxygen supply to tissues (Storey \& Storey, 1988). However, the results presented here indicate that the regulation of PK, and perhaps metabolic rate in general, is not prioritized during freezing to the extent that it is during anoxia and that the animal may respond differently to each condition. There are a number of theories that could explain this observation. First, the low-temperature conditions associated with freezing as a stress occur slowly relative to anoxia. For instance, in the animal experiments performed in this study, whole-body freezing was observed around 
the first hour of incubation at $-6^{\circ} \mathrm{C}$. As such, oxygen availability would be gradually decreased over the course of this treatment On the contrary, anoxia-treated animals were removed from oxygen immediately. It is possible that differences in PK regulation are due to an abrupt versus a progressive exposure to low oxygen, with abrupt changes initiating a more pronounced response. A second hypothesis is that the low temperatures associated with freezing may be sufficient to maintain a low metabolic rate and therefore regulation of metabolic enzymes is not necessary. Contrarily, low temperatures are not necessarily present during anoxia exposure, and therefore enzymatic regulation is necessary to mediate metabolic arrest. Similar stress-response patterns to that observed in this study have been observed in other animals. In the freeze tolerant wood frog, for example, lactate dehydrogenase is regulated in response to dehydration such that fermentation of pyruvate is prioritized. However, when the enzyme was investigated in response to freezing stress, no changes were observed compared to the control animal (Abboud \& Storey, 2013). Simply put, animals may exhibit different adaptations to cope with a specific environmental stress.

The differences observed in the relative stabilities and kinetic properties of PK purified from control, frozen and anoxic tissues suggest that structural differences between the three forms may be responsible for the observed changes. Often, these changes are due to stable, reversible covalent modifications to the proteins, more specifically RPP. Therefore, SDS-PAGE followed by western-blotting with antibodies specific for phosphorylated amino acid residues was performed to assess the relative phosphorylation states of all three forms of PK (figure 3.4). Phosphorylation of threonine and tyrosine residues was assessed and it was found that levels of threonine 
phosphorylation was significantly higher for the anoxic form of PK than both the control and frozen forms. Levels of tyrosine phosphorylation did not differ between the three forms (figure 3.4). PK is known to be phosphorylated in many systems though primarily in vertebrates and mammals which possess tissue-specific isozymes of which the liver isozyme is highly regulated by phosphorylation (Titanji et al, 1976; Ljungstrom et al, 1976, Eigenbrodt et al., 1977). Phosphorylation of muscle PK is less common and has so far been observed mostly in invertebrates where the presence of tissue-specific isozymes varies widely from species to species (Wu et al., 1978). For instance, the channeled marine whelk muscle tissue exhibits increased phosphorylation of $\mathrm{PK}$ in response to anoxia exposure, supposedly responsible for suppressed of the enzyme (Plaxton \& Storey 1984b, 1985). Further, a previous study on PK from the foot muscle of Littorina littorea also determined that phosphorylation was responsible kinetic differences observed between control and anoxic forms of PK (Russell \& Storey, 1995). However, contrary to the results found here, this study suggested that PK was dephosphorylated in response to anoxia. These contradictory results can likely be accounted for by noting that the study by Brooks \& Storey used crude enzyme preparations while the current study purified the enzyme before investigating its phosphorylation state. Further, the previous study determined the phosphorylation state by examining the enzyme's elution profile from ion-exchange chromatography while the present study used western blotting of purified samples, a more robust method to assess phosphorylation states of proteins.

Anoxia-exposure in intertidal spaces can be considered a relatively brief period of environmental stress. Typically lasting for only a few hours, it would therefore not be economical to degrade enzymes that need to be suppressed during this period only to 
have them re-synthesized a few hours later. Enzyme regulation via RPP is a desirable alternative regulatory mechanism and based on the results from this study, is employed to suppress the activity of PK during periods of anoxia. It is also interesting to note that the activity of PK in response to freezing does not change significantly relative to the control, and neither does its phosphorylation state. This lends further support to the suggestion that RPP is the regulatory mechanism responsible for suppression of PK activity during anoxia.

Purified PK from L. littorea foot muscle exhibits distinct kinetic properties in response to anoxia and freezing stress compared to the control form of the enzyme. Anoxic PK was found to be significantly less active than the corresponding control or frozen forms of the enzyme, and it was also significantly more susceptible to allosteric regulation by alanine and aspartate. Through western-blotting analysis, it was found that the anoxic form of the enzyme is significantly more phosphorylated on threonine residues than both the control and frozen forms of the enzyme, and it is possible that this phosphorylation is responsible for the observed changes in kinetic properties. By suppressing the activity of PK, anoxia-exposed animals are better able to maintain a lower metabolic rate and initiate alternative pathways of carbohydrate fermentation as anoxia-exposure wears on. 
Table 3.1. Purification scheme of PK from control L. Littorea foot muscle tissue

\begin{tabular}{llllll}
\hline Purification Step & $\begin{array}{l}\text { Total } \\
\text { Protein } \\
(m g)\end{array}$ & $\begin{array}{l}\text { Total } \\
\text { Activity }\end{array}$ & $\begin{array}{l}\text { Specific } \\
\text { Activity } \\
(U)\end{array}$ & $\begin{array}{l}\text { Fold } \\
\text { Purification }\end{array}$ & \% Yield \\
& 4.22 & 0.99 & 0.23 & --- & \\
\hline Crude & 0.57 & 0.40 & 0.71 & 2.2 & 40.0 \\
$\mathrm{CM}^{-} \mathrm{pH}$ & 0.11 & 0.31 & 3.00 & 13 & 31.7 \\
Hydroxyapatite & 0.11 & & & \\
\hline
\end{tabular}


Table 3.2. Kinetic properties of PK purified from control, frozen and anoxic foot muscle of $L$. littorea. Data are mean $\pm \mathrm{SEM}, \mathrm{n}=4$.

\begin{tabular}{llll}
\hline Kinetic Parameter & Control & Frozen & Anoxic \\
\hline $\mathrm{K}_{\mathrm{m}}$ PEP $(\mathrm{mM})$ & $0.16 \pm 0.03^{a}$ & $0.11 \pm 0.03^{a}$ & $0.36 \pm 0.03^{b}$ \\
$\mathrm{~K}_{\mathrm{m}}$ ADP $(\mathrm{mM})$ & $0.62 \pm 0.03$ & $0.47 \pm 0.05$ & $0.41 \pm 0.09$ \\
& & & \\
$\mathrm{~V}_{\max }(\mathrm{U} / \mathrm{g}$ wet weight $)$ & $2.96 \pm 0.08$ & $3.09 \pm 0.04$ & $2.83 \pm 0.05$ \\
\hline
\end{tabular}

For each parameter measured, values that are not statistically different from each other share the same superscript letter notation. Differences determined by one-way ANOVA, Tukeys's post-hoc, $\mathrm{P}<0.05$. 
Table 3.3. Effects of various inhibitor compounds on the $\mathrm{V}_{\max }$ of pyruvate kinase from control, frozen and anoxic foot muscle of $L$. littorea. Data are mean $+/-\mathrm{SEM}, \mathrm{n}=4$ determinations on purified enzyme samples.

\begin{tabular}{lllll}
\hline Substrate & Parameter & Control & Frozen & Anoxic \\
\hline Urea $(\mathrm{M})$ & $\mathrm{I}_{50}$ & $1.72 \pm 0.08$ & $1.65 \pm 0.11$ & $1.71 \pm 0.14$ \\
$\mathrm{NH}_{4}(\mathrm{M})$ & $\mathrm{I}_{50}$ & $0.19 \pm 0.01^{a}$ & $0.27 \pm 0.01^{b}$ & $0.40 \pm 0.02^{c}$ \\
$\mathrm{ATP}(\mathrm{mM})$ & $\mathrm{I}_{50}$ & $6.44 \pm 0.48$ & $6.18 \pm 0.45$ & $8.77 \pm 0.28$ \\
$\mathrm{KCl}(\mathrm{M})$ & $\mathrm{I}_{50}$ & $0.54 \pm 0.04^{a}$ & $0.65 \pm 0.04^{a}$ & $0.11 \pm 0.004^{b}$ \\
$\mathrm{NaCl}(\mathrm{M})$ & $\mathrm{I}_{50}$ & $0.14 \pm 0.004$ & $0.14 \pm 0.01$ & $0.17 \pm 0.02$ \\
Alanine (mM) & $\mathrm{I}_{50}$ & $0.59 \pm 0.05^{a}$ & $0.58 \pm 0.05^{a}$ & $0.26 \pm 0.04^{b}$ \\
AMP $(\mathrm{mM})$ & $\mathrm{I}_{50}$ & $0.67 \pm 0.06$ & $0.44 \pm 0.07$ & $0.57 \pm 0.01$ \\
\hline
\end{tabular}

For each parameter measured, values that are not statistically different from each other share the same superscript letter notation. Differences determined by one-way ANOVA, Tukeys's post-hoc, $\mathrm{P}<0.05$. 
Table 3.4. Effects of various activating compounds on the $\mathrm{V}_{\max }$ of pyruvate kinase from control, frozen and anoxic foot muscle of $L$. littorea. Data are mean +/- SEM, n=3 determinations on purified enzyme samples.

\begin{tabular}{lllll}
\hline Substrate & Parameter reported & Control & Frozen & Anoxic \\
\hline FBP & $\mathrm{K}_{\mathrm{a}}(\mathrm{mM})$ & $0.09 \pm 0.01$ & $0.04 \pm 0.01$ & $0.08 \pm 0.02$ \\
& Fold-activation & $0.24 \pm 0.01$ & $0.26 \pm 0.08$ & $0.40 \pm 0.01$ \\
& & & & \\
Aspartate & $\mathrm{K}_{\mathrm{a}}(\mathrm{mM})$ & $0.49 \pm 0.16$ & $0.27 \pm 0.03$ & $0.56 \pm 0.19$ \\
& Fold-activation & $0.37 \pm 0.05^{\mathrm{a}}$ & $0.44 \pm 0.06^{\mathrm{a}}$ & $0.76 \pm 0.09^{\mathrm{b}}$ \\
& & & & \\
Isoleucine & $\mathrm{K}_{\mathrm{a}}(\mathrm{mM})$ & $0.86 \pm 0.32$ & $1.45 \pm 0.48$ & $2.27 \pm 0.44$ \\
& Fold-activation & $0.24 \pm 0.06$ & $0.18 \pm 0.02$ & $0.58 \pm 0.06$ \\
\hline
\end{tabular}

For each parameter measured, values that are not statistically different from each other share the same superscript letter notation. Differences determined by one-way ANOVA, Tukeys's post-hoc, $\mathrm{P}<0.05$. 


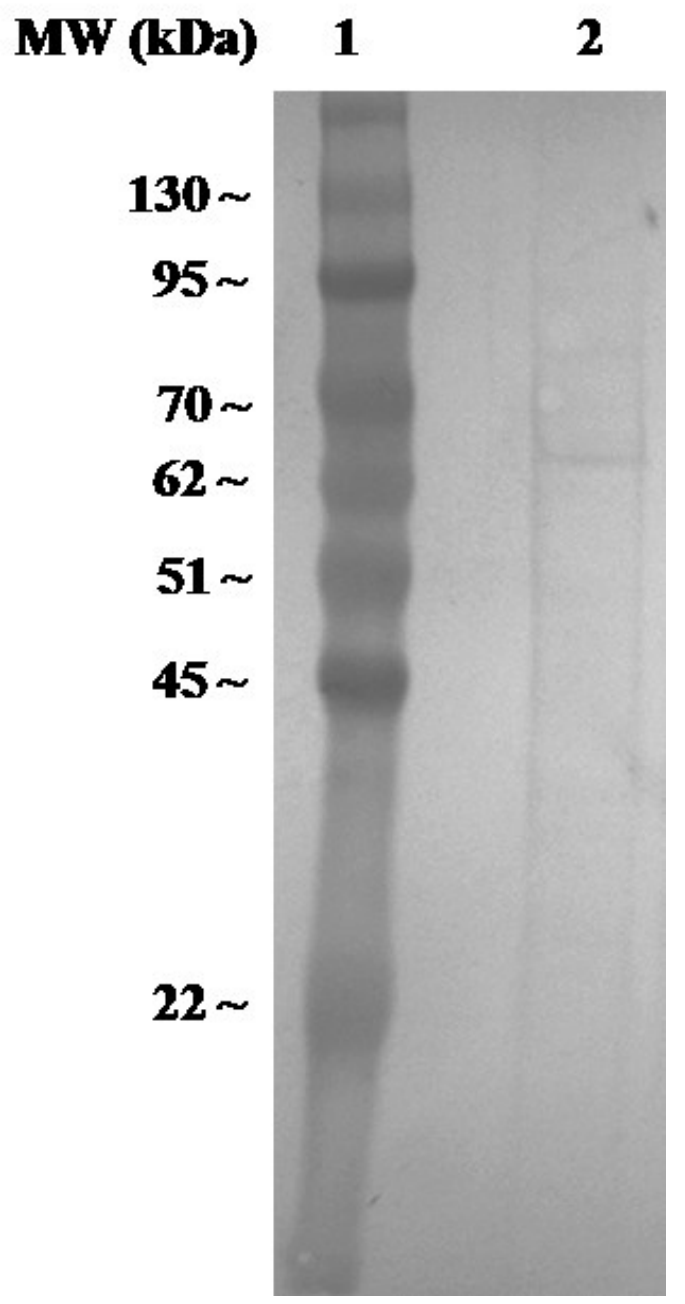

Figure 3.1. 10\% SDS-PAGE gel showing purified PK from control foot muscle of $L$. littorea. Lanes (1): Molecular weight ladder (Froggabio); (2): pooled peak fractions after elution Hydroxyapatite columns. 


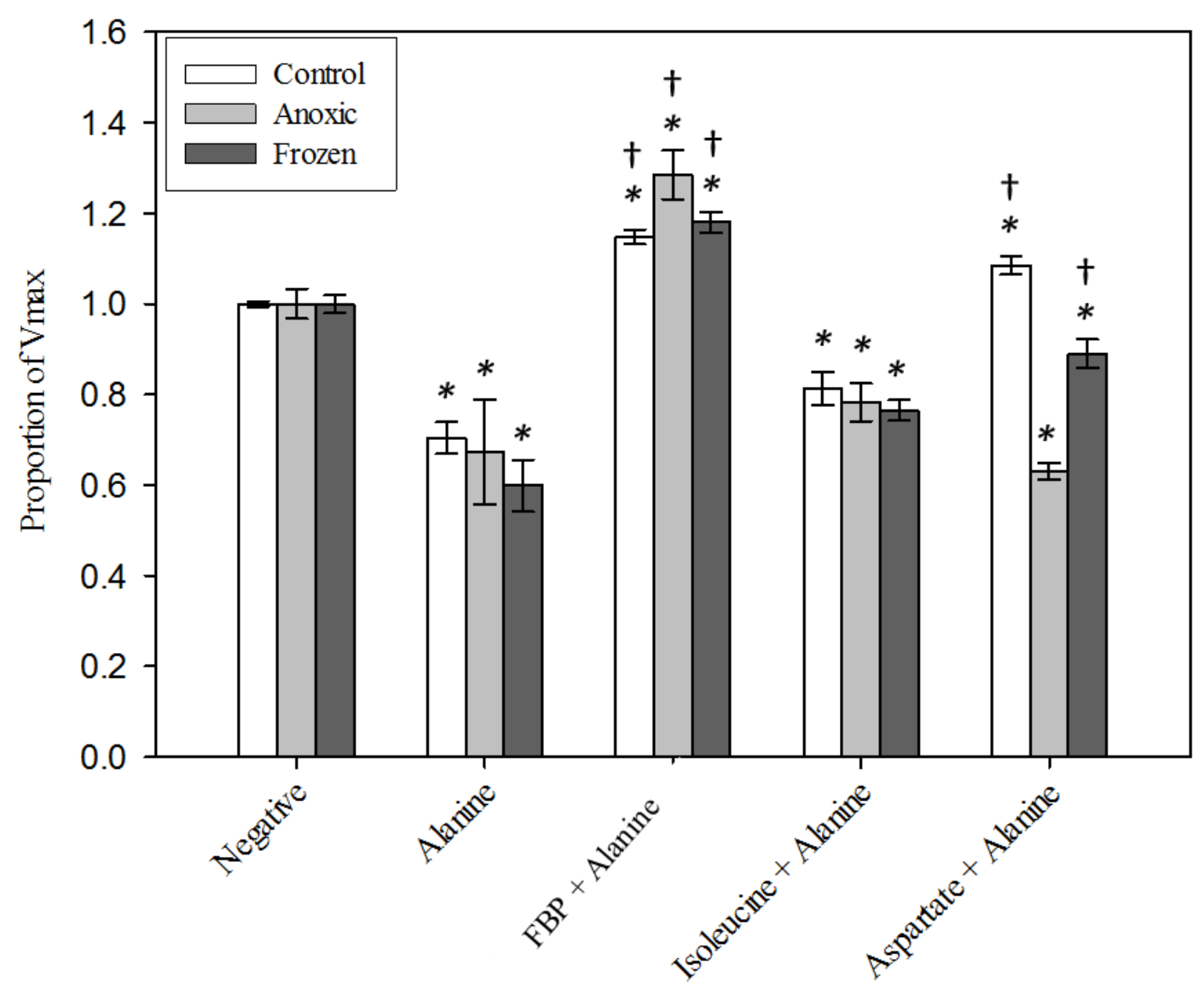

Figure 3.2. Effect of alanine and combinations of alanine with various activating compounds (FBP, Isoleucine, and Aspartate) on the $\mathrm{V}_{\text {maz }}$ of purified PK from the foot muscle of L. littorea. Significant differences in relative $\mathrm{V}_{\max }$ of the experimental treatments compared to the corresponding negative, uninhibited value of the same animal condition are indicated by an asterisk, Student's $t$-test, $P<0.05$. Significant differences in relative $\mathrm{V}_{\max }$ compared to the corresponding alanine-inhibited values are indicated by “†”. Student's $t$-test, $P<0.05$. Data are mean $\pm \mathrm{SEM}, \mathrm{n}=4$. All data were normalized to the corresponding negative value of the same animal condition which was set to 1.0. 


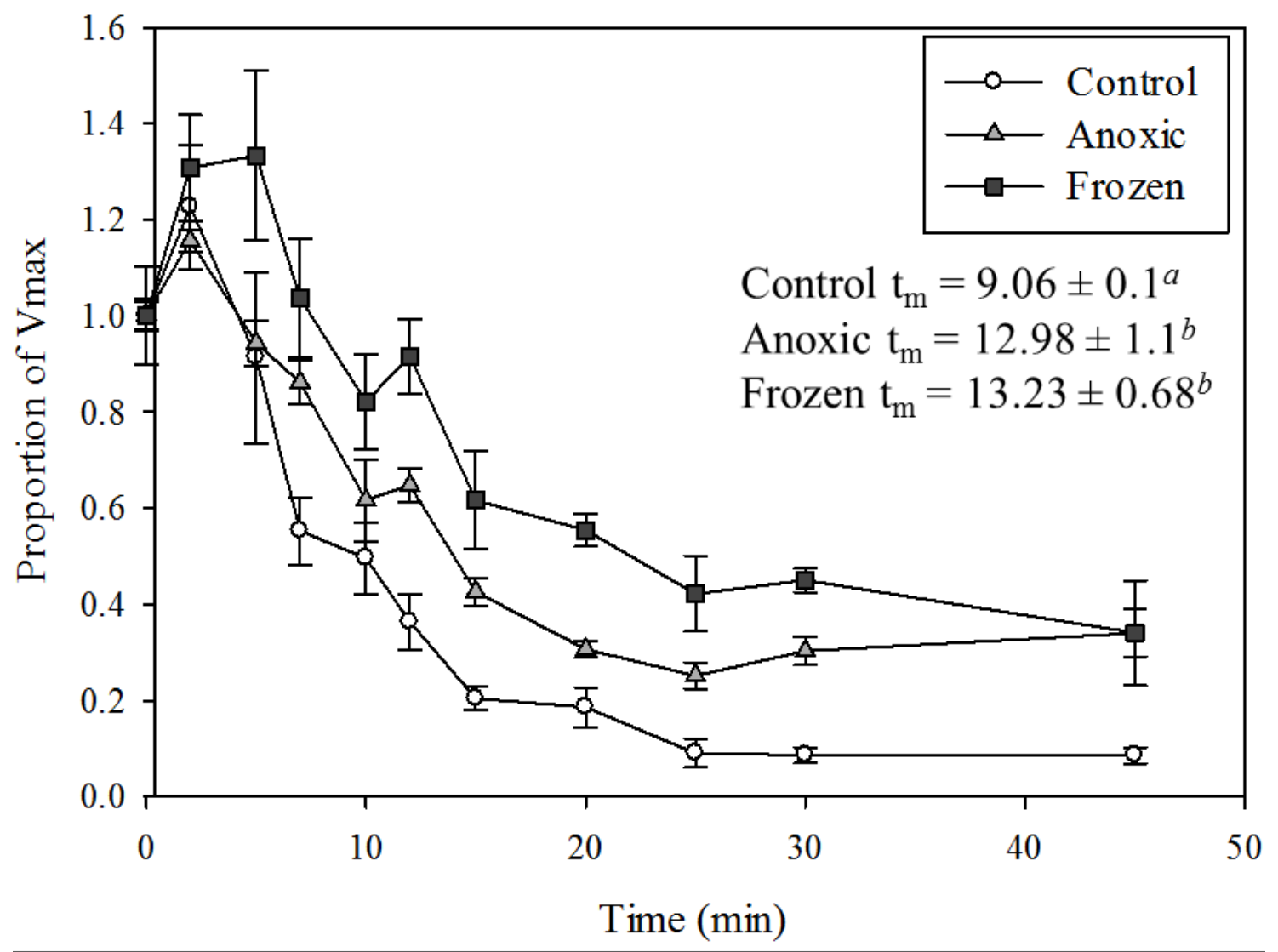

Figure 3.3. Relative stability of purified pyruvate kinase from L. littorea foot muscle determined through enzyme incubations at $60^{\circ} \mathrm{C}$. The reported $t_{\mathrm{m}}$ value is the incubation time that resulted in a $\mathrm{V}_{\max }$ reduced to $50 \%$ of the non-incubated. Values that are not statistically different from each other share the same superscript letter notation. Differences determined by one-way ANOVA, Tukeys's post-hoc, $\mathrm{P}<0.05$. 


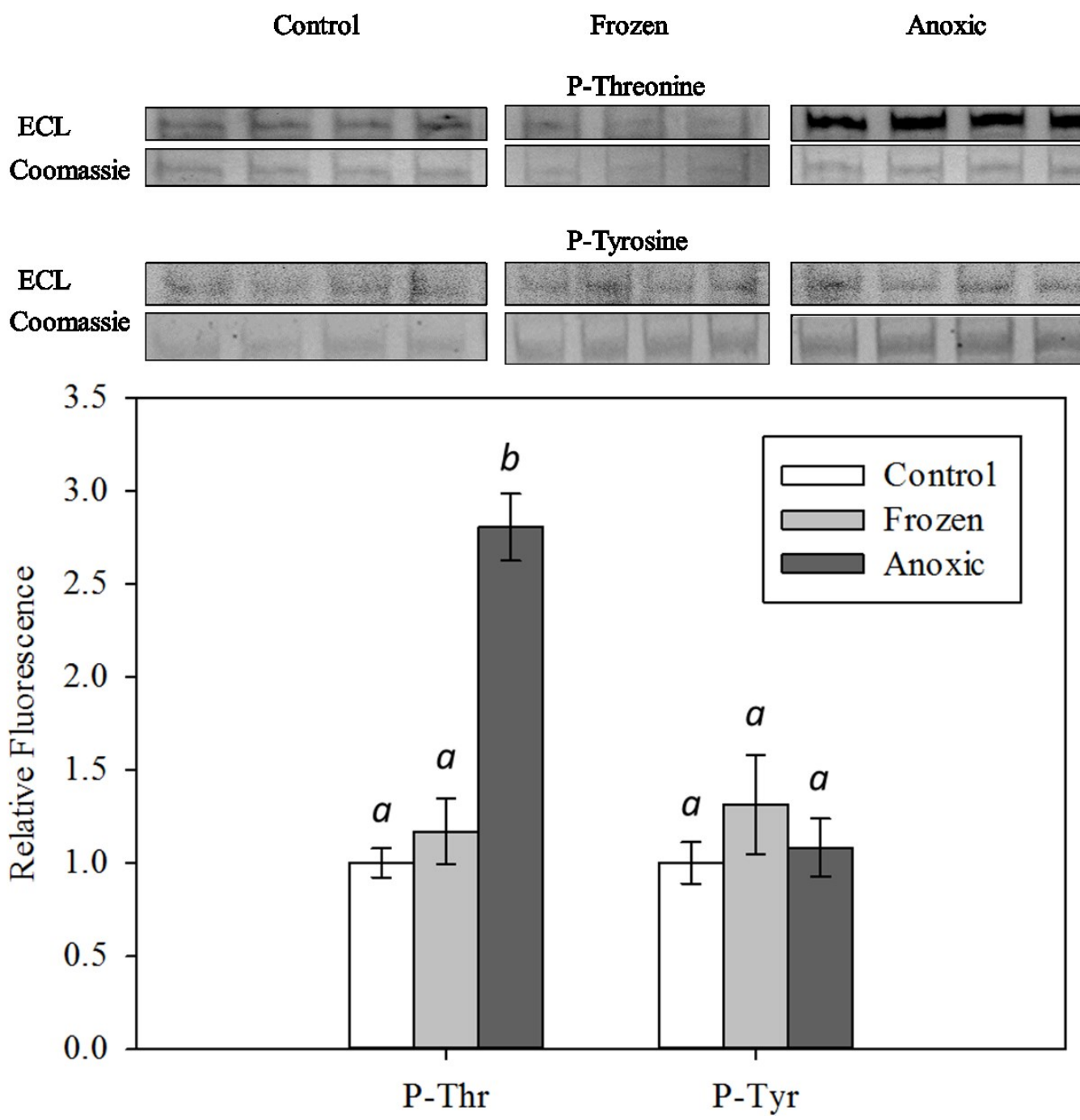

Figure 3.4: Relative levels of threonine and tyrosine phosphorylation of purified pyruvate kinase from control, frozen and anoxic foot muscle tissue of L. littorea determined through western blotting. Chemiluminescence signal intensities were standardized to corresponding coomassie protein amount, and the values for the frozen and anoxic forms were expressed relative to the control value that was set to 1 . For each target reported, values that are not statistically different from each other share the same superscript letter notation. Differences determined by one-way ANOVA, Tukeys's posthoc, $\mathrm{P}<0.05$. Data are mean $\pm \mathrm{SEM}, n=3,4$ determinations on purified enzyme samples. 
Chapter 4

\section{Purification and Characterization of Pyruvate Kinase from the Liver of the Hibernating Richardson's Ground Squirrel}




\section{Introduction}

Seasonal fluctuations of temperature and resource availability are common problems confronting animals living in northern environments. The arrival of extreme winter conditions requires that these animals either undergo a seasonal migration to more forgiving climates, survive on the scarce resources available throughout the winter, or seek shelter and enter a dormant state to escape the stress and wait for more favorable conditions. Mammalian hibernation is an excellent example of the third strategy and is characterized by an animal entering into a dormant state, known as torpor, which is interspersed by brief periods of arousal, dubbed interbout arousals (figure A2.2). These periods of torpor last anywhere between a few days to 5 weeks while the interbout arousals typically last between 12 and 24 h (Carey et al., 2003; Storey, 2010). During hibernation, animals enter a hypometabolic state which is characterized by major physiological and biochemical changes. For instance, mammalian hibernators are able to decrease their metabolic rate by up to $95 \%$ resulting in significant energy savings and enabling survival on limited energy stores (Storey \& Storey, 2010). Physiologically, changes include a drop in heart rate to just $5 \%$ of its non-torpid rate, and breathing rates that drop from $>40$ to $<1$ beats per minute (McArthur \& Milsom, 1991; Zatzman, 1984; Storey, 2004a). Torpor periods during hibernation are also marked by a sharp drop in body temperature $(\mathrm{Tb})$. Endothermic mammals normally maintain a $\mathrm{Tb}$ around $37^{\circ} \mathrm{C}$, but during the torpor cycle this can drop to anywhere between $0^{\circ} \mathrm{C}$ to $5^{\circ} \mathrm{C}$ (Geiser, 2004; Storey, 2004a). During the entry to and arousal from torpor there are a number of major molecular and biochemical adaptations that aid in establishing and lifting a strong metabolic rate depression. For instance, energy-costly processes like transcription and 
translation are suppressed during entry into torpor. This has been previously confirmed through studies showing lower rates of mRNA and protein synthesis, expression of less active forms of RNA polymerase II, and inhibition of ribosomal factors via RPP during hibernation, ultimately hindering both mRNA and protein synthesis (Frerichs et al., 1998; Hittel \& Storey, 2002; Moring \& Storey, 2006; Chen et al., 2001). The investigation of consistent and rapid cycling from torpor to arousal, from metabolically depressed to active and back is certainly a fascinating phenomenon that could provide novel insight into mammalian metabolic regulation.

Richardson's ground squirrel (Urocitellus richardsonii) are a well-studied hibernator model and are the particular animal studied in this chapter. These animals are found across the prairies of southern Canada and northern United States and hibernate for 7-9 months between September and May (Michener, 1983). Indeed, during hibernation these animals are known to enter a hypometabolic state similar to other mammalian hibernators and are estimated to save up to $96 \%$ of their total energy budget by entering a state of torpor (Wang, 1979). Furthermore, differential regulation of metabolic enzymes in this animal suggests that metabolic remodeling to optimize energy consumption efficiency is occurring during hibernation (Thatcher \& Storey, 2001).

Energy production in mammalian hibernators switches from primarily carbohydrate sources in the summer and fall to mostly fatty acids and lipid sources during hibernation in the winter (John, 2005). In fact, the respiratory quotient (RQ) of many hibernators shifts from 1 to 0.7 - 0.8 during torpor, suggesting a significant shift towards lipid metabolism occurs during this period (Buck \& Barnes, 2000). This shift is observed in almost all organs, including the liver, and is primarily effected through torpor-induced 
changes in the levels of circulating hormones. High levels of circulating glucagon during hibernation stimulates the release of free fatty acids from white adipose tissue (WAT) where it is stored in preparation for winter. Meanwhile, insulin levels decrease during torpor due to a lack of feeding during dormancy and in some instances insulin resistance can develop (Bauman et al., 1987; Martin, 2008). Decreases in insulin levels has two main effects: first, it is thought to decrease rates of lipogenesis and glycogen synthesis through decreased PI3K/Akt signaling (Eddy \& Storey, 2003; Cai et al., 2004). Secondly, decreased insulin levels results less uptake of glucose by cells, ultimately decreasing glucose availability and therefore carbohydrate metabolism. This effect is amplified further through enzymatic regulation via RPP. In the liver of the Djungarian hamster (Phodopus sungorus), for example, an inactivation of PDH was observed in response to daily torpor, and this change in activity was consistent with regulation by RPP (Heldmaier et al., 1999). Similar results were observed in the hibernating mouse Zapus hudsonius which exhibited stress-responsive inactivation of GP, PFK and PK consistent with RPP-regulatory mechanisms (Storey, 1987b). Inactivation of these enzymes limits glycolytic activity and the entrance of pyruvate into the TCA, ultimately reducing the rate of carbohydrate metabolism and energy production in general. Clearly, carbohydrate metabolism is highly regulated in mammalian liver tissue such that it can be suppressed during hibernation.

The state of gluconeogenesis in the livers of hibernators is uncertain but evidence shows that it is likely increased in response to hibernation and during interbout arousals. In hibernating 13-lined ground squirrels, the activity of cytoplasmic PEPCK, a crucial enzyme for gluconeogenesis, increases in both liver and kidney tissues during 
hibernation. This increase could then serve to regenerate glucose levels to enable thermogenesis during arousal periods. Furthermore, in 13-lined ground squirrels, the rate of gluconeogenesis increases from a variety of precursors, especially glycerol and propionate suggesting that the regeneration of glucose is prioritized during hibernation. (Green et al., 1984). Similarly, in hepatic tissues of the hibernating ground squirrel (Citellus tridecemlineatus), Burlington and Klain (1967) observed increased rates of gluconeogenesis from glycerol, amongst other precursors. Finally, Klain \& Whitten (1968) observed an increased capacity for labelled $\mathrm{CO}_{2}$ incorporation into glucose and glycogen in the livers of torpid and interbout animals compared to the non-hibernating euthermic controls. This suggests that increased rates of gluconeogenesis occur throughout the torpor-arousal cycle of mammalian hibernation. Given the evident decrease in carbohydrate catabolism and increased rates of gluconeogenesis in hibernator livers, it stands to reason that hepatic carbohydrate metabolism is highly regulated during hibernation.

Pyruvate kinase is the terminal enzyme of glycolysis which catalyzes the transfer of a phosphate group from PEP to ADP. It is located at a locus of ATP production and both its substrate (PEP) and product (pyruvate) have multiple potential metabolic fates. For these reasons, PK is commonly a regulatory target via RPP, especially in mammalian liver tissue. For example, in response to glucagon signaling, mammalian PK is typically inactivated via phosphorylation such that gluconeogenesis in prioritized (Blair et al., 1976). Furthermore, PK is highly regulated by multiple allosteric effectors, including FBP, ATP and alanine (Jurica et al., 1998; Tanaka et al., 1967; Veelen et al., 1979). Given the complex nature of PK regulation and its important function in carbohydrate 
metabolism, it follows that this enzyme is regulated in response to hibernation such that metabolic rate depression is enabled and gluconeogenesis is favored over glycolysis. In order to test this hypothesis, PK was investigated in the liver of a model hibernating mammal, Richardson's ground squirrel (Urocitellus richardsonii) with respect to its kinetic and regulatory properties.

\section{Materials and Methods}

\section{Animals}

The protocols used for care and handling of Richardson's ground squirrels, $U$. richardsonii, were as reported previously (MacDonald \& Storey, 1999; Thatcher \& Storey, 2001). Briefly, animals were captured in late summer near Calgary, Alberta. All 21 animals were individually housed in rat cages with free access to food and water at $22^{\circ} \mathrm{C}$ and on an autumn photoperiod (10 h light, $14 \mathrm{~h}$ dark). After 8 weeks under this regime, half of the animals were maintained under these control (euthermic) conditions. The others (hibernating) were moved into a $4^{\circ} \mathrm{C}$ cold room that was maintained in darkness; free access to water was maintained but food was removed. Squirrels were allowed to enter torpor and animals were sampled after 2 days of continuous torpor (rectal temperature $5-8^{\circ} \mathrm{C}$ ). Euthermic animals were sampled on the same day. Both hibernating and euthermic animals were killed by decapitation and tissues were immediately excised, frozen in liquid nitrogen and then stored in $-80^{\circ} \mathrm{C}$.

\section{Preparations of tissue}

PK was isolated from euthermic and hibernating liver tissues of U. richardsonii. Samples were quickly weighed and added to 5 volumes of ice-cold homogenization 
buffer A which included; 10 mM MES, pH 6.0, 2 mM EDTA, 2 mM EGTA, 15 mM $\beta$ GP, $15 \mathrm{mM} \beta-\mathrm{MeSH}, 10 \% \mathrm{v} / \mathrm{v}$ glycerol, with a small scoop of phenylmethylsulphonyl fluoride (PMSF) crystals added immediately before homogenization. Samples were homogenized completely using a Polytron homogenizer (Brinkmann Instruments, Westbury, NY, USA) and spun in an Eppendorf 5810R centrifuge (22331 Hamburg, GER) for $30 \mathrm{~min}$ at $13500 \mathrm{x} \mathrm{g}$ and $5^{\circ} \mathrm{C}$. The supernatant (crude homogenate) was decanted and held on ice until use.

\section{Pyruvate Kinase Assay}

Pyruvate kinase activity was measured as previously described in chapter 2 , except that optimal conditions included $8 \mathrm{mM}$ PEP for euthermic animals and $4 \mathrm{mM}$ PEP for hibernating animals.

\section{Purification of Pyruvate Kinase}

A $2 \mathrm{~mL}$ aliquot of crude homogenate was added to a $\mathrm{CM}^{-}$sephadex column $(0.75$ $\mathrm{cm}$ X $10 \mathrm{~cm}$ ) that had been previously equilibrated with $20 \mathrm{~mL}$ of buffer A. The column was then washed with $15 \mathrm{~mL}$ of buffer A and the enzyme was eluted with $20 \mathrm{~mL}$ of buffer B (same as buffer A, but pH 6.5). Using an automated fraction collector (Gilson Medical Electronics, Inc., Middleton, WI, USA) $1.2 \mathrm{~mL}$ fractions of column eluant were collected. To determine where PK eluted from the column, $10 \mu \mathrm{L}$ of each fraction was taken and used to measure PK activity spectrophotometrically as previously described in chapter 2. Peak activity fractions were pooled and added to a Cibacron Blue 3GA (Sigma-Aldrich) column $(0.75 \mathrm{~cm} \mathrm{X} 5 \mathrm{~cm})$ that had been previously equilibrated with buffer C (10 mM MOPS, pH 7.0, 2 mM EDTA, 2 mM EGTA, 15 mM $\beta$ - 
glycerophosphate, $15 \mathrm{mM} \beta-\mathrm{MeSH}$ and $10 \% \mathrm{v} / \mathrm{v}$ glycerol). PK was eluted from the column with a $0-1 \mathrm{M} \mathrm{KCl}$ gradient made in buffer $\mathrm{C}$ and collected in $1.2 \mathrm{~mL}$ fractions which were then assayed for PK activity using $10 \mu \mathrm{L}$ from each fraction, as before. After fractions containing maximal PK activity were pooled, low molecular weight metabolites were removed from the sample via centrifugation (2 min @ $2000 \mathrm{rpm}$ ) through $5 \mathrm{~mL}$ columns of Sephadex G-25 (Sigma-Aldrich) equilibrated in buffer C. The sample was then loaded onto an HA column $(0.75 \mathrm{~cm} \mathrm{X} 2 \mathrm{~cm})$ equilibrated in buffer $\mathrm{C}$ and $\mathrm{PK}$ was eluted with a $0-500 \mathrm{mM}$ potassium phosphate gradient. The fractions were assayed for PK activity and peak fractions were pooled and used for all subsequent experiments. Protein concentrations were determined using Coomassie blue G-250 dye-binding reagent (Bio-Rad, Hercules, CA, USA) as instructed by the manufacturer using bovine serum albumin as a standard (Bradford, 1976). The purity of PK was confirmed using SDS-PAGE followed by coomassie staining as previously described.

\section{Incubation experiments}

Temperature incubation experiments to determine the stability of PK at high concentrations of urea were performed as previously described in chapter 2 .

\section{SDS Polyacrylamide Gel Electrophoresis and Immunoblotting}

Western blots were performed as previously described in chapter 2 to compare the phosphorylation states of the control, frozen and anoxic forms of PK. The following primary antibodies were used for western blotting:

(1) rabbit anti-phosphoserine (Cat. \#618100, Invitrogen, Carlsbad, CA, USA); (2) rabbit anti-phosphothreonine (Cat. \#718200, Invitrogen, Carlsbad, CA, USA); (3) mouse anti- 
phosphotyrosine (Cat. \#615800, Invitrogen, Carlsbad, CA, USA); (4) rabbit antimethylated lysine (SPC-158F, StressMarq, Biosciences Inc., Victoria, BC, Canada).

Purity of PK was confirmed by SDS-PAGE and staining with Coomassie blue staining as previously described in chapter 2 .

\section{Data and Statistical Analyses}

All data and statistical analyses were performed as previously described in chapter 2 .

\section{Results}

\section{Purification of Pyruvate Kinase}

PK was successfully purified from euthermic and hibernating $U$. richardsonii liver using a combination of ion-exchange and affinity column chromatography (table 4.1, figure 4.1). PK was eluted from the first column by increasing the $\mathrm{pH}$ of the elution buffer from $\mathrm{pH} 6.0$ to $\mathrm{pH}$ 6.5. This step resulted in 6.6-fold purification with a $30 \%$ yield. The second step, a 0-1 M KCl gradient elution from a Cibacron blue column, resulted in a 10 -fold purification with a $24 \%$ yield The final purification step was potassium elution from an HA column which resulted in a final 34 -fold purification with a $15 \%$ yield. The purified PK had a molecular weight of $62 \mathrm{kDa}$ (figure 4.1).

\section{Kinetic activity of PK}

The $\mathrm{V}_{\max }$ of purified euthermic PK was determined to be $2.60 \mathrm{U} / \mathrm{mg}$ of protein while hibernating $\mathrm{PK}$ at $22^{\circ} \mathrm{C}$ had a $\mathrm{V}_{\max }$ of $0.84 \mathrm{U} / \mathrm{mg}$ of protein; a nearly 2-fold 
decrease (table 4.2). When measured at $5^{\circ} \mathrm{C}$, the trend held as the $\mathrm{V}_{\max }$ of euthermic PK was still significantly greater than that of hibernating PK $(0.7 \mathrm{U} / \mathrm{mg}$ Vs $0.30 \mathrm{U} / \mathrm{mg})$. The $\mathrm{K}_{\mathrm{m}} \mathrm{PEP}$ of PK decreased significantly in the hibernating animals $(2.08 \pm 0.16 \mathrm{mM})$ when compared to the euthermic animals $(6.42 \pm 0.26 \mathrm{mM})$ (table 4.2). A similar trend was observed at $5^{\circ} \mathrm{C}$ where the $\mathrm{K}_{\mathrm{m}} \mathrm{PEP}$ decreased from $0.60 \mathrm{mM}$ to $0.29 \mathrm{mM}$ between euthermic and hibernating tissues. The $\mathrm{K}_{\mathrm{m}} \mathrm{ADP}$ of PK was also found to decrease in the hibernating animals at room temperature $(0.88 \mathrm{mM}$ Vs $0.32 \mathrm{mM})$, but did not change significantly at $5^{\circ} \mathrm{C}(0.26 \mathrm{mM})$. Finally, the activation energy of $\mathrm{PK}$ was found to be an average $34 \mathrm{~kJ} / \mathrm{mol}$ and was the same for both euthermic and hibernating PK.

The activity of PK was also investigated at $\mathrm{pH} 8.0$ (table 4.3). In both euthermic and hibernating tissues, the increased $\mathrm{pH}$ had no effect on neither the Vmax nor the $\mathrm{K}_{\mathrm{m}} \mathrm{PEP}$. However, the $\mathrm{K}_{\mathrm{m}} \mathrm{ADP}$ of hibernating PK decreased significantly at $\mathrm{pH} 8.0$ compared to at $\mathrm{pH} 7.2(0.17$ vs. $0.32 \mathrm{mM})$. No changes were observed in the $\mathrm{K}_{\mathrm{m}} \mathrm{ADP}$ of euthermic $\mathrm{PK}$ in response to $\mathrm{pH}$ changes.

Known allosteric regulators of PK, FBP and ATP, were also examined with respect to their effects on the euthermic and hibernating forms of PK. The $\mathrm{K}_{\mathrm{a}} \mathrm{FBP}$ was significantly greater for the hibernating form of PK (4.06 mM Vs $1.96 \mathrm{mM})$, while the fold-activation (FA) decreased significantly (1.35 Vs 1.70). The $\mathrm{I}_{50} \mathrm{ATP}$ did not change significantly between the two forms of PK and was $22.9 \mathrm{mM}$. 


\section{Post-translational modifications of PK}

Western blotting was used to assess the possible differences in the posttranslational modifications of purified liver PK from euthermic and hibernating conditions (figure 4.2). Phosphorylation via serine and threonine residues increased 2fold in hibernating liver samples relative to the euthermic control. Levels of tyrosine phosphorylation and lysine methylation between euthermic and hibernating PK did not differ significantly.

\section{Structural stability of PK}

Structural stability of pyruvate kinase was investigated by examining stability under incubations in various concentrations of urea (figure 4.3). The euthermic and hibernating forms of PK retained similar amounts of activity to each other in the $1 \mathrm{M}, 2$ $\mathrm{M}$ and $3 \mathrm{M}$ urea incubations. However, in the $4 \mathrm{M}$ incubation, the euthermic PK retained $11 \%$ of its original, non-incubated $\mathrm{V}_{\max }$ while the hibernating PK retained $20 \%$. 


\section{Discussion}

Mammalian hibernation during winter is characterized by long periods of torpor where metabolic rates can drop to only $5 \%$ of their normal value, interspersed with brief periods of interbout arousal where metabolic rates return to normal. Though many hypotheses exist, it is thought that these periods of arousal are in part needed as an opportunity to conduct gluconeogenesis in liver and other tissues to restore levels of glucose needed to sustain the brain and other carbohydrate-consuming organs upon reentry into torpor. This is especially important in the liver, where glycolysis is inhibited and gluconeogenesis is activated during torpor and arousal, respectively, in order to maintain blood and brain glucose levels and supply fuel for thermogenesis. Regulation of glycolysis and gluconeogenesis during hibernation is typically mediated in part by the regulation of one or more enzymes within these pathways, and the results of this study indicate the pyruvate kinase is one such regulatory point. Via phosphorylation, this enzyme is regulated in the liver such that metabolic rate and glucose metabolism is suppressed during hibernation, which provides the opportunity for gluconeogenesis to occur.

The characterization of PK began with an investigation of its kinetic properties, and many differences between the euthermic and hibernating forms of the enzyme were observed. Crucially, PK purified from torpid mammals exhibited a significantly smaller $\mathrm{V}_{\max }$ than PK purified from euthermic animals. This was the case under all conditions tested; at room temperature, $5^{\circ} \mathrm{C}$, and at both $\mathrm{pH}$ values (table $4.2,4.3$ ). This indicates that PK is inactivated during hibernation in Richardson's ground squirrel liver through a mechanism that induces a stable change in the enzyme resulting two distinct forms of the 
enzyme: a high-activity euthermic form and a low-activity torpid form. During hibernation, Richardson's ground squirrels maintain a $\mathrm{Tb}$ around $5^{\circ} \mathrm{C}$, while euthermic animals are far closer to room temperature. Therefore, the most physiologically-relevant comparison to investigate is the euthermic form of $\mathrm{PK}$ at $22^{\circ} \mathrm{C}$ compared to the hibernating form of $\mathrm{PK}$ at $5^{\circ} \mathrm{C}$. This comparison provides the most accurate picture of how the enzyme behaves while animals are euthermic or torpid. At these conditions, the $\mathrm{V}_{\max }$ dropped by nearly $90 \%$ from the euthermic to the torpid forms of PK $(5.20 \mathrm{U} / \mathrm{mg} \mathrm{Vs}$ $0.30 \mathrm{U} / \mathrm{mg}$; table 4.2). This shows that during hibernation, liver PK in the ground squirrel is significantly less active than it is in the euthermic animal. Although it can also be noted that the $\mathrm{K}_{\mathrm{m}}$ constants of both PEP and ADP were smaller for the torpid form of PK compared the euthermic form (table 4.2), such a sharp decline in $V_{\max }$ would make these decreases in substrate affinity negligible. Overall, this fits well into the known metabolic landscape of liver during mammalian hibernation by contributing to a general metabolic rate depression, limiting carbohydrate catabolism and enabling more efficient gluconeogenesis. A less active form of PK present during hibernation decreases the rate of carbohydrate metabolism, therefore decreasing energy production and ensuring the actions of glycolysis do not counter gluconeogenic activity. In general, metabolic rate is strongly suppressed during hibernation by up to $95 \%$ and this is also the case in the liver of Richardson's ground squirrels. For example, in the liver of hibernating 13-lined ground squirrels (13-LGS), rates of mitochondrial respiration were found to decrease by as much as $70 \%$ compared to euthermic values (Muleme et al., 2006; Brown et al., 2013), exhibiting a clear decrease in mitochondrial metabolism and energy production.

Suppressing the activity of PK, a key enzyme of glycolysis and energy production, would 
contribute to this effect by limiting the amount of pyruvate available for the TCA cycle in the mitochondria. It will also contribute to an overall metabolic rate depression directly by decreasing substrate-level phosphorylation of ATP, a product of PK catalysis.

As well as undergoing a strong metabolic rate depression, most organs of hibernators switch from carbohydrate metabolism to primarily lipid oxidation during torpor to meet the energetic needs of the cell (Buck \& Barnes, 2000; Tashima, 1970). This is true in the liver as well, where a number of enzymes of carbohydrate metabolism have been shown to be negatively regulated in response to hibernation. For example, hibernating meadow jumping mice (Zapus hudsonius) exhibit inactivation of three enzymes of carbohydrate metabolism in response to both short term $(<24 \mathrm{~h})$ and long term (5-8 days) hibernation periods. These enzymes include GP, PFK and PK, and inactivation of these enzymes would contribute to both an overall metabolic rate depression and suppression of carbohydrate metabolism (Storey, 1987b). A similar suppression of a key carbohydrate-utilizing enzyme was observed in 13-LGS where both the total GP activity and the proportion of GP in the active form was decreased significantly in response to hibernation (Brooks \& Storey, 1992). Together with the results found in this study showing a significantly decreased $\mathrm{V}_{\max }$ of $\mathrm{PK}$ during hibernation, there is strong evidence that PK contributes to the suppression of carbohydrate metabolism in Richardson's ground squirrel liver. It also shows that enzymatic regulation is an important mediator of carbohydrate metabolism reduction during hibernation overall.

Inhibition of PK activity during hibernation would also be beneficial due to the role played by the liver in supporting gluconeogenesis during hibernation and interbout 
arousals as it would compete less with enolase for PEP as a substrate as glycolysis is run in the glucose synthesizing direction. Suppression of PK activity, and therefore the rate of forward glycolysis, creates an environment more conducive to running gluconeogenesis. This is crucial to mammalian hibernators which require gluconeogenic activity to restore limited glucose stores needed to fuel the brain and maintain blood glucose levels. While this study shows that PK activity decreases in mammalian hibernation, the activity of PEPCK, a key gluconeogenic enzyme, has been shown to increase (Green et al., 1984), enhancing gluconeogenic capacity. There is also ample evidence suggesting that regulation of PK specifically plays a role in controlling gluconeogenesis. For example, a study by Krebs \& Eggleston (1964) showed that rats fed low carbohydrate diets had liver PK activity of about $1 / 3$ of those fed a control diet. Meanwhile, rats fed a highcarbohydrate diet had liver PK activity approximately 10-fold higher than the low carbohydrate rats. These results suggest that PK activity can be inhibited during times of low carbohydrate availability to conserve this fuel and the authors suggested it was to facilitate gluconeogenesis. A similar effect was observed in rat hepatocytes treated with the diabetes treatment metformin. In this study, metformin was found to decrease rates of gluconeogenesis while glycolytic flux through PK was found to increase (Argaud et al., 1993). This suggests that increased PK activity was inhibiting gluconeogenesis.

Furthermore, mammalian L-type PK is known to be inactivated via phosphorylation by cAMP-dependent kinase in response to starvation. The effect of this inhibition is an increased rate of gluconeogenesis, suggesting that hibernation may elicit a similar response to starvation with respect to $\mathrm{PK}$ and gluconeogenic regulation (Berkel et al., 1978; Berkel et al., 1977; Feliu \& Hers, 1976). Perhaps, then, hibernating RGS can 
initiate gluconeogenesis by taking advantage of preexisting metabolic regulatory mechanisms, namely the inhibition of PK via phosphorylation. Together, there is ample evidence showing that PK is inactivated in Richardson's ground squirrel liver during hibernation to suppress glycolysis and contribute to an environment that is more conducive to gluconeogenesis. It also shows how animals surviving in extreme conditions can make use of inherent properties of metabolic enzymes, in this case PK's ability to regulate gluconeogenic rate, to enhance their survival.

PK is highly regulated by allosteric effectors, especially in mammalian liver. This study investigated the response of PK to a variety of known allosteric effectors to determine whether or not PK from euthermic and hibernating squirrel liver was differentially affected by these allosteric molecules contributing to the metabolically depressed phenotype. ATP exhibited similar effects on PK from euthermic and hibernating tissues. It is interesting to note that ATP, a known inhibitor of PK, had $\mathrm{I}_{50}$ values ( $\sim 22 \mathrm{mM}$, table 4.3$)$ well in excess of expected cellular concentrations, suggesting that ATP is not an effective regulatory mechanism of PK in this animal. Compared to the $\mathrm{I}_{50} \mathrm{ATP}$ value found in rat liver $(0.16 \mathrm{mM}$; Tanaka et al., 1967), it would seem as though ATP allosteric regulation is a non-factor in Richardson's ground squirrel. Contrary to ATP, the degree of FBP activation of PK differed between euthermic and hibernating tissues. FBP is known to activate the liver form of PK in mammals through binding to a regulatory site separate from the active site (Tanaka et al, 1967, Taylor \& Bailey, 1967, Jurica et al., 1998). The $\mathrm{K}_{\mathrm{a}} \mathrm{FBP}$ was 1-fold greater for the torpid form of PK compared to the euthermic form while the fold-activation was significantly smaller (1.35 Vs 1.70, table 4.4). This suggests that the torpid PK is less sensitive to FBP activation, and in a 
system that discourages glycolysis, decreasing the impact of feed-forward activation of PK would be of benefit. Other studies have revealed similar stress-responsive changes to FBP activation including PK in the hepatopancreas of anoxia-tolerant oysters and marine whelks, where the $\mathrm{K}_{\mathrm{a}} \mathrm{FBP}$ increased in response to anoxia exposure (Greenway \& Storey, 2000; Plaxton \& Storey, 1984). These systems also favored suppressed PK activity, suggesting that reduced activation capacity of PK by FBP may be a conserved regulatory mechanism of the enzyme in response to environmental stress.

The above-mentioned hibernation-responsive kinetic changes of PK suggest that structural changes may also be occurring to the enzyme during torpor. To test this hypothesis, the stability of PK was investigated through chemical denaturation experiments (figure 4.3). The results of these experiments show that torpid PK is significantly more stable after incubation in $4 \mathrm{M}$ urea than is the euthermic PK. Similar increases in enzyme stability have been observed in other hibernating species, including GAPDH in the 13-LGS and the hibernating jerboa (Jaculus orientalis). In both of these studies, stability of GAPDH increased during hibernation, suggesting enzyme stability is prioritized during hibernation (Iddar et al, 2003; Bell et al., 2014). Though the reasons for this are not clear, it is likely linked to the need to maintain protein viability during a state of hypometabolism. While in a hypometabolic state like hibernation, non-essential cellular processes like protein turnover are suppressed to conserve energy (Storey \& Storey, 2004a). Indeed, protein turnover is a very energy-expensive process as the formation of a single peptide bond requires nearly 5 equivalents of ATP or higher and has been estimated to account for up to $22 \%$ of a cell's energy budget (Milward et al., 1976; Lobley et al, 1980; Land \& Hochachka, 1994). Therefore, organisms must ensure that 
mechanisms are in place to maintain protein stability during periods of torpor and hypometabolism. Accordingly, there is strong evidence supporting an increased expression of protein chaperones, heat shock proteins and antioxidant defenses during mammalian hibernation. In the 13-LGS, for example, proteomics and gene screening studies suggest that there is an upregulation of proteins of the Hsp70 family in the liver during torpor (Epperson et al., 2010; Storey, 2003). These protein chaperones assist in maintaining protein stability during hibernation, reducing the need for protein synthesis. Meanwhile, antioxidant defenses are also upregulated during torpor in the form of increased antioxidant enzyme activity and small antioxidant metabolites like glutathione (Okamoto et al., 2006; Carey et al., 2003). This further contributes to creating a more stable cellular environments and limits the rate of protein turnover. Clearly protein stability and cellular preservation are prioritized during bouts of torpor and it would therefore be advantageous for organisms to ensure that metabolic enzymes are held in a stable conformation throughout this period. The results from this study suggest that PK is one such enzyme.

Both the changes in kinetic parameters and structural stability of PK suggest that the enzyme is covalently modified during hibernation, as is commonly the case in stressresponsive adaptations of metabolic enzymes. RPP is particularly effective as a mediator of metabolic rate depression as its reversible nature means that enzymes can be activated/inactivated without the need to degrade and resynthesize proteins when energy stores are limited. For this reason, the relative phosphorylation states of PK from euthermic and hibernating tissues were compared via western blotting and a 2 -fold increase in both serine and threonine phosphorylation of torpid PK was observed (figure 
4.2). Certainly, reversible stress-responsive phosphorylation of enzymes is a welldocumented regulatory mechanism in mammalian hibernators and contributes to the establishment of a global metabolic rate depression. For example, phosphorylation of $\mathrm{Na}^{+} / \mathrm{K}^{+}$-ATPase and $\mathrm{Ca}^{+}$-ATPase reduces the activity of these pumps during hibernation in the golden mantled ground squirrel. This results in decreased ATP hydrolysis which enables the sharp drop in core body temperature observed during torpor (Storey \& Storey, 2004; MacDonald \& Storey, 1999). Decreases in the rates of carbohydrate metabolism can also be attributed to RPP of glycolytic enzymes. These include GAPDH in the 13lined ground squirrel which exhibits decreased phosphorylation of tyrosine residues resulting in suppression of enzyme activity during hibernation (Bell et al, 2014) and HK from Richardson's ground squirrel which, similarly is less phosphorylated during hibernation and also both less active and has less affinity for its substrate (Abnous \& Storey, 2008). It is likely that PK, along with GAPDH and HK, serve as control points of carbohydrate metabolism that is regulated via RPP of serine and threonine residues during hibernation. Again, this inactivation of PK would contribute to a general metabolic rate depression as well as facilitating effective gluconeogenesis in the liver. Ltype PK is thought to be phosphorylated by cAMP-dependent kinase (PKA) in response to fasting and this kinase is therefore a strong candidate for phosphorylating PK during hibernation (Blair et al., 1976). Indeed, studies from two model hibernators, RGS and the little brown bat (Myotis lucifugus) have suggested that PKA may very well play a role in regulating the hibernation response. In RGS brown adipose tissue it was found that PKA phosphorylates different target proteins during hibernation compared to euthermic conditions which would allow it to selectively phosphorylate specific proteins at low 
temperature (MacDonald \& Storey, 1998). In the little brown bat muscle tissue, it appeared that PKA was more active during torpor than it was when in a euthermic state suggesting an important role is played by PKA during hibernation (Holden \& Storey, 1998). Regrettably, it has yet to be studied in a hibernator's liver tissue and until this has been done, few inferences can be made other than it is a reasonable candidate for catalyzing the phosphorylation of PK in RGS liver tissue.

This study has characterized the kinetic, structural, and regulatory properties of PK in the liver of Richardson's ground squirrel in euthermic and torpid conditions. The results from this study support a role for the regulation of PK as a means for enhancing survival during mammalian hibernation. By suppressing the activity of PK in the liver, Richardson's ground squirrels are better-able to initiate a global metabolic rate depression, switch from carbohydrate to lipid metabolism, and effect gluconeogenesis. The results also suggest that RPP of serine and threonine residues is responsible for the inactivation and stabilization of the enzyme during hibernation. Further studies will be necessary to fully understand the role of PK and other glycolytic and gluconeogenic enzymes in regulating the complex metabolic landscape of mammalian hibernation. 
Table 4.1: Typical purification scheme of PK from euthermic $U$. richardsonii liver tissue

\begin{tabular}{llllll}
\hline $\begin{array}{l}\text { Purification } \\
\text { Step }\end{array}$ & $\begin{array}{l}\text { Total } \\
\text { Protein } \\
(\mathrm{mg})\end{array}$ & $\begin{array}{l}\text { Total } \\
\text { Activity } \\
(\mathrm{U})\end{array}$ & $\begin{array}{l}\text { Specific } \\
\text { Activity } \\
(\mathrm{U} / \mathrm{mg})\end{array}$ & $\begin{array}{l}\text { Fold } \\
\text { Purification }\end{array}$ & $\%$ Yield \\
\hline Crude & 39.11 & 4.08 & 0.10 & --- & --- \\
$\mathrm{CM}^{-}$ & 1.81 & 1.24 & 0.69 & 6.59 & 29.7 \\
Cibacron Blue & 0.92 & 0.97 & 1.04 & 10.0 & 23.7 \\
G25 & 0.56 & 0.66 & 1.17 & 11.7 & 16.2 \\
Hydroxyapatite & 0.18 & 0.61 & 3.39 & 33.9 & 14.9 \\
\hline
\end{tabular}


Table 4.2: Kinetic properties of liver PK from euthermic and hibernating U. richardsonii. Data are mean \pm SEM, $\mathrm{n}=4$.

\begin{tabular}{ll:l}
\hline Kinetic Parameter & Euthermic & Hibernating \\
\hline $\mathrm{K}_{\mathrm{m}} \mathrm{PEP} 22^{\circ} \mathrm{C}(\mathrm{mM})$ & $6.42 \pm 0.26$ & $2.08 \pm 0.16^{a}$ \\
$\mathrm{~K}_{\mathrm{m}} \mathrm{PEP} 5^{\circ} \mathrm{C}(\mathrm{mM})$ & $0.60 \pm 0.07$ & $0.22 \pm 0.05^{a}$ \\
& & \\
$\mathrm{~K}_{\mathrm{m}} \mathrm{ADP} 22^{\circ} \mathrm{C}(\mathrm{mM})$ & $0.88 \pm 0.13$ & $0.32 \pm 0.01^{a}$ \\
$\mathrm{~K}_{\mathrm{m}} \mathrm{ADP} 5^{\circ} \mathrm{C}(\mathrm{mM})$ & $0.29 \pm 0.01$ & $0.23 \pm 0.01$ \\
& & \\
$\mathrm{~V}_{\max } 22^{\circ} \mathrm{C}(\mathrm{U} / \mathrm{mg})$ & $5.20 \pm 0.59$ & $1.61 \pm 0.31^{a}$ \\
$\mathrm{~V}_{\max } 5^{\circ} \mathrm{C}(\mathrm{U} / \mathrm{mg})$ & $0.70 \pm 0.06$ & $0.30 \pm 0.08^{a}$ \\
$\mathrm{E}_{\mathrm{a}}(\mathrm{kJ} / \mathrm{mol})$ & & \\
\hline
\end{tabular}

$a$ indicates significant difference from the corresponding control value, Student's $t$-test, $P$ $<0.05$. 
Table 4.3: Effect of $\mathrm{pH}$ on liver $\mathrm{PK}$ from euthermic and hibernating U. richardsonii. Data are mean \pm SEM, $n=4$.

\begin{tabular}{lll:ll}
\hline Kinetic Parameter & Euthermic & & \multicolumn{2}{|l}{ Hibernating } \\
\hline & $p H 7.2$ & $p H 8.0$ & $p H 7.2$ & $p H 8.0$ \\
$\mathrm{~K}_{\mathrm{m}} \mathrm{PEP} 22^{\circ} \mathrm{C}(\mathrm{mM})$ & $6.42 \pm 0.26$ & $5.48 \pm 0.30$ & $2.08 \pm 0.16$ & $5.17 \pm 1.06$ \\
$\mathrm{~K}_{\mathrm{m}} \mathrm{ADP} 22^{\circ} \mathrm{C}(\mathrm{mM})$ & $0.88 \pm 0.13$ & $0.56 \pm 0.08$ & $0.32 \pm 0.01$ & $0.17 \pm 0.02^{a}$ \\
$\mathrm{~V}_{\max } 22^{\circ} \mathrm{C}(\mathrm{U} / \mathrm{mg})$ & $2.60 \pm 0.59$ & $2.33 \pm 0.23$ & $0.80 \pm 0.31$ & $1.56 \pm 0.298$ \\
& & & & \\
\hline
\end{tabular}

$a$ indicates significant difference from the corresponding control value of the same condition at $\mathrm{pH} 7.2$, Student's $t$-test, $P<0.05$. 
Table 4.4: Effects of allosteric regulators on PK from liver of euthermic and hibernating $U$. richardsonii. Data are mean $\pm \mathrm{SEM}, \mathrm{n}=4$.

\begin{tabular}{ll|l}
\hline Kinetic Parameter & Euthermic & Hibernating \\
\hline & & \\
$\mathrm{K}_{\mathrm{a}} \mathrm{FBP}(\mathrm{mM})$ & $1.96 \pm 0.64$ & $4.06 \pm 0.32^{a}$ \\
Fold-Activation & $1.70 \pm 0.10$ & $1.35 \pm 0.07^{a}$ \\
& & \\
$\mathrm{I}_{50} \mathrm{ATP}(\mathrm{mM})$ & $22.4 \pm 0.94$ & $23.41 \pm 0.98$ \\
\hline
\end{tabular}

$a$ indicates significant difference from the corresponding control value, Student's $t$-test, $P$ $<0.05$. 


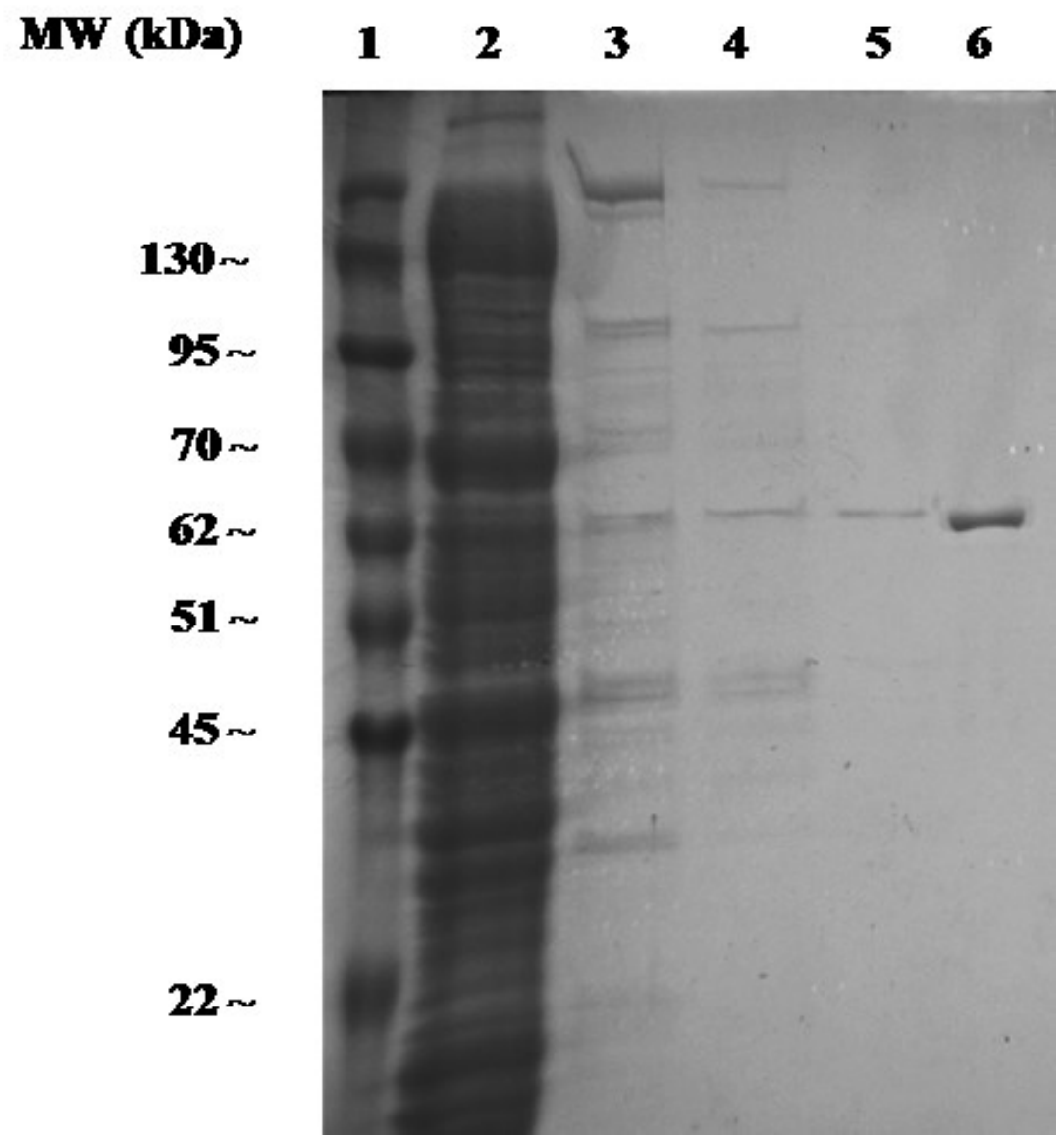

Figure 4.1: 10\% SDS-PAGE gel showing entire purification of PK from euthermic liver U. richardsonii. Lanes (1): molecular weight ladder (Froggabio); (2): crude homogenate; (3) pooled peak fraction after elution from $\mathrm{CM}^{-}$Sephadex column with $\mathrm{pH}$; (4) pooled peak fraction after elution from Cibacron Blue with $\mathrm{KCl}$; (5) pooled peak fraction after elution from HA with $\mathrm{K}_{2} \mathrm{HPO}_{4}$; (6) commercially-available purified rabbit $\mathrm{PK}$ (positive control; Sigma life sciences). 
Euthermic

Hibernating

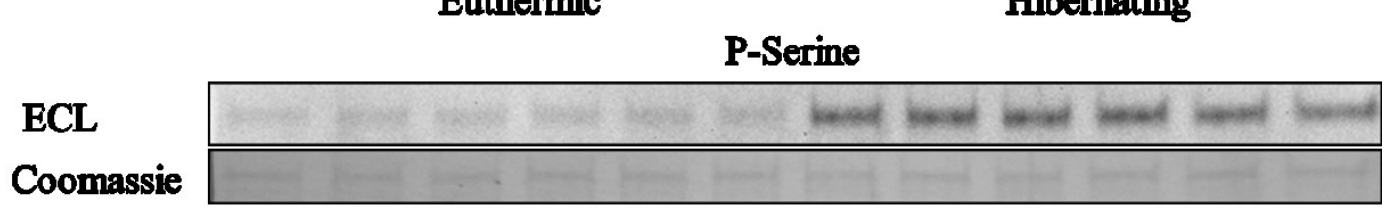

P-Threonine

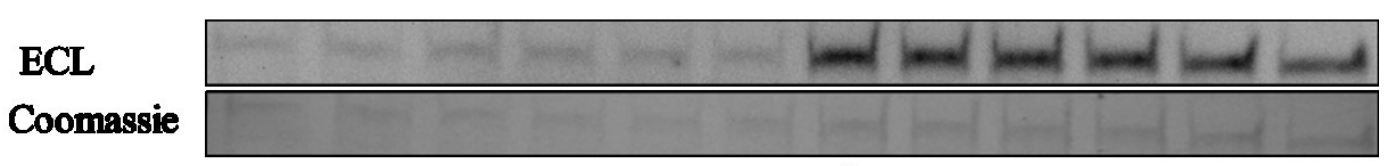

P-Tyrosine

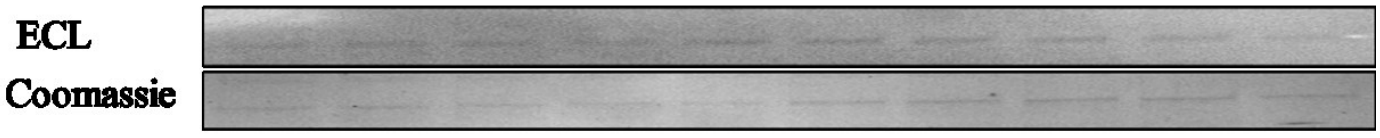

Methyl-Lysine

ECL

Coomassie
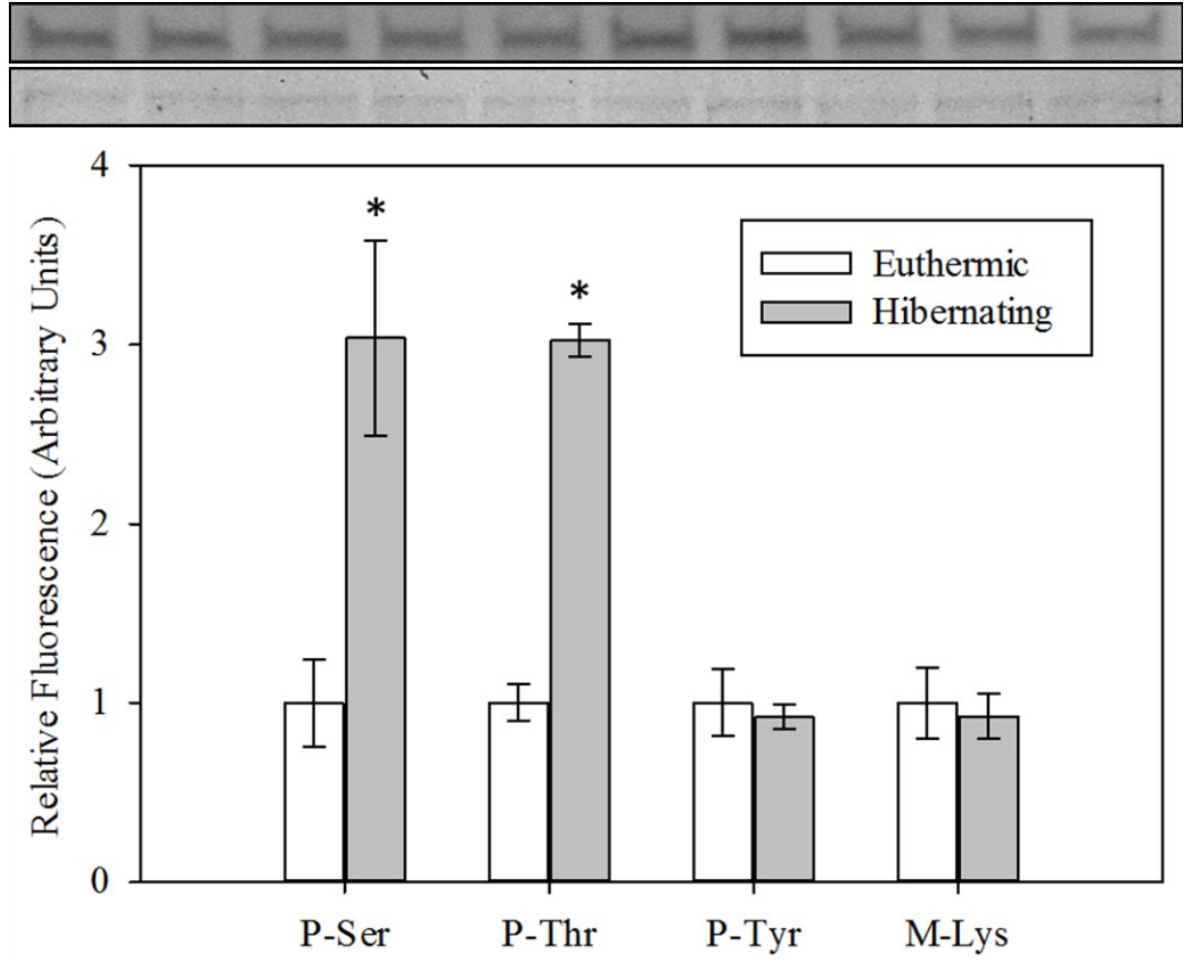

Figure 4.2: Relative levels of post-translational modifications determined through western blotting of purified pyruvate kinase from euthermic and hibernating liver tissue of $U$. richardsonii. Chemiluminescence signal intensities were standardized to protein amount, and the value for hibernating PK was expressed relative to the euthermic value that was set to 1 . Data are mean $\pm \mathrm{SEM}, n=5,6$ determinations on purified enzyme samples. Asterisk indicates significant difference from the corresponding control value, Student's $t$-test, $P<0.01$. 


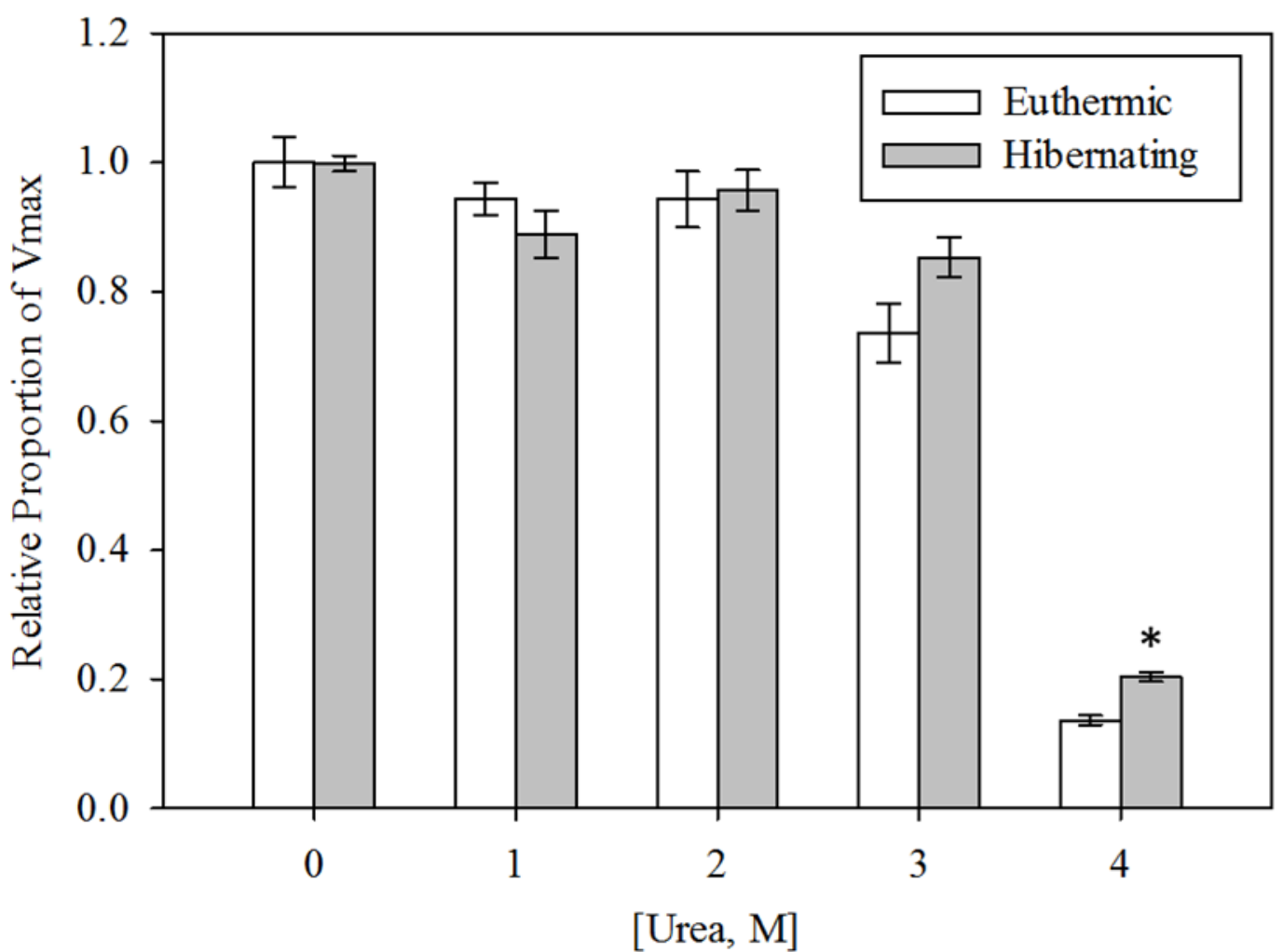

Figure 4.3: Relative stability of purified pyruvate kinase from euthermic and hibernating liver tissue of $U$. richardsonii determined through 90 min incubations at high concentrations of urea. The urea-treated values are expressed relative to the non-treated negatives of the same condition, which were set to 1 . Data are mean $\pm \mathrm{SEM}, n=4$ determinations on purified enzyme samples. Asterisk indicates significant difference from the corresponding control value, Student's $t$-test, $P<0.05$. 
Chapter 5

\section{General Discussion}


Survival in unforgiving environmental conditions is heavily reliant upon an animal's ability to survive on scarce resources and energy. It is imperative that these animals can ration fuel reserves accumulated during better conditions, however, this stored energy is sometimes not enough. Therefore, one of the most common strategies of survival for these organisms is the initiation of metabolic rate depression in which a new balance between energy production and energy consumption is established. This is usually mediated through a combination of altered gene expression, reprioritization of fuel usage and regulation of metabolic enzymes.

The ability to depress their metabolic rate, or enter a state of hypometabolism, allows animals to accrue significant energy savings. Indeed, many animals are able to drop their metabolic rate by nearly $95 \%$ during periods of environmental stress (Storey et al., 2013; Storey \& Storey, 2004). The mechanisms underlying this ability are varied, but regulation of metabolic enzymes involved in energy-producing and consuming pathways is certainly key. Furthermore, due to the reversible and sometimes unpredictable nature of environmental stress, the ability to reversibly regulate enzyme activity is critical and ensures that energy is not consumed degrading enzymes at the onset of the stress, only to have them resynthesized post-stress. This is accomplished through the actions of protein kinases and phosphatases which reversibly phosphorylate enzymes to regulate their activity in response to stress. Indeed, this form of metabolic regulation has been observed in animals surviving extreme cold, dehydration, and anoxic conditions and contributes to the regulation of pathways including glycolysis, fatty acid metabolism and amino acid metabolism (Frank et al., 1998; Dieni \& Storey, 2010; Bell \& Storey, 2010). The importance of reversible protein phosphorylation in surviving extreme environments led 
to the decision to investigate its potential role in mediating the activity of pyruvate kinase, a key enzyme of glycolysis, in three animals which enter a hypometabolic state in response to different environmental stresses.

The first animal studied was the common periwinkle L. littorea. This animal inhabits the intertidal spaces along the coastlines of the Atlantic Ocean where, during low tide, it is exposed to anoxic conditions and depending on the climate, potentially freezing conditions as well (Storey et al., 2010). Although less is known about this animal's response to freezing, in response to anoxia the periwinkle enters a hypometabolic state and engages multiple alternative pathways of anaerobic respiration, one of which bypasses the action of pyruvate kinase altogether by shunting PEP through PEPCK and into the succinate/propionate pathway (Storey, 1993). The North American wood frog, Rana sylvatica, survives regular periods of long-term, whole body freezing every winter. The conditions associated with freezing means that these animals are also confronted with ischemia, anoxia and cellular dehydration as well (Storey, 1990). Survival in these conditions requires that the wood frog enter a hypometabolic state to conserve energy throughout the winter. Equally important to survival is the accumulation of glucose which acts as a cryoprotectant to prevent intracellular freezing and dehydration (Storey, 1987a). Finally, Richardson's ground squirrel is a mammalian hibernator which enters a state of aerobic torpor (hibernation) to survive the winter when food sources are scarce. During hibernation the ground squirrel prioritizes fatty acid metabolism over carbohydrate energy sources and to conserve energy they significantly decrease nearly all physiological processes (including heart rate and breathing rate) (Storey \& Storey, 2010; Storey, 2003). Despite the similarities shared by these animals, their metabolic 
requirements for stress-survival differ significantly making them interesting models to study.

The research presented in this thesis focuses on the regulation of pyruvate kinase in three animals which undergo metabolic rate depression to survive extreme conditions. There are numerous reason for which control of PK would be advantageous in all living systems, let alone animals entering a hypometabolic state. This enzyme catalyzes the final reaction of glycolysis, and directly produces ATP via substrate-level phosphorylation. Its product, pyruvate, can be readily channeled into the mitochondria to undergo further oxidation or, if oxygen is lacking, it can be fermented through the actions of LDH. Its substrate, PEP, is located at a metabolic branch point where PEP has multiple potential metabolic fates. Finally, this enzyme is known to be heavily regulated both allosterically and via reversible protein phosphorylation, and along with hexokinase and phosphofructokinase is one of the major control site of glycolysis (Tanaka et al., 1967; van Veelen et al., 1979; Blair et al., 1976). These reasons together with the fact that it is situated in one of most important pathways of cellular energetics makes it a likely target of regulation during metabolic rate depression. The studies undertaken in this thesis suggest that many factors could be influencing the activity of PK in hypometabolic states, including reversible phosphorylation, allosteric regulation and other environmental factors. Some of these regulatory mechanisms were conserved between all three animals while some mechanisms appeared to be animal- or stress-specific.

\section{Kinetic properties of PK in hypometabolic states}

When comparing the regulation of PK in all three animal models studied, a number of trends are apparent. Arguably the most important trend observed is a general 
inactivation of PK in response to stress, regardless of the type of stress or animal. In the periwinkle and the wood frog, this was primarily manifested as a decrease in affinity for the substrate PEP in response to stress (table 2.2; table 3.2). In the ground squirrel, however, a sharp decrease in the $\mathrm{V}_{\max }$ of $\mathrm{PK}$ indicated that the enzyme was being inactivated during hibernation (table 4.2). This suggests that the suppression of PK activity is beneficial to all three animals in response to different environmental stress and may be a conserved mechanism of regulating hypometabolism. This is supported by a number of prior studies which show similar results, including suppression of PK activity in the spadefoot toad (S. couchii) in response to estivation and both the marine oyster (C.virginica) and whelk (B.canaliculatum) in response to anoxia exposure (Cowan \& Storey, 1999; Greenway \& Storey, 2000; Plaxton \& Storey, 1984). By decreasing the activity of PK, it is possible not only to limit the amount of ATP-production through substrate-level phosphorylation, but also the rate of fuel entering the mitochondria for further oxidation and ATP production. In doing so, the rate of cellular energy generation is reduced and metabolic rate is decreased, contributing to one of the central necessities for survival in extreme environments. Taken together, the results obtained in these studies and from the literature provide ample reason to suggest that pyruvate kinase is a common regulatory target that is often inactivated in support of metabolic rate depression.

Together, the results from this thesis also demonstrate the diverse roles that PK can play as a regulator of carbon flow and metabolism. In each of these studies PK was similarly inhibited and each animal would benefit from the decreased metabolic rate afforded by inhibition of PK. However, other implications of the enzyme's inhibition were vastly different between the three animals. In the wood frog, suppression of PK is 
thought to enhance the efficiency of gluconeogenesis to preserve cryoprotectants for freezing survival. In L. littorea, decreased PK activity would increase the favorability of PEP being shunted into the succinate pathway via PEPCK. In RGS, suppressing PK would encourage gluconeogenesis to restore carbohydrate levels which are quickly consumed during long hibernation periods. Despite each of these animals having different survival requirements, regulating the activity of $\mathrm{PK}$ in all three is beneficial to survival which shows the importance of $\mathrm{PK}$ as a regulatory target and the variety of roles this enzyme can play indirectly. Interestingly, this phenomenon is not unique to PK. GDH is another enzyme exhibiting similar behavior in response to varying environmental conditions. For example, the estivating land snail $O$. lactea accumulates high concentrations of urea to retain water during dehydration. In this animal, GDH was activated and this would increase the amount of ammonia available to produce urea for survival (Bell et al., 2012). GDH was also observed to be activated during torpor in the liver of RGS, however this animal does not accumulate urea like $O$. lactea. In this case, activation of GDH was thought to promote amino acid oxidation as an alternative for energy production. In response to anoxia, however, GDH is inhibited in the freshwater turtle T.s. elegans to facilitate a general metabolic rate depression (Bell \& Storey, 2012). The overlying theme here is that different animals surviving in extreme environments have evolved distinct functions for the same metabolic enzymes, including both PK and GDH, to enable their survival. This appears to be a common theme, though only future studies of other enzymes can confirm this.

Another trend that was observed through kinetic analyses was that there may be unique regulatory mechanisms of PK in place that rely on the particular environment of 
the animal. For instance, at low temperatures the $\mathrm{V}_{\max }$ of $\mathrm{PK}$ in Richardson's ground squirrel decreases significantly compared to the $\mathrm{V}_{\max }$ at room temperature, suggesting that the ambient temperatures experienced during hibernation may further contribute to the inactivation of PK in this animal (table 4.2). Similar environmental effects were observed in the wood frog which accumulates up to $90 \mathrm{mM}$ urea during freezing and dehydration (Constanzo \& Lee, 2005). The studies performed in this thesis revealed that these very concentrations of urea decreased the affinity of PK for its substrate, further contributing to the inactivation of the enzyme in the wood frog during freezing (table 2.3). Likewise, it was observed in the periwinkle that PK purified from anoxic periwinkles was significantly (4-fold) more sensitive to $\mathrm{KCl}$ inhibition than the control form of the enzyme (table 3.3). This is of interest since the periwinkle is a marine invertebrate which can dehydrate at low tide causing intracellular solute concentrations to increase, including the concertation of $\mathrm{KCl}$. Increased sensitivity to $\mathrm{KCl}$ during this period would therefore contribute to metabolic rate depression as increased concentrations of $\mathrm{KCl}$ during dehydration would more-strongly inhibit $\mathrm{PK}$ at low tides. Also observed in the periwinkle was that PK from anoxic animals was more susceptible to inhibition by alanine than was PK from control animals (table 3.3). Alanine is known to accumulate in marine invertebrate tissue as a result of anaerobic respiration (Storey \& Korycan, 1983). Therefore, if PK is more sensitive to alanine inhibition during anoxia and concentrations of alanine increase during anoxia exposure, it would appear as though alanine inhibition of PK may be a stress-specific regulatory mechanism of the enzyme. Meanwhile, the enzyme's activity was found to be activated by aspartate which is a primary fuel of the periwinkle during anaerobiosis. This has a similar effect on PK's 
activity, ensuring that anaerobic respiration via PK is gradually reduced as the pools of aspartate are depleted. Interestingly, very different results were observed in the muscle tissue of the wood frog. In this case, neither aspartate nor alanine were found to have any effect on enzyme activity (table 2.4). Overall these results suggest that, although PK is negatively stress-responsive in all three animals, there are some regulatory mechanisms present in each animal that are specific to the stress or environment of the organism. This allows for additional fine-tuning of the activity of PK on top of the phosphorylationmediated inhibition of this enzyme which was observed in all three animals studied in this thesis.

\section{Phosphorylation of PK in hypometabolic states}

One of the most important mechanisms known to control stress-responsive changes in enzyme structure and kinetic properties is reversible protein phosphorylation (reviewed in Storey \& Storey, 2013; Krebs \& Beavo, 1979; Storey, 1997b). For that reason the phosphorylation state of PK in all three animals studied was assessed, and it was found that reversible phosphorylation was likely regulating PK in response to freezing, dehydration, anoxia, and during hibernation. In all three animals, it was a highphosphate, low-activity form of PK that was present during environmental stress exposure. However, the particulars of this regulation varied between the animals investigated. In the periwinkle it was threonine residues that were found to be phosphorylated, while in the wood frog, it was serine residues (Figure $2.3 ; 2.4 ; 3.4$ ). In the ground squirrel, both serine and threonine residues exhibited increased phosphorylation during hibernation (Figure 4.3). There have been many studies to date characterizing PK in response to environmental stress, and many of these have implicated 
phosphorylation as a suppressor of PK's activity. This is especially true in invertebrates where inactivation of PK by phosphorylation has been observed in the estivating snail $O$. lactea, the anoxia-tolerant marine whelk (Busycotypus canaliculatum), the oyster (Crassostrea virginica), and now the anoxia and freeze-tolerant periwinkle, L. littorea.

PK is a known phosphorylation target in mammalian liver, and is phosphorylated by cAMP-dependent kinases which causes a decrease in the enzyme's activity (Ljungstrom et al, 1974; Titanji et al., 1976). Contrarily, the mammalian muscle form of PK is typically not phospho-regulated. Therefore, it was not wholly unexpected to observe increased phosphorylation of PK in the ground squirrel liver and a corresponding decrease in the enzyme's activity. The status of PK phosphorylation in lower vertebrates and invertebrates, however, is less clear and makes the results of these studies increasingly interesting. Although some frog species are known to possess tissue-specific PK isozymes that are kinetically similar to those in mammals, whether or not they obey the same phospho-regulation patterns is not known (Schloen et al., 1974). Indeed, at least one other study is known to implicate phosphorylation as a regulator of muscle-type PK activity in a frog. Cowan \& Storey (2005) found that increased phosphorylation of PK during estivation in the spadefoot toad, S. couchii, resulted in a 0.6 -fold increase in the $\mathrm{K}_{\mathrm{m}} \mathrm{PEP}$, which is very similar to the results presented here in $R$. sylvatica. Together with the research presented here, this suggests that muscle-type PK from frogs can be regulated by reversible phosphorylation, unlike mammalian muscle-type PK. Moreover, based on its presence in invertebrates, lower vertebrates and mammals, it appears that phosphorylation of PK may be a conserved regulatory mechanism during metabolic rate depression. 
Another factor to consider when examining the results of this study, and phosphoregulation of enzymes in general, is the effects of site-specific phosphorylation. Although PK was regulated similarly in each animal studied here, this is not always necessarily the case as was previously demonstrated with GDH. And, indeed, the present studies have shown that PK can at least be phosphorylated on both serine and threonine residues. It is interesting to speculate, then, that PK could perhaps be differentially regulated depending on its residue-specific phosphorylation state. This normally requires the actions of multiple, different protein kinases with each kinase capable of phosphorylating a different site on the same enzyme. A well-characterized example of an enzyme exhibiting regulation by site-specific phosphorylation patterns is the pyruvate dehydrogenase complex which converts pyruvate into acetyl-CoA to be used as fuel for the TCA cycle in the mitochondria. The first catalytic component of this complex, E1, possesses three serine residues that are phosphorylated by four different pyruvate dehydrogenase kinases (PDKs; PDK1, PDK2, PDK3, PDK4). Phosphorylation of these residues by PDKs results in inactivation of the complex (Holness \& Sugden, 2003). However, only certain PDKs can phosphorylate specific sites and apparently the mechanism of inactivation is different for phosphorylation of each specific residue (Korotchkina \& Patel, 2001a; Korotchkina \& Patel, 2001b). It is interesting to speculate that PK may also have multiple inhibitory phosphorylation sites, especially given the presence of both increased serine and threonine phosphorylation of PK from RGS during hibernation (figure 4.2).

\section{Stability of PK in hypometabolic states}

Protein structure can be heavily influenced by post-translational modification, including phosphorylation. The differences in kinetic properties of PK between control 
and stressed states and the corresponding changes in phosphorylation states observed in each of the animals investigated warranted an investigation into the enzyme's relative stabilities. Through incubation studies in chemical and/or thermal denaturants, it was determined that PK was more stable in every animal studied in response to their associated stress. For example, the length of time for which PK in the periwinkle was stable at high temperature was $\sim 0.5$-fold greater in both anoxic and frozen conditions relative to control conditions (figure 3.3). This difference was even more pronounced in the wood frog where the frozen form of the enzyme exhibited a 3.5-fold increase in the amount of time for which it was stable at high temperature (figure 2.2). Finally, the stability of PK from hibernating and euthermic ground squirrels was investigated through incubations in high concentrations of urea. It was found that PK from hibernating animals maintained $20 \%$ of its activity in $4 \mathrm{M}$ urea, while that from euthermic animals maintained only $11 \%$ (figure 4.4). These results suggest that stability of PK during hypometabolism is prioritized along with inactivation of the enzyme. Indeed, increased enzyme stabilization is a common theme amongst animals surviving in extreme conditions. For example, GAPDH exhibits greater stability in a pair of hibernating mammals; Jaculus orientalis and Ictidomys tridecemlineatus while MnSOD was shown to be more stable in the wood frog during freezing (Iddar et al, 2003; Bell et al., 2014; Dawson et al, 2015). This can be explained as being due to the high energetic cost of protein turnover, which can account for up to $22 \%$ of a cell's energetic budget (Lobley et al, 1979; Land \& Hochachka, 1994). By increasing the stability of proteins, the rate at which proteins are damaged and must be resynthesized is reduced and cellular energy is preserved at a time when resources are scarce. This is particularly important when facing environmental 
stress, as anoxic and dehydrating conditions can result in the accumulation of harmful ROS and other chemical denaturants like urea that can increase the rate protein denaturation (Joanisse \& Storey, 1996; Grundy \& Storey, 1998). Furthermore, in each of the animals studied in this thesis, prioritization of protein stability and cellular preservation has been demonstrated by means other than increased enzyme stability. This includes increased expression of small molecule antioxidants, antioxidant enzymes and protein chaperones (Pannunzio \& Storey, 1998; Storey, 2007; Dawson et al., 2015). Together with the results from the studies performed in this thesis, this suggests that protein stabilization is prioritized during hypometabolism and that PK may be a common target of enzyme stabilization.

\section{Future directions}

The research presented in this thesis primarily characterized the relative kinetic properties and phosphorylation states of PK in control and hypometabolic states of three different animals. These studies revealed that PK may be a common target for regulation in response to environmental stress and that phosphorylation is key to this regulation. In doing so many viable paths forward for this research now exist and would assist in better understanding the nature of the regulation of PK in hypometabolic states.

The data presented here can be expanded upon directly through experiments that attempt to determine a causal link between the observed kinetic differences and phosphorylation changes of PK from animals in control and stressed environments. As previously mentioned, protein kinases and phosphatases are responsible for mediating the transfer of phosphate groups to and from a given protein, and therefore are likely acting on PK in the animals studied here. To determine which kinases and phosphatases 
specifically are acting on PK, crude homogenate samples from each animal can be incubated in conditions that stimulate the activity of individual kinases and phosphatases. This will reveal whether in vitro (de)phosphorylation of the enzyme results in similar changes in kinetic parameters of PK to those observed between animals in control and hypometabolic conditions. These studies will be crucial in identifying the true influence that phosphorylation is having on PK in these animals. Aside from only phosphorylation, however, is a variety of different post-translational modifications that could also influence the activity of PK. Although PK is traditionally thought to be only regulated via phosphorylation, there is now evidence to suggest that it can be methylated, nitrosylated and acetylated and these modifications may lead to PK inactivation of degradation (Zhou et al., 2013; Gao et al., 2005; Yang et al., 2013). Furthermore, PTM-crosstalk is now an established phenomenon and describes how one post-translational modification, often phosphorylation, can act as a signal for further post-translational modifications (like sumoylation and ubiquitination; reviewed in Hunter, 2007). Given the amount of complexity of how PTMs can regulate enzymes, future studies on PK and other stressresponsive metabolic enzymes may warrant more detailed post-translational modification analysis. This can be performed through western-blotting as was done in this thesis or through comparative mass-spectrometry analysis of purified enzyme samples as in Bell et al. (2014).

Further experiments can be continued directly on PK by looking at the regulation of this enzyme in the same animals studied here, but in different tissues. Given the known tissue-specific isozymes of $\mathrm{PK}$ in frogs and mammals, it is particularly important to investigate PK in the liver of the wood frog and in muscle tissue in Richardson's ground 
squirrel to provide a fuller picture of the role PK plays in hypometabolic states. While negative regulation of PK was observed in wood frog muscle during freezing, it has not yet been characterized in the liver. This organ is responsible for mobilizing and distributing the vast amounts of glucose required as cellular cryoprotectants during freezing (Storey \& Storey, 1984). Therefore, carbohydrate metabolism is likely highly regulated in that organ and PK may play a large role in it. In Richardson's ground squirrel, however, PK has not yet been characterized in muscle tissue, where it may or may not play a significant role in hibernation survival. Although the organ undergoes metabolic rate depression, it also remains at least partly active in order to conduct shivering thermogenesis and therefore predictions of PK's activity in that tissue are difficult to make.

\section{Conclusion}

This thesis has demonstrated that the regulation of PK may play an important if not varied role in hypometabolic systems. PK was found to have suppressed activity in each of the animals studied which together modelled freezing, aerobic hibernation and anoxic stress. In the periwinkle, suppression of PK activity in response to anoxia exposure contributes to depressing the animal's metabolic rate and enabling the activation of alternative fermentation pathways. In the wood frog, suppression of PK activity appears to support both a metabolic rate depression and conservation of cryoprotectants. In Richardson's ground squirrel liver tissue, suppression of PK activity enables both reduction in the animal's metabolic rate and allows gluconeogenesis to proceed unimpeded. These general decreases in activity were found to be mediated by a variety of mechanisms, some common to all three animals while others were distinct to a 
specific animal. Protein phosphorylation appears to play a significant role in mediating PK's activity in all three animals, while allosteric regulation seems more relevant in the periwinkle than in the wood frog. Increased stability of PK during stress also appears to be a priority in all three animals studied and this may contribute to energy savings during periods of environmental stress. Taken together, these results provide novel insights into the role that PK plays in the survival of environmental stress. 


\section{References}


Abboud, J., \& Storey, K. B. (2013). Novel control of lactate dehydrogenase from the freeze tolerant wood frog: role of posttranslational modifications. PeerJ, 1, e12.

Argaud, D., Roth, H., Wiernsperger, N., \& Leverve, X. M. (1993). Metformin decreases gluconeogenesis by enhancing the pyruvate kinase flux in isolated rat hepatocytes. European Journal of Biochemistry, 213(3), 1341-1348.

Aust, A .E., \& Suelter, C. H. (1978). Homogeneous pyruvate kinase isolated from yeast by two different methods is indistinguishable from pyruvate kinase in cell-free extract. Journal of Biological Chemistry, 253(20), 7508-7512.

Bauer, V. W., Squire, T. L., Lowe, M. E., \& Andrews, M. T. (2001). Expression of a chimeric retroviral-lipase mRNA confers enhanced lipolysis in a hibernating mammal. American Journal of Physiology-Regulatory, Integrative and Comparative Physiology, 281(4), R1186-R1192.

Baysdorfer, C., \& Bassham, J. A. (1984). Spinach Pyruvate Kinase Isoforms Partial Purification and Regulatory Properties. Plant physiology, 74(2), 374-379.

Bell, R. A., \& Storey, K. B. (2010). Regulation of liver glutamate dehydrogenase by reversible phosphorylation in a hibernating mammal. Comparative Biochemistry and Physiology Part B: Biochemistry and Molecular Biology, 157(3), 310-316.

Bell, R. A., \& Storey, K. B. (2012). Regulation of liver glutamate dehydrogenase from an anoxia-tolerant freshwater turtle. HOAJ Biology, 1(1), 3.

Bell, R. A., Dawson, N. J., \& Storey, K. B. (2012). Insights into the in vivo regulation of glutamate dehydrogenase from the foot muscle of an estivating land snail. Enzyme research, 2012.

Bell, R. A., Smith, J. C., \& Storey, K. B. (2014). Purification and properties of glyceraldehyde-3phosphate dehydrogenase from the skeletal muscle of the hibernating ground squirrel, Ictidomys tridecemlineatus. PeerJ, 2, e634.

Berg, J.M., Tymoczko, J.L., Stryer, L. (2002). The Glycolytic Pathway Is Tightly Controlled. In: Biochemistry $5^{\text {th }}$ Edition. W H Freeman, New York.

Biggar, K. K., \& Storey, K. B. (2010). The emerging roles of microRNAs in the molecular responses of metabolic rate depression. Journal of molecular cell biology, mjq045.

Biggar, K. K., \& Storey, K. B. (2012). Evidence for cell cycle suppression and microRNA regulation of cyclin D1 during anoxia exposure in turtles. Cell Cycle, 11(9), 1705-1713. 
Biggar, K. K., Kornfeld, S. F., Maistrovski, Y., \& Storey, K. B. (2012). MicroRNA regulation in extreme environments: differential expression of microRNAs in the intertidal snail Littorina littorea during extended periods of freezing and anoxia. Genomics, proteomics \& bioinformatics, 10(5), 302-309.

Biggar, K. K., Dawson, N. J., \& Storey, K. B. (2012). Real-time protein unfolding: a method for determining the kinetics of native protein denaturation using a quantitative real-time thermocycler. Biotechniques, 53(4), 231.

Blair, J. B., Cimbala, M. A., Foster, J. L., \& Morgan, R. A. (1976). Hepatic pyruvate kinase. Regulation by glucagon, cyclic adenosine 3'-5'-monophosphate, and insulin in the perfused rat liver. Journal of Biological Chemistry, 251(12), 3756-3762.

Bradford, M. M. (1976). A rapid and sensitive method for the quantitation of microgram quantities of protein utilizing the principle of protein-dye binding. Analytical biochemistry, 72(1-2), 248-254.

Brooks, S. P., \& Storey, K. B. (1992a). Mechanisms of glycolytic control during hibernation in the ground squirrel Spermophilus lateralis. Journal of Comparative Physiology B, 162(1), 23-28.

Brooks, S. P. (1992b). A simple computer program with statistical tests for the analysis of enzyme kinetics. Biotechniques, 13(6), 906-911.

Brooks, S. P. (1994). A program for analyzing enzyme rate data obtained from a microplate reader. BioTechniques, 17(6), 1154-1161.

Brooks, S. P. J., \& Storey, K. B. (1997). Glycolytic controls in estivation and anoxia: a comparison of metabolic arrest in land and marine molluscs. Comparative Biochemistry and Physiology Part A: Physiology, 118(4), 1103-1114.

Burlington, R. F., \& Klain, G. J. (1967). Gluconeogenesis during hibernation and arousal from hibernation. Comparative biochemistry and physiology,22(3), 701-708.

Carey, H. V., Andrews, M. T., \& Martin, S. L. (2003). Mammalian hibernation: cellular and molecular responses to depressed metabolism and low temperature. Physiological reviews, 83(4), 1153-1181.

Childers, C. L., \& Storey, K. B. (2016). Post-translational Regulation of Hexokinase Function and Protein Stability in the Aestivating Frog Xenopus laevis. The Protein Journal, 1-11.

Churchill, T. A., \& Storey, K. B. (1994). Metabolic responses to dehydration by liver of the wood frog, Rana sylvatica. Canadian Journal of Zoology,72(8), 1420-1425.

Churchill, T. A., \& Storey, K. B. (1995). Metabolic effects of dehydration on an aquatic frog, Rana pipiens. Journal of Experimental Biology, 198(1), 147-154. 
Churchill, T. A., \& Storey, K. B. (1996). Metabolic responses to freezing and anoxia by the periwinkle Littorina littorea. Journal of thermal biology, 21(1), 57-63.

Cohen, P. (2002). The origins of protein phosphorylation. Nature Cell Biology,4(5), E127-E130.

Costanzo, J. P., \& Claussen, D. L. (1990). Natural freeze tolerance in the terrestrial turtle, Terrapene carolina. Journal of Experimental Zoology, 254(2), 228-232

Costanzo, J.P., Lee, R.E. \& Lortz, P.H. (1993) Glucose concentration regulates freeze tolerance in the wood frog Rana sylvatica. Journal of Experimental Biology. 181:245-255.

Costanzo, J. P., Lee, R. E., \& Lortz, P. H. (1993). Physiological responses of freeze-tolerant andintolerant frogs: clues to evolution of anuran freeze tolerance. American Journal of Physiology-Regulatory, Integrative and Comparative Physiology, 265(4), R721-R725.

Costanzo, J. P., \& Lee, R. E. (2005). Cryoprotection by urea in a terrestrially hibernating frog. Journal of Experimental Biology, 208(21), 4079-4089.

Cottam, G., Hollenberg, P., \& Coon, M. (1969). Subunit Structure of Rabbit Muscle Pyruvate Kinase. Journal of Biological Chemistry, 244(6), 1481-1486

Cowan, K. J., \& Storey, K. B. (1999). Reversible phosphorylation control of skeletal muscle pyruvate kinase and phosphofructokinase during estivation in the spadefoot toad, Scaphiopus couchii. Molecular and cellular biochemistry, 195(1-2), 173-181.

Cowan, K. J., \& Storey, K. B. (2001). Freeze-thaw effects on metabolic enzymes in wood frog organs. Cryobiology, 43(1), 32-45.

Crerar, M. M., David, E. S., \& Storey, K. B. (1988). Electrophoretic analysis of liver glycogen phosphorylase activation in the freeze-tolerant wood frog. Biochimica et Biophysica Acta - Molecular Cell Research, 971(1), 72-84.

Dawson, N. J., Katzenback, B. A., \& Storey, K. B. (2015). Free-radical first responders: the characterization of $\mathrm{CuZnSOD}$ and MnSOD regulation during freezing of the freezetolerant North American wood frog, Rana sylvatica. Biochimica et Biophysica Acta (BBA)-General Subjects, 1850(1), 97-106.

Dawson, N. J., \& Storey, K. B. (2016). A hydrogen peroxide safety valve: The reversible phosphorylation of catalase from the freeze-tolerant North American wood frog, Rana sylvatica. Biochimica et Biophysica Acta (BBA)-General Subjects, 1860(3), 476-485.

De Vries, F. P. (1975). The cost of maintenance processes in plant cells.Annals of botany, 39(1), 77-92.

Dieni, C. A., \& Storey, K. B. (2009). Creatine kinase regulation by reversible phosphorylation in frog muscle. Comparative Biochemistry and Physiology Part B: Biochemistry and Molecular Biology, 152(4), 405-412. 
Dieni, C. A., \& Storey, K. B. (2010). Regulation of glucose-6-phosphate dehydrogenase by reversible phosphorylation in liver of a freeze tolerant frog. Journal of Comparative Physiology B, 180(8), 1133-1142.

Dieni, C. A., \& Storey, K. B. (2011). Regulation of hexokinase by reversible phosphorylation in skeletal muscle of a freeze-tolerant frog. Comparative Biochemistry and Physiology Part B: Biochemistry and Molecular Biology, 159(4), 236-243.

Dieni, C. A., \& Storey, K. B. (2014). Protein kinase C in the wood frog, Rana sylvatica: reassessing the tissue-specific regulation of PKC isozymes during freezing. PeerJ, 2, e558.

Dworkin, M. B., Segil, N., \& Dworkin-Rastl, E. (1987). Pyruvate kinase isozymes in oocytes and embryos from the frog Xenopus laevis. Comparative Biochemistry and Physiology Part B: Comparative Biochemistry, 88(3), 743-749.

Edwards, J. R., Jenkins, J. L., \& Swanson, D. L. (2004). Seasonal effects of dehydration on glucose mobilization in freeze-tolerant chorus frogs (Pseudacris triseriata) and freezeintolerant toads (Bufo woodhousii and B. cognatus). Journal of Experimental Zoology Part A: Comparative Experimental Biology, 301(6), 521-531.

Eigenbrodt, E., Abdel-fattah Mostafa, M., \& Schoner, W. (1977). Inactivation of pyruvate kinase type M 2 from chicken liver by phosphorylation, catalyzed by a cAMP-independent protein kinase. Hoppe-Seyler's Zeitschrift für physiologische Chemie, 358(2), $1047-$ 1056.

Famme, P., Knudsen, J. E. N. S., \& Hansen, E. S. (1981). Effect of oxygen on the aerobicanaerobic metabolism of the marine bivalve, Mytilus edulis L.Marine biology letters.

Flanders, L.E., Bamburg, J.R., Sallach, H.J. (1971). Pyruvate kinase isozymes in adult tissue and eggs of Rana pipiens. Biochimica et Biophysica Acta 242:566-579.

Flanders, L. E., Bamburg, J. R., \& Sallach, H. J. (1971). Pyruvate kinase isozymes in adult tissue and eggs of Rana pipiens. II. Physical and kinetic studies of purified skeletal and heart muscle pyruvate kinases. Biochimica et Biophysica Acta (BBA)-Enzymology, 242(3), 566-579.

Fournier, P., \& Guderley, H. (1986). Evolution of the functional properties of pyruvate kinase isozymes: pyruvate kinase L from Rana pipiens. Journal of Comparative Physiology B, 156(5), 691-699.

Frank, C. L., Brooks, S. P., Harlow, H. J., \& Storey, K. B. (1998). The influence of hibernation patterns on the critical enzymes of lipogenesis and lipolysis in prairie dogs. Experimental Biology Online, 3(9), 1-8. 
Gao, C., Guo, H., Wei, J., Mi, Z., Wai, P. Y., \& Kuo, P. C. (2005). Identification of Snitrosylated proteins in endotoxin-stimulated RAW264.7 murine macrophages. Nitric Oxide, 12(2), 121-126.

Geiser, F. (2004). Metabolic rate and body temperature reduction during hibernation and daily torpor. Annual Review of Physiology, 66 239-274.

Gill, M., France, J., Summers, M., McBride, B. W., \& Milligan, L. P. (1989). Simulation of the energy costs associated with protein turnover and $\mathrm{Na}^{+}, \mathrm{K}+$-transport in growing lambs. The Journal of nutrition, 119(9), 1287-1299.

Green, C. J., Brosnan, J. T., Fuller, B. J., Lowry, M., Stubbs, M., \& Ross, B. D. (1984). Effect of hibernation on liver and kidney metabolism in 13-lined ground squirrels. Comparative Biochemistry and Physiology Part B: Comparative Biochemistry, 79(2), 167-171.

Greenway, S. C., \& Storey, K. B. (2000). Seasonal change and prolonged anoxia affect the kinetic properties of phosphofructokinase and pyruvate kinase in oysters. Journal of Comparative Physiology B, 170(4), 285-293.

Greenway, S. C., \& Storey, K. B. (2001). Effects of seasonal change and prolonged anoxia on metabolic enzymes of Littorina littorea. Canadian journal of zoology, 79(5), 907-915.

Grundy, J. E., \& Storey, K. B. (1998). Antioxidant defenses and lipid peroxidation damage in estivating toads, Scaphiopus couchii. Journal of Comparative Physiology B, 168(2), 132142.

Hall, E. R., \& Cottam, G. L. (1978). Isozymes of pyruvate kinase in vertebrates: their physical, chemical, kinetic and immunological properties. International Journal of Biochemistry, 9(11), 785-794.

Hand, S.C., \& Hardewig, I. (1996). Downregulation of cellular metabolism during environmental stress: mechanisms and implications. Annual review of physiology, 58(1), 539-563.

Holden, C. P., \& Storey, K. B. (1996). Signal transduction, second messenger, and protein kinase responses during freezing exposures in wood frogs. American Journal of PhysiologyRegulatory, Integrative and Comparative Physiology, 271(5), R1205-R1211.

Holden, C. P., \& Storey, K. B. (1997). Second messenger and cAMP-dependent protein kinase responses to dehydration and anoxia stresses in frogs. Journal of Comparative Physiology $B, 167(4), 305-312$.

Holden, C. P., \& Storey, K. B. (1998). Protein kinase A from bat skeletal muscle: a kinetic study of the enzyme from a hibernating mammal. Archives of biochemistry and biophysics, 358(2), 243-250. 
Holden, C. P., \& Storey, K. B. (2000). Purification and characterization of protein kinase A from liver of the freeze-tolerant wood frog: role in glycogenolysis during freezing. Cryobiology, 40(4), 323-331.

Holness, M. J., \& Sugden, M. C. (2003). Regulation of pyruvate dehydrogenase complex activity by reversible phosphorylation. Biochemical Society Transactions, 31(6), 1143-1151.

Hoyaux, J., Gilles, R., \& Jeuniaux, C. (1976). Osmoregulation in molluscs of the intertidal zone. Comparative Biochemistry and Physiology Part A: Physiology, 53(4), 361-365.

Humphrey, S. J., James, D. E., \& Mann, M. (2015). Protein Phosphorylation: A Major Switch Mechanism for Metabolic Regulation. Trends in Endocrinology \& Metabolism, 26(12), 676-687.

Hunter, T. (2007). The age of crosstalk: phosphorylation, ubiquitination, and beyond. Molecular cell, 28(5), 730-738.

Ibsen, K. H., Cardin, J. P., Chiu, R. H., Garratt, K. N., Marles, S. W., \& Doty, J. R. (1980). Distribution of pyruvate kinase isozymes in adult and developing Xenopus laevis. Comparative Biochemistry and Physiology Part B: Comparative Biochemistry, 65(3), 473-480.

Jensen, O. N. (2006). Interpreting the protein language using proteomics. Nature Reviews Molecular Cell Biology, 7(6), 391-403.

Johnson, L. N., \& Barford, D. (1993). The effects of phosphorylation on the structure and function of proteins. Annual review of biophysics and biomolecular structure, 22(1), 199232.

Johnson, L. N. (2009). The regulation of protein phosphorylation. Biochemical Society Transactions, 37(4), 627-641.

Joanisse, D. R., \& Storey, K. B. (1996). Oxidative damage and antioxidants in Rana sylvatica, the freeze-tolerant wood frog. American Journal of Physiology-Regulatory, Integrative and Comparative Physiology, 271(3), R545-R553.

Jurica, M. S., Mesecar, A., Heath, P. J., Shi, W., Nowak, T., \& Stoddard, B. L. (1998). The allosteric regulation of pyruvate kinase by fructose-1, 6-bisphosphate. Structure, 6(2), 195-210.

Khan, A. H. P. J., \& Pessin, J. (2002). Insulin regulation of glucose uptake: a complex interplay of intracellular signalling pathways. Diabetologia, 45(11), 1475-1483.

Klain, G. J., \& Whitten, B. K. (1968). Carbon dioxide fixation during hibernation and arousal from hibernation. Comparative biochemistry and physiology, 25(1), 363-366. 
Korotchkina, L. G., \& Patel, M. S. (2001a). Site specificity of four pyruvate dehydrogenase kinase isoenzymes toward the three phosphorylation sites of human pyruvate dehydrogenase. Journal of Biological Chemistry, 276(40), 37223-37229.

Korotchkina, L. G., \& Patel, M. S. (2001). Probing the mechanism of inactivation of human pyruvate dehydrogenase by phosphorylation of three sites. Journal of Biological Chemistry, 276(8), 5731-5738.

Korycan, S. A., \& Storey, K. B. (1983). Organ-specific metabolism during anoxia and recovery from anoxia in the cherrystone clam, Mercenaria mercenaria. Canadian journal of zoology, 61(12), 2674-2681.

Krebs, H. A., \& Eggleston, L. V. (1965). The role of pyruvate kinase in the regulation of gluconeogenesis. Biochemical Journal, 94(1), 3C-4C.

Krebs, E. G., \& Beavo, J. A. (1979). Phosphorylation-dephosphorylation of enzymes. Annual review of biochemistry, 48(1), 923-959.

Krivoruchko, A., \& Storey, K. B. (2010). Regulation of the heat shock response under anoxia in the turtle, Trachemys scripta elegans. Journal of Comparative Physiology B, 180(3), 403414.

Krivoruchko, A., \& Storey, K. B. (2015). Turtle anoxia tolerance: Biochemistry and gene regulation. Biochimica et Biophysica Acta (BBA)-General Subjects, 1850(6), 1188-1196.

Kumar, S., Barth, A. (2010). Phosphoenolpyruvate and Mg 2+ binding to pyruvate kinase monitored by infrared spectroscopy. Biophysical journal, 98(9), 1931-1940.

Lama, J. L., Bell, R. A., \& Storey, K. B. (2013). Glucose-6-phosphate dehydrogenase regulation in the hepatopancreas of the anoxia-tolerant marine mollusc, Littorina littorea. PeerJ, 1 , e21.

Lama, J. L., Bell, R. A., \& Storey, K. B. (2013). Hexokinase regulation in the hepatopancreas and foot muscle of the anoxia-tolerant marine mollusc, Littorina littorea. Comparative Biochemistry and Physiology Part B: Biochemistry and Molecular Biology, 166(1), 109116.

Larade, K., \& Storey, K. B. (2002). Reversible suppression of protein synthesis in concert with polysome disaggregation during anoxia exposure in Littorina littorea. Molecular and cellular biochemistry, 232(1-2), 121-127.

Larade, K., \& Storey, K. B. (2007). Arrest of transcription following anoxic exposure in a marine mollusc. Molecular and cellular biochemistry, 303(1-2), 243-249.

Lenzen, S. (2014). A fresh view of glycolysis and glucokinase regulation: history and current status. Journal of Biological Chemistry, 289(18), 12189-12194. 
Llorente, P., Marco, R., \& Sols, A. (1970). Regulation of liver pyruvate kinase and the phosphoenolpyruvate crossroads. European Journal of Biochemistry, 13(1), 45-54.

Ljungström, O., Hjelmquist, G., \& Engström, L. (1974). Phosphorylation of purified rat liver pyruvate kinase by cyclic 3', 5'-AMP-stimulated protein kinase. Biochimica et Biophysica Acta (BBA)-Enzymology, 358(2), 289-298.

Ljungstrom, O., Berglund, L., \& Engstrom, L. (1976). Studies on the Kinetic Effects of Adenosine-3': 5'-Monophosphate Dependent Phosphorylation of Purified Pig-Liver Pyruvate Kinase Type L. European Journal of Biochemistry, 68(2), 497-506.

MacDonald, J. A., \& Storey, K. B. (1998). cAMP-dependent protein kinase from brown adipose tissue: temperature effects on kinetic properties and enzyme role in hibernating ground squirrels. Journal of Comparative Physiology B, 168(7), 513-525.

Marsin, A. S., Bertrand, L., Rider, M. H., Deprez, J., Beauloye, C., Vincent, M. F., \& Hue, L. (2000). Phosphorylation and activation of heart PFK-2 by AMPK has a role in the stimulation of glycolysis during ischaemia.Current biology, 10(20), 1247-1255.

McArthur, M. D., \& Milsom, W. K. (1991). Changes in ventilation and respiratory sensitivity associated with hibernation in Columbian (Spermophilus columbianus) and goldenmantled (Spermophilus lateralis) ground squirrels. Physiological zoology, 940-959.

McClanahan, L. (1967). Adaptations of the spadefoot toad, Scaphiopus couchii, to desert environments. Comparative Biochemistry and Physiology 20: 73-79

Melatunan, S., Calosi, P., Rundle, S.D., Moody, A.J., \& Widdicombe, S. (2011). Exposure to elevated temperature and $\mathrm{Pco} 2$ reduces respiration rate and energy status in the periwinkle Littorina littorea. Physiological and Biochemical Zoology. 84, 583-594.

Milsom, W.K., Zimmer, M.B., \& Harris, M.B. (1999) Regulation of cardiac rhythm in hibernating mammals. Comparative Biochemistry and Physiology, A 124 383-391.

Milton, S. L., \& Prentice, H. M. (2007). Beyond anoxia: the physiology of metabolic downregulation and recovery in the anoxia-tolerant turtle. Comparative Biochemistry and Physiology Part A: Molecular \& Integrative Physiology, 147(2), 277-290.

Morgan, H. E., \& Parmeggiani, A. (1964). Regulation of glycogenolysis in muscle III. Control of muscle glycogen phosphorylase activity. Journal of Biological Chemistry, 239(8), 24402445.

Muir, J.T., Costanzo, J., \& Richard, E. (2008). Metabolic depression induced by urea in organs of the wood frog, Rana sylvatica: effects of season and temperature. Journal of Experimental Zoology, 309, 111-116. 
Muir, T. J., Costanzo, J. P., \& Lee, R. E. (2010). Evidence for urea-induced hypometabolism in isolated organs of dormant ectotherms. Journal of Experimental Zoology Part A: Ecological Genetics and Physiology, 313(1), 28-34.

Muirhead, H., Clayden, D. A., Barford, D., Lorimer, C. G., Fothergill-Gilmore, L. A., Schiltz, E., \& Schmitt, W. (1986). The structure of cat muscle pyruvate kinase. The EMBO journal, $5(3), 475$.

Muñoz, M. E., \& Ponce, E. (2003). Pyruvate kinase: current status of regulatory and functional properties. Comparative Biochemistry and Physiology Part B: Biochemistry and Molecular Biology, 135(2), 197-218.

Newell, R.C. (1979). Biology of Intertidal Animals. Marine ecological surveys. In: Biology of Intertidal Animals, Marine Ecological Surveys Ltd, Faversham, UK

Oliveira, A. P., \& Sauer, U. (2012). The importance of post-translational modifications in regulating Saccharomyces cerevisiae metabolism. FEMS yeast research, 12(2), 104-117.

Pannunzio, T. M., \& Storey, K. B. (1998). Antioxidant defenses and lipid peroxidation during anoxia stress and aerobic recovery in the marine gastropod Littorina littorea. Journal of Experimental Marine Biology and Ecology, 221(2), 277-292.

Plaxton, W. C., \& Storey, K. B. (1984). Phosphorylation in vivo of red-muscle pyruvate kinase from the channelled whelk, Busycotypus canaliculatum, in response to anoxic stress. European journal of biochemistry, 143(2), 267-272.

Plaxton, W.C., \& Storey, K.B. (1984). Purification and properties of aerobic and anoxic forms of pyruvate kinase from red muscle tissue of the channelled whelk, Busycotypus canaliculatum. European journal of biochemistry, 143(2), 257-265.

Plaxton, W. C., \& Storey, K. B. (1985). Tissue specific isozymes of pyruvate kinase in the channelled whelk Busycotypus canaliculatum: enzyme modification in response to environmental anoxia. Journal of Comparative Physiology B, 155(3), 291-296.

Prabakaran, S., Lippens, G., Steen, H., \& Gunawardena, J. (2012). Post-translational modification: nature's escape from genetic imprisonment and the basis for dynamic information encoding. Wiley Interdisciplinary Reviews: Systems Biology and Medicine, 4(6), 565-583.

Rider, M. H., Hussain, N., Horman, S., Dilworth, S. M., \& Storey, K. B. (2006). Stress-induced activation of the AMP-activated protein kinase in the freeze-tolerant frog Rana sylvatica. Cryobiology, 53(3), 297-309.

Riou, J. P., Claus, T. H., \& Pilkis, S. J. (1978). Stimulation of glucagon of in vivo phosphorylation of rat hepatic pyruvate kinase. Journal of Biological Chemistry, 253(3), 656-659. 
Rognstad, R., \& Katz, J. (1977). Role of pyruvate kinase in the regulation of gluconeogenesis from L-lactate. Journal of Biological Chemistry, 252(6), 1831-1833.

Russell, E.L., \& Storey, K.B., (1995). Anoxia and freezing exposures stimulate covalent modification of enzymes of carbohydrate metabolism in Littorina littorea. Journal of Comparative Physiology B 165, 132-142.

Saheki, S., Saheki, K., \& Tanaka, T. (1982). Peptide structures of pyruvate kinase isozymes: 1. Comparison of the four pyruvate kinase isozymes of the rat. Biochimica et Biophysica Acta (BBA)-Protein Structure and Molecular Enzymology, 704(3), 484-493.

Scopes, R. K. (1977). Purification of glycolytic enzymes by using affinity-elution chromatography. Biochemical Journal, 161(2), 253-263.

Scrutton, M. C., \& Utter, M. F. (1968). The regulation of glycolysis and gluconeogenesis in animal tissues. Annual review of biochemistry, 37(1), 249-302.

Shahriari, A., Dawson, N. J., Bell, R. A., \& Storey, K. B. (2013). Stable suppression of lactate dehydrogenase activity during anoxia in the foot muscle of Littorina littorea and the potential role of acetylation as a novel posttranslational regulatory mechanism. Enzyme research, 2013.

Shick, J. M., De Zwaan, A., \& De Bont, A. T. (1983). Anoxic metabolic rate in the mussel Mytilus edulis L. estimated by simultaneous direct calorimetry and biochemical analysis. Physiological Zoology, 56-63.

Sinclair, B. J., Stinziano, J. R., Williams, C. M., MacMillan, H. A., Marshall, K. E., \& Storey, K. B. (2013). Real-time measurement of metabolic rate during freezing and thawing of the wood frog, Rana sylvatica: implications for overwinter energy use. Journal of Experimental Biology, 216(2), 292-302.

Sokolova, I. M., Bock, C., \& Pörtner, H. O. (2000). Resistance to freshwater exposure in White Sea Littorina spp. I: Anaerobic metabolism and energetics. Journal of Comparative Physiology B, 170(2), 91-103.

Storey, K. B., \& Storey, J. M. (1984). Biochemical adaption for freezing tolerance in the wood frog, Rana sylvatica. Journal of Comparative Physiology B, 155(1), 29-36.

Storey, J. M., \& Storey, K. B. (1985). Triggering of cryoprotectant synthesis by the initiation of ice nucleation in the freeze tolerant frog, Rana sylvatica. Journal of Comparative Physiology B, 156(2), 191-195.

Storey, K. B. (1986). Aspartate activation of pyruvate kinase in anoxia tolerant molluscs. Comparative Biochemistry and Physiology Part B: Comparative Biochemistry, 83(4), 807-812. 
Storey, K. B., \& Storey, J. M. (1986a). Freeze tolerance and intolerance as strategies of winter survival in terrestrially-hibernating amphibians. Comparative Biochemistry and Physiology Part A: Physiology, 83(4), 613-617.

Storey, K. B., \& Storey, J. M. (1986b). Freeze tolerant frogs: cryoprotectants and tissue metabolism during freeze-thaw cycles. Canadian Journal of Zoology, 64(1), 49-56.

Storey, K. B. (1987a). Glycolysis and the regulation of cryoprotectant synthesis in liver of the freeze-tolerant wood frog. Journal of Comparative Physiology B, 157, 373-380.

Storey, K. B. (1987b). Regulation of liver metabolism by enzyme phosphorylation during mammalian hibernation. Journal of Biological Chemistry, 262(4), 1670-1673.

Storey, K. B., Storey, J. M. (1988). Freeze tolerance in animals. Physiological Reviews 68:2784.

Storey, K.B., \& Storey, J.M., (1990). Metabolic rate depression and biochemical adaptation in anaerobiosis, hibernation and estivation. Quarterly Review of Biology, 65, 145-174.

Storey, K.B. (1990). Life in a frozen state: adaptive strategies for natural freeze tolerance in amphibians and reptiles. American Journal of Physiology, 258 R559-R568.

Storey, K. B., \& Storey, J. M. (1992). Natural freeze tolerance in ectothermic vertebrates. Annual Review of Physiology, 54(1), 619-637.

Storey, K.B. (1993). Molecular mechanisms of metabolic arrest in mollusks. In Surviving hypoxia: mechanisms of control and adaptation. Edited by P.W. Hochachka, P.L. Lutz, T. Sick, M. Rosenthal, and G. van den Thillart. CRC Press, Boca Raton, Fla. pp. 253269.

Storey, K. B., Mosser, D. D., Douglas, D. N., Grundy, J. E., \& Storey, J. M. (1996). Biochemistry below 0 degrees C: nature's frozen vertebrates. Brazilian journal of medical and biological research 29(3), 283-307.

Storey, K. B. (1997a). Organic solutes in freezing tolerance. Comparative Biochemistry and Physiology Part A: Physiology, 117(3), 319-326.

Storey, K. B. (1997b). Metabolic regulation in mammalian hibernation: enzyme and protein adaptations. Comparative Biochemistry and Physiology Part A: Physiology, 118(4), 1115-1124.

Storey, K.B. (2002). Life in the slow lane: Molecular mechanisms of estivation. Comparative Biohemistry and. Physiology, A 133: 733-754.

Storey, K. B. (2003) Mammalian hibernation: transcriptional and translational controls. Advances in Experimental Medicine and Biology, 543:21-38. 
Storey, K. B., \& Storey, J. M. (2004a). Metabolic rate depression in animals: transcriptional and translational controls. Biological Reviews, 79(1), 207-233

Storey, K. B., \& Storey, J. M. (2004b). Oxygen limitation and metabolic rate depression. In: Functional metabolism: regulation and adaptation, Wiley-Liss, Hoboken, NJ, 415-442.

Storey, K.B., \& Storey, J.M. (2004c). Physiology, biochemistry and molecular biology of vertebrate freeze tolerance: the wood frog. In: Life in the Frozen State, CRC Press, Boca Raton, 243-274.

Storey, K. B. (2007). Antioxidant defense in hibernation: cloning and expression of peroxiredoxins from hibernating ground squirrels, Spermophilus tridecemlineatus. Archives of biochemistry and biophysics, 461(1), 59-65.

Storey, K. B., \& Storey, J. M. (2010). Metabolic rate depression: the biochemistry of mammalian hibernation. Advances in clinical chemistry, 52, 78.

Storey, K. B. (2010). Out cold: biochemical regulation of mammalian hibernation-a minireview. Gerontology, 56(2), 220-230.

Storey, K. B., Storey, J. M. (2012). Insect cold hardiness: metabolic, gene, and protein adaptation. Canadian Journal of Zoology, 90(4), 456-475.

Storey, K. B., Lant, B., Anozie, O. O., \& Storey, J. M. (2013). Metabolic mechanisms for anoxia tolerance and freezing survival in the intertidal gastropod, Littorina littorea. Comparative Biochemistry and Physiology Part A: Molecular \& Integrative Physiology, 165(4), 448459.

Storey, K. B. (2013). Real-time measurement of metabolic rate during freezing and thawing of the wood frog, Rana sylvatica: implications for overwinter energy use. Journal of Experimental Biology. 216, 292-302.

Storey, K. B., Storey, J. M. (2013). Molecular biology of freezing tolerance. Comprehensive Physiology, 3(3), 1283-308

Squire, T. L., Lowe, M. E., Bauer, V. W., \& Andrews, M. T. (2003). Pancreatic triacylglycerol lipase in a hibernating mammal. II. Cold-adapted function and differential expression. Physiological genomics, 16(1), 131-140.

Tanaka, T., Sue, F., \& Morimura, H. (1967). Feed-forward activation and feed-back inhibition of pyruvate kinase type $\mathrm{L}$ of rat liver. Biochemical and biophysical research communications, 29(3), 444-449.

Titanji, V. P., Zetterqvist, Ö., \& Engström, L. (1976). Regulation in vitro of rat liver pyruvate kinase by phosphorylation-dephosphorylation reactions, catalyzed by cyclic-AMP 
dependent protein kinases and a histone phosphatase. Biochimica et Biophysica Acta (BBA)-Enzymology, 422(1), 98-108.

Underwood, A. H., \& Newsholme, E. A. (1965). Properties of phosphofructokinase from rat liver and their relation to the control of glycolysis and gluconeogenesis. Biochemical Journal, 95(3), 868.

Vazquez-Illanes, D. \& Storey, K. B. (1993). 6-Phosphofructo-2-kinase and control of cryoprotectant synthesis in freeze-tolerant frogs. Biochimica et. Biophysica. Acta, 1158, $29-32$.

Veelen, C. W., Verbiest, H., Zülch, K. J., van Ketel, B. A., van der Vlist, M. J., Vlug, A. M., \& Staal, G. E. (1979). 1- $\alpha$-Alanine inhibition of pyruvate kinase from tumors of the human central nervous system. Cancer research, 39(10), 4263-4269.

Wang, L.C.H. (1989) Ecological, physiological and biochemical aspects of torpor in mammals and birds, In: Advances in Comparative and Environmental Physiology, vol. 4, 361-401.

Whitman, R.E., \& Storey, K.B. (1990). Pyruvate kinase from the land snail Otala lactea: regulation by reversible phosphorylation during estivation and anoxia. Journal of experimental biology, 154(1), 321-337.

Wieser, W. (1980). Metabolic end products in three species of marine gastropods. Journal of the Marine Biological Association of the United Kingdom, 60(01), 175-180.

Wilson, B. E., Deeb, S., \& Florant, G. L. (1992). Seasonal changes in hormone-sensitive and lipoprotein lipase mRNA concentrations in marmot white adipose tissue. American Journal of Physiology-Regulatory, Integrative and Comparative Physiology, 262(2), R177-R181.

Wu, S. W. N., Wong, S. C., \& Yeung, D. (1978). Comparative studies of vertebrate and invertebrate pyruvate kinases. Comparative Biochemistry and Physiology Part B: Comparative Biochemistry, 61(1), 93-98.

Wu, C. W., \& Storey, K. B. (2012). Pattern of cellular quiescence over the hibernation cycle in liver of thirteen-lined ground squirrels. Cell Cycle, 11(9), 1714-1726.

Xiong, Z. J., \& Storey, K. B. (2012). Regulation of liver lactate dehydrogenase by reversible phosphorylation in response to anoxia in a freshwater turtle. Comparative Biochemistry and Physiology Part B: Biochemistry and Molecular Biology, 163(2), 221-228.

Zatzman, M. L. (1984). Renal and cardiovascular effects of hibernation and hypothermia. Cryobiology, 21(6), 593-614.

Zhang, J., \& Storey, K. B. (2012). Cell cycle regulation in the freeze tolerant wood frog, Rana sylvatica. Cell cycle, 11(9), 1727-1742. 
Zhou, W., Capello, M., Fredolini, C., Racanicchi, L., Dugnani, E., Piemonti, L., Petricoin, E. F. (2013). Mass spectrometric analysis reveals O-methylation of pyruvate kinase from pancreatic cancer cells. Analytical and bioanalytical chemistry, 405(14), 4937-4943.

Zierler, K. (1999). Whole body glucose metabolism. American Journal of PhysiologyEndocrinology And Metabolism, 276(3), E409-E426. 


\section{Appendix I}

Study of the Effects Dehydration and Anoxia on the Activity of PK in the Muscle of $R$. sylvatica 
The data presented in this appendix was collected by another student, under my own supervision. It contributes to the data presented in chapter 2 of this thesis concerning the effects of freezing on the activity of PK in $R$. sylvatica muscle. It is discussed in chapter 2 as it contributes to forming a more complete picture of how $\mathrm{PK}$ is regulated in this animal in response to environmental stress.

Table A1.1: $\mathrm{K}_{\mathrm{m}} \mathrm{PEP}$ of skeletal muscle pyruvate kinase taken from control, frozen, dehydrated and anoxic muscle samples of $R$. sylvatica. Dehydrated and anoxic values were collected by J. Mattice, control and frozen values were collected by M. Smolinski. Data are mean $\pm \mathrm{SEM}, \mathrm{n}=4$.

\begin{tabular}{lllll}
\hline Kinetic Parameter & Control & Frozen & Dehydrated & Anoxic \\
\hline $\mathrm{K}_{\mathrm{m}}$ PEP $(\mathrm{mM})$ & $0.065 \pm 0.003$ & $0.098 \pm 0.003^{a}$ & $0.092 \pm 0.008^{a}$ & $0.073 \pm 0.002$ \\
\hline
\end{tabular}

$a$ indicates significant difference from the corresponding control value, one-way ANOVA, Dunnett's post-hoc, $\mathrm{P}<0.05$. 


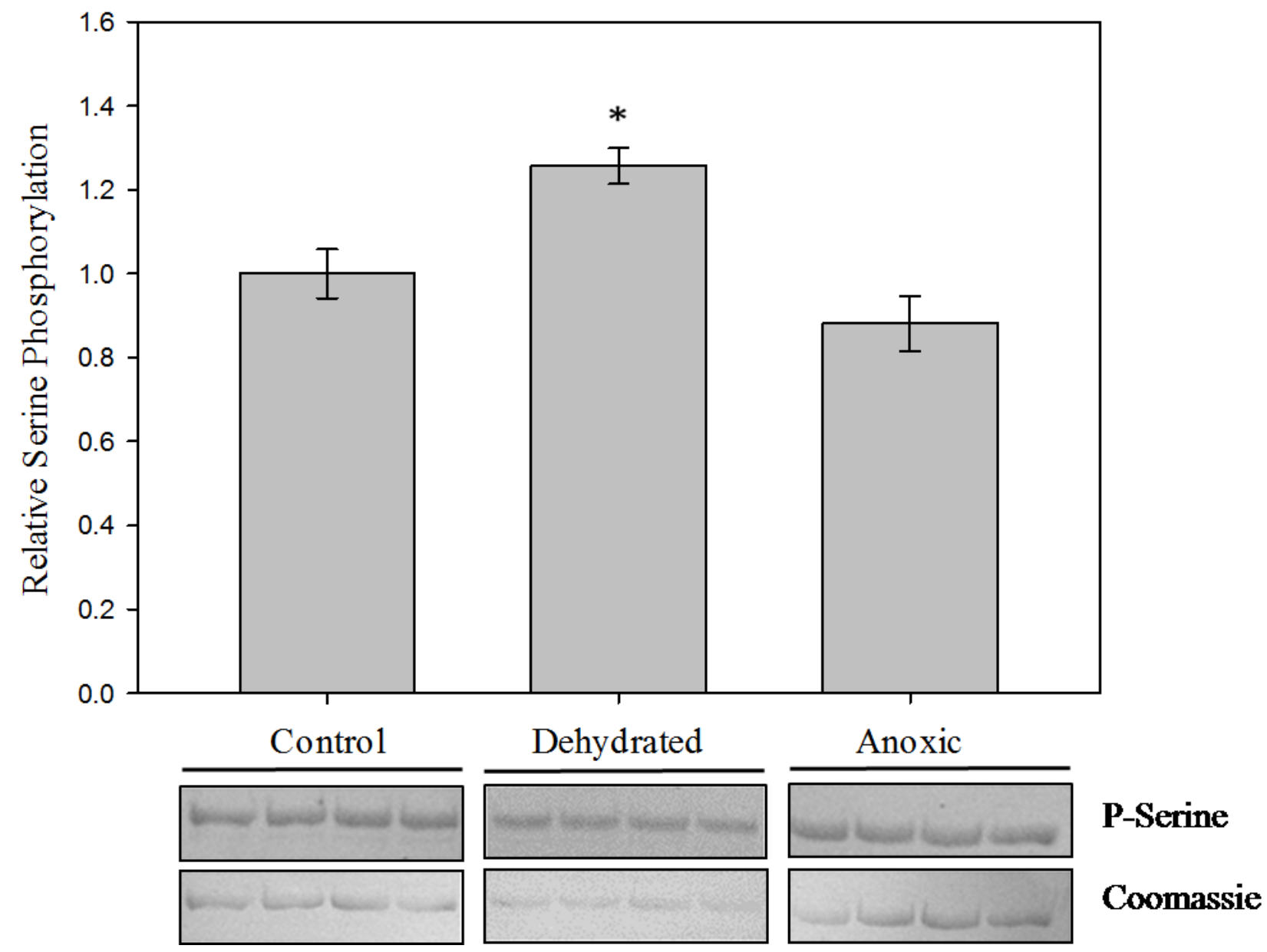

Figure A1.1: Relative levels of serine phosphorylation of purified pyruvate kinase from control dehydrated and anoxic muscle tissue of Rana sylvatica determined through western blotting. Chemiluminescence signal intensities were standardized to corresponding coomassie protein amount, and the values for the dehydrated and anoxic forms were expressed relative to the control value that was set to 1 . Data are mean \pm SEM, $n=4$ determinations on purified enzyme samples. Asterisk indicates significant difference from the control value, one-way ANOVA, Dunnett's post-hoc, $P<0.05$. 


\section{Appendix II}

\section{Supplementary Figures}




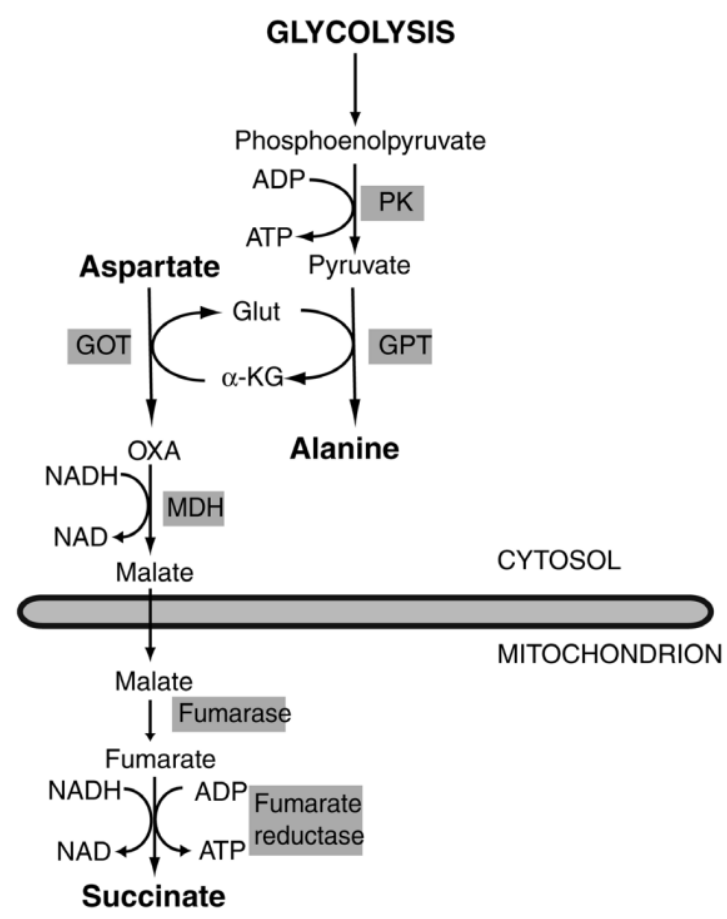

(a)

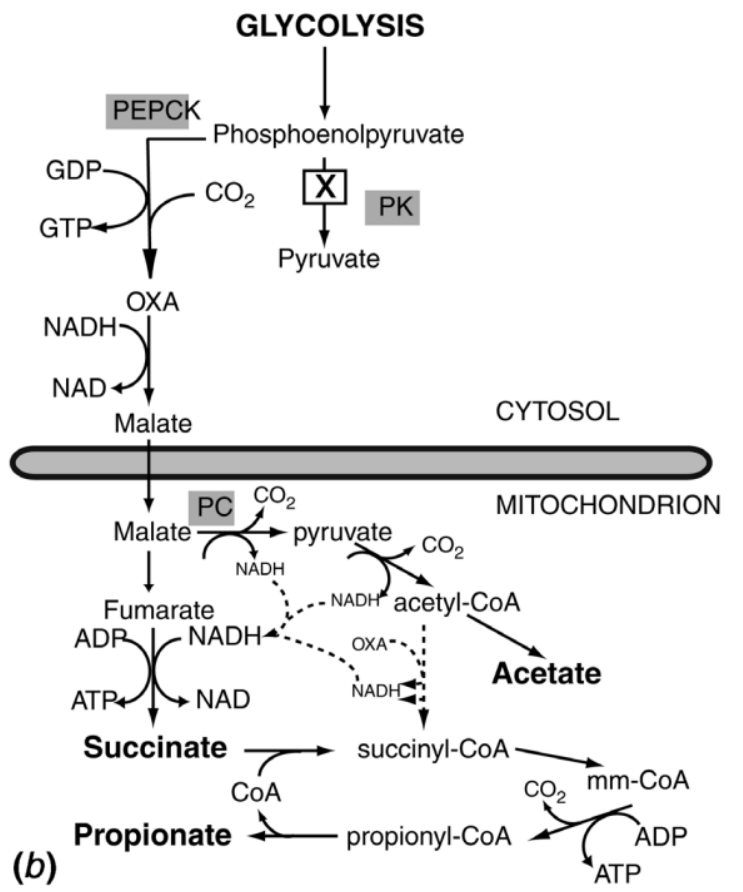

Figure A2.1: Patterns of anaerobic metabolism in marine invertebrates (a) early in anoxia exposure and (b) late in anoxia exposure. Late-stage anaerobic metabolism is characterized by inhibition of pyruvate kinase and PEP being shunted directly towards succinate synthesis through the conversion of PEP into oxaloacetate by PEPCK (Taken from Storey \& Storey, 2004b) 


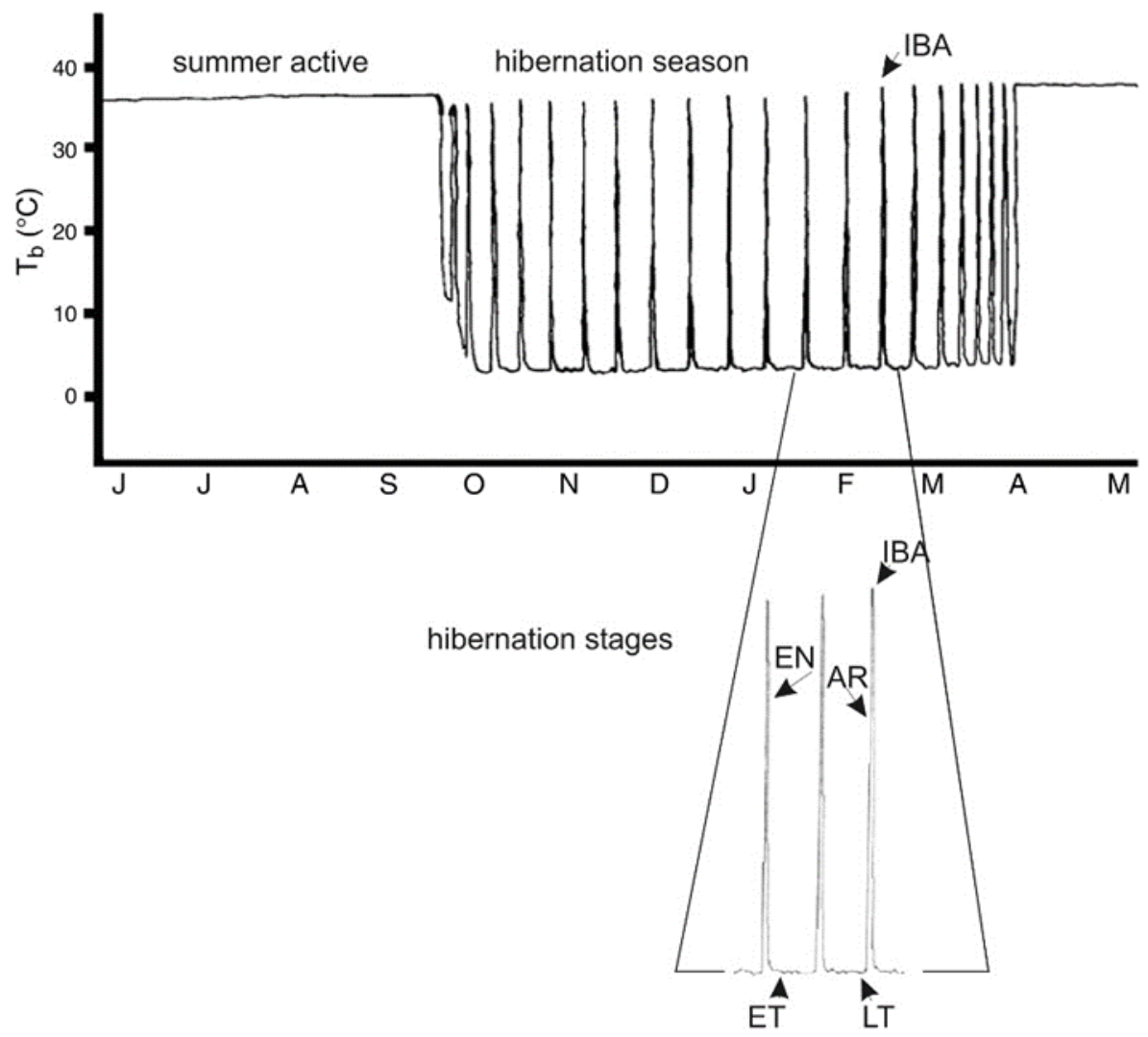

Figure A2.2. Body temperature of a model mammalian hibernator, the golden-mantled ground squirrel (Callospermophilus lateralis), displaying the many torpor-arousal cycles of hibernation. Inset depicts the entrance into torpor (EN), early torpor (ET), late torpor (LT), arousal (AR), and interbout arousal (IBA) (Taken from Carey et al., 2003). 


\section{Appendix III}

Communications at Scientific Meetings 


\section{List of Conferences}

Smolinski, M., Mattice, J. Storey, K.B. Purification and Characterization of Pyruvate Kinase in the Freeze Tolerant Wood Frog, Rana Sylvatica. (Poster Presentation). Concordia University Chemistry and Biochemistry Graduate Research Conference (2015).

Smolinski, M., Luu, B., Waddington Lamont, E., Abizaid Bucio, A., Storey, K.B. Differential regulation of microRNAs induced by social defeat stress in the brain. (Poster presentation). University of Ottawa Institute of Mental Health Research Young Researchers Conference (2016).

Smolinski, M., Storey, K.B. Post-Translational Regulation of Glucose-6-Phosphate Dehydrogenase in the Larvae of the Freeze-Tolerant Gall Fly, Eurosta solidaginis. (Poster Presentation). Concordia University Chemistry and Biochemistry Graduate Research Conference (2014). 


\section{Appendix IV}

\section{Thesis Defense Lecture Slides}




\section{REGULATION OF PYRUVATE KINASE}

IN HYPOMETABOLIC STATES

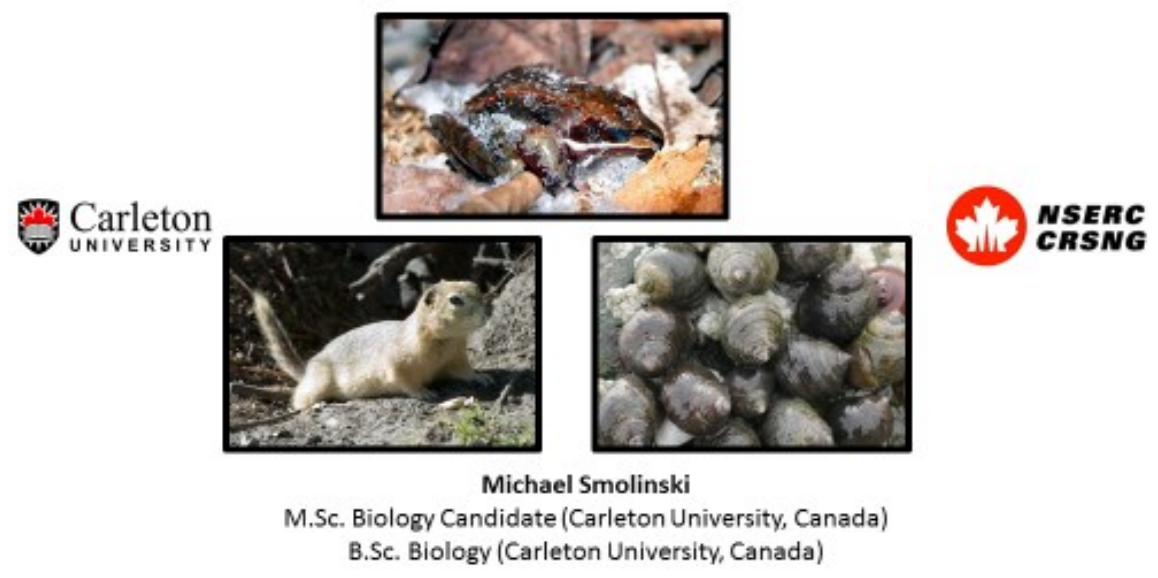

\section{Presentation Outline}

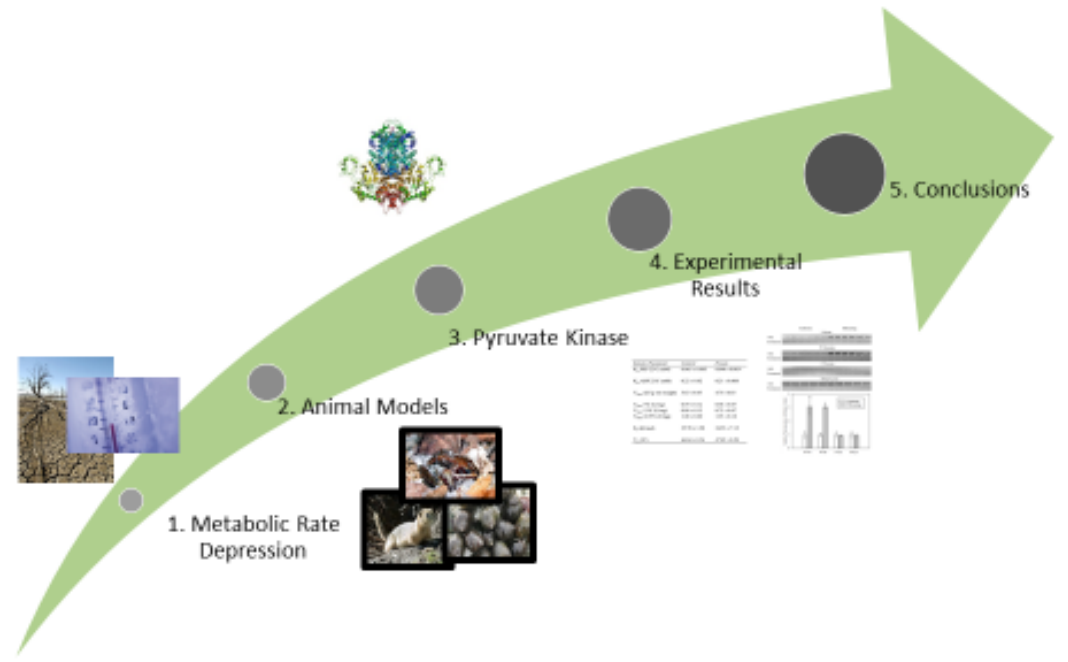




\section{Metabolic Rate Depression}
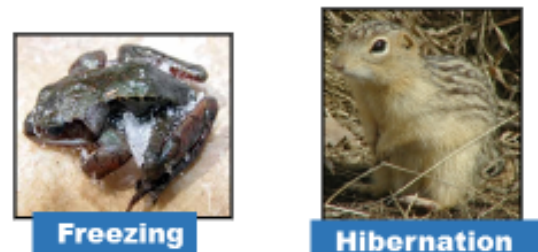

\section{Environmental Stress}

Extreme Temperatures

Oxygen Deprivation

Food Restriction

Water Limitation

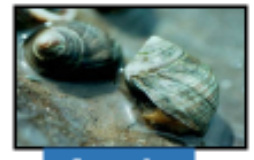

Anoxia

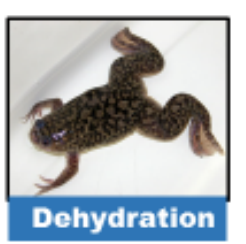

CONSERVE ENERGY
1. Metabolic Rate Depression
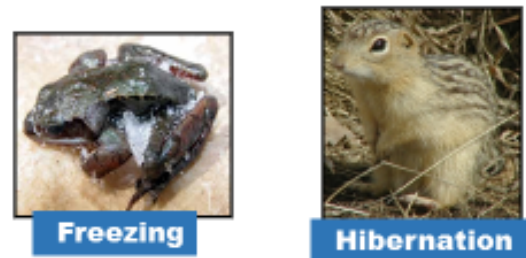

Environmental Stress

Extreme Temperatures

Oxygen Deprivation

Food Restriction

Water Limitation
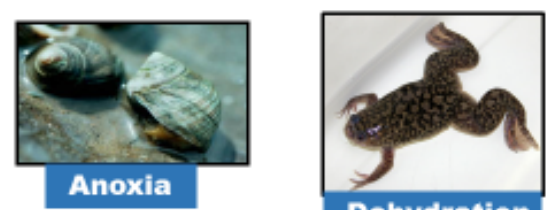

\section{Adaptive Responses}

Metabolic Processes

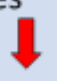

Energy-Expensive Processes

Enzyme Regulation 


\section{Model Animals - Wood Frog (Rana sylvatica)}
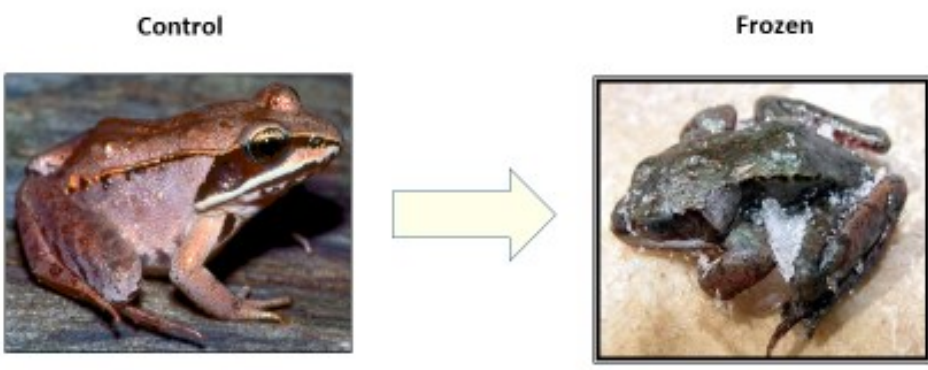

Consequences of

\section{Freezing}

Heart beat and breathing cease

Up to $70 \%$ total body water freezes

Cells dehydrate and are exposed to anoxia

Antioxidant defenses increase

${ }^{*}$ Glucose management is key for cryoprotection*

Glucose accumulates as a cryoprotectant

\section{Model Animals - Common Periwinkle (Littorina littorea)}
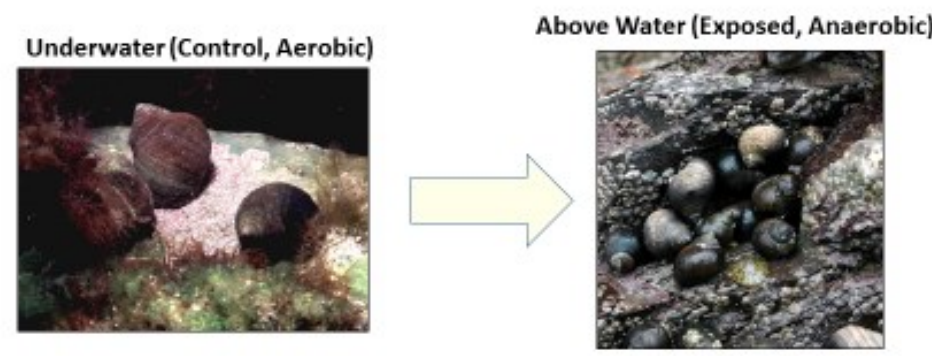

*Glucose metabolism must be managed to conserve energy*
Consequences of Aerial Exposure

Shifts to anaerobic metabolism

Metabolic rate must be depressed

Engages multiple anaerobic pathways

Increases antioxidant defense capacity 


\section{Model Animals - Richardson's Ground Squirrel (Urocitellus richardsonii)}
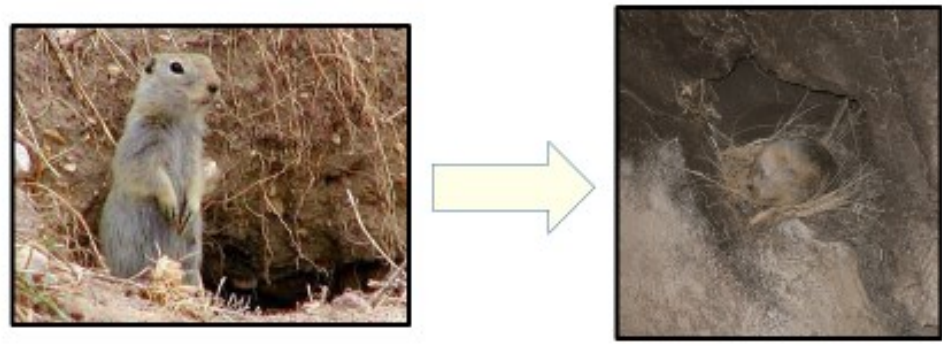

\section{Consequences of Hibernation}

Tb drops from $35^{\circ} \mathrm{C}$ to as low as $5^{\circ} \mathrm{C}$.

Heart rate drops from $350 \mathrm{bpm}$ to $5 \mathrm{bpm}$

Breathing rate drops from $40 \mathrm{bpm}$ to $<1 \mathrm{bpm}$

Shifts from primarily carbohydrates to lipids as an energy source

*Glucose metabolism is regulated to allow a shift to lipid metabolism*

\section{Pyruvate Kinase}

- Pyruvate kinase is a highly-regulated enzyme.

- Requires many activating compounds and has many known allosteric regulators.

- Known to be regulated by reversible phosphorylation
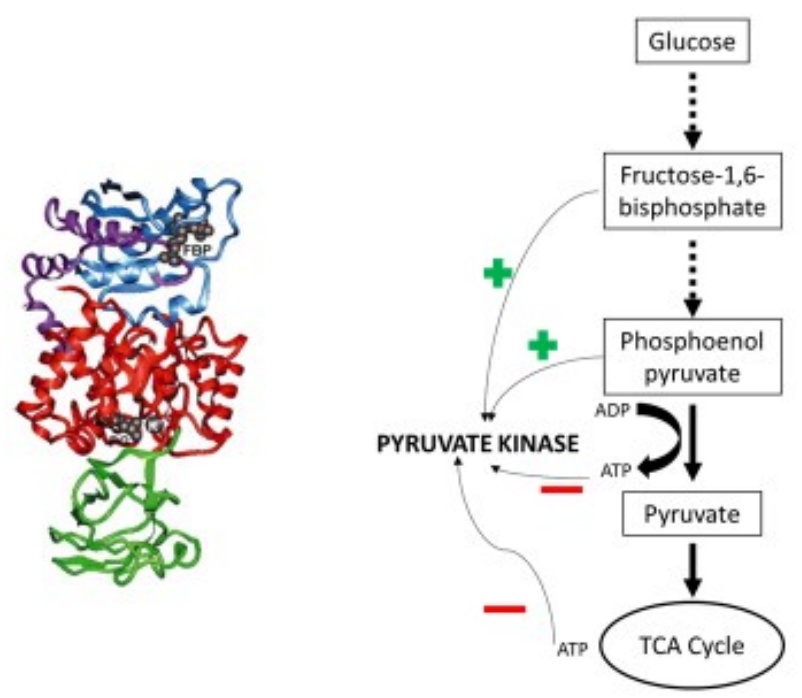


\section{Pyruvate Kinase}

- Pyruvate kinase is a highly-regulated enzyme.

- Requires many activating compounds and has many known allosteric regulators.

- Known to be regulated by reversible phosphorylation
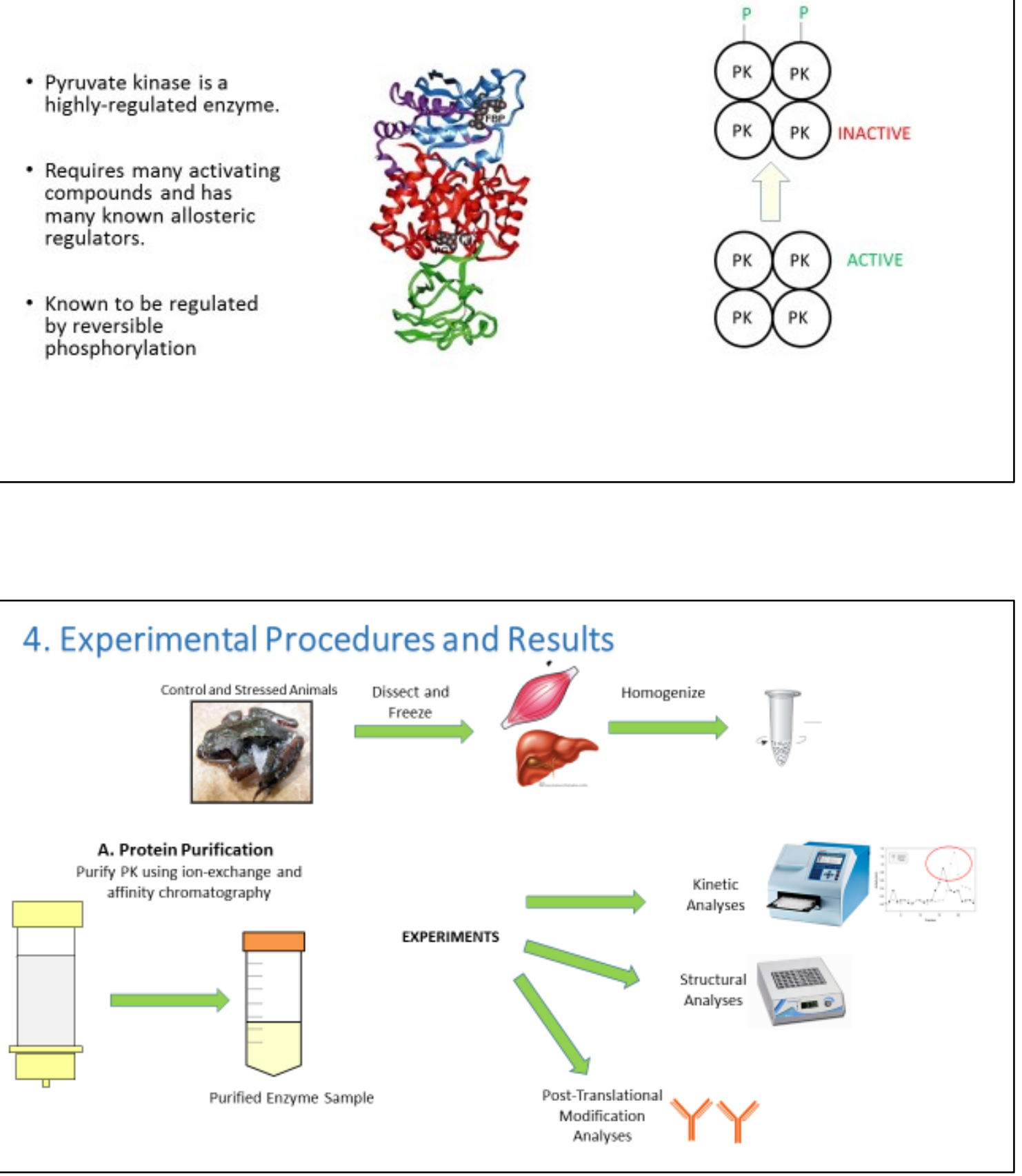

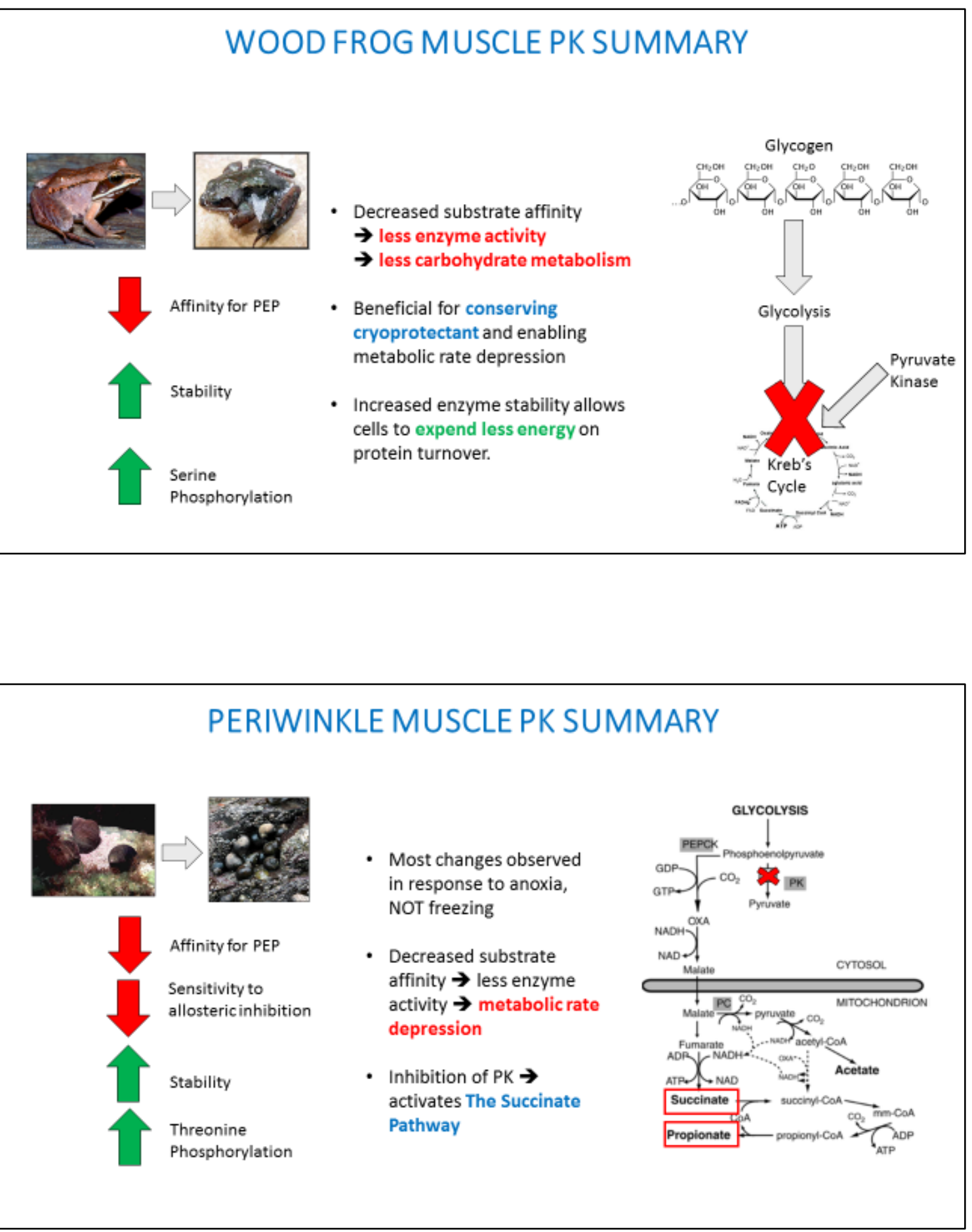


\section{GROUND SQUIRREL LIVER PK SUMMARY}

Ground Squirrel PK

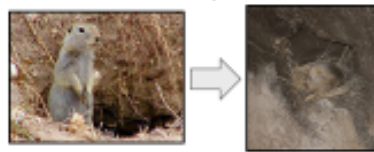

- Although substrate affinity increases, the decrease in $\mathrm{V}_{\max }$ would still limit the overallenzyme activity

Carbohydrate Metabolism

- Decreased enzyme activity $\rightarrow$ metabolic rate depression promoted

Increased Affinity for PEP

- Inhibition of PK helps to activate gluconeogenic pathways to restore

Serine + Threonine

Phosphorylation circulating levels of glucose for blood and brain.

Fatty Acid Metabolism

Stability

\section{General Conclusions}

PK from all three animals exhibited altered kinetic and structural properties in response to freezing, anoxia and hibernation, generally consistent with decreased enzyme activity.

Reversible protein phosphorylation proved to be extremely important in regulating PK in all three animals.
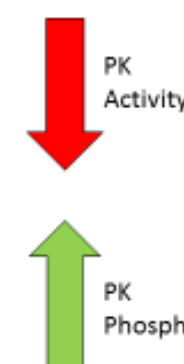

PK

Phosphorylation

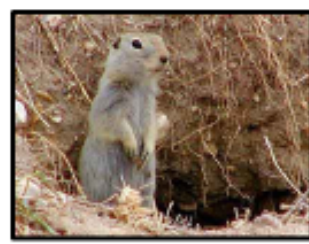

PK was found to be more stable in response to stress in all three animals suggesting that protein stability and cellular preservation are prioritized in response to these stress.
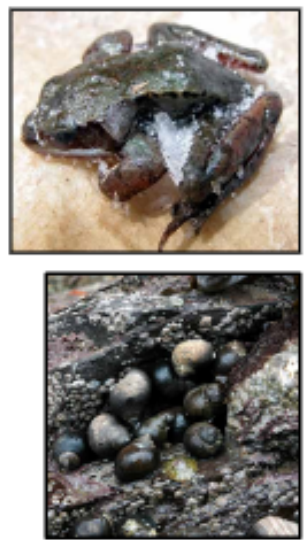